\title{
Mechanisms of exclusion and discrimination in the accounting profession: an ethnicity-focused study
}

Guozhen G. Huang

\author{
PhD thesis \\ Victoria University of Wellington, New Zealand \\ School of Accounting and Commercial Law
}

April 14, 2015 


\section{Attestation of Authorship}

I hereby declare that this submission is my own work, and to the best of my knowledge it contains no material previously published or written by another person, or substantial proportions of materials which have been accepted for the award of any other degree or diploma at Victoria University of Wellington or any other educational institutions, except where due acknowledgement is made in this dissertation. Any contribution made to the research by others, with whom I have worked at Victoria University of Wellington or elsewhere, is explicitly acknowledged in this dissertation.

I also declare that the intellectual content of this dissertation is the product of my own work, except to the extent that assistance from others in the project's design and conception or in style, presentation and linguistic expression is acknowledged.

Signature:

Date: 


\section{Acknowledgements}

There are many people who offered their support and encouragement to me along the journey of my $\mathrm{PhD}$ study.

First, I would like to thank Professor Rachel Baskerville and Associate Professor Carolyn Fowler, my two supervisors. Together they took complementary roles to keep me on track. Rachel provided a critical control of both the scope and core of my research and the analysis. She helped me avoid a never-ending literature review, slipping into other research topics, or missing the ethnic "guts". Her academic acuity on Bourdieu's habitus and symbolic capital assisted me to consolidate the theoretical platform for this research.

Carolyn enlightened me with her sharp insight. She also worked patiently checking my work in all the detail. Her comment "if you use Bourdieu's theory you will need to do it in Bourdieu's way" directed me to a path full of enlightenment and excitement. Her "fussy" checks on research method brought my thinking and writing back to a coherent finish.

Rachel and Carolyn also offered a benevolent support to me in my family life and helped me over the crisis with my Leukemia daughter.

Second, I would like to thank all the participants of this research, in particular those who showed a continuing interest in the research, and spent much time contributing their views and validating the findings. My gratitude is also given to those who had no hesitation in introducing new interviewees. Without their participation the completion of this research would not have been possible.

Third, I would like to thank Professor Trevor Hopper and Dr. Mingsheng Li who, although off-site, offered helpful insights for my research. Trevor had introduced me to Rachel, who later proved to be a good supervisor. Mingsheng was my "buddy" and answered my ad hoc queries along this $\mathrm{PhD}$ journey. 
Fourth, I would like to thank Professor Ian Eggleton, Associate Professor Carolyn Cordery, the scholarships officers and other staff at the Faculty of Graduate Research at Victoria University who offered understanding of my situations, and provided their help to support my study.

Fifth, I would like to thank The Open Polytechnic, my employer who allowed sufficient time for me to complete this research, and also funded my presentation of a significant part of the research methodology at an accounting conference in New Zealand.

Lastly, I would offer special thanks to all my family members who offered persistent non-abating support, both mentally and financially. They always sat on my side over this long hard journey.

Thank you all! 


\begin{abstract}
This study addresses mechanisms of exclusion and discrimination in the accounting profession. It illustrates how people are potentially discriminated against, based on their ethnicities, when entering the accounting profession; and strategies they have used to overcome such potential discrimination. In investigating these issues, Bourdieu's practice theory is used as the directing theory.
\end{abstract}

The sample used in this study comprises 45 accounting graduates who have wished to enter the accounting profession via the accountant employment market in New Zealand. They are of 20 different ethnic backgrounds. Their experiences and perceptions are collected through interview analysis, such interviews undertaken with semi-structured questioning. In data analysis, the researcher first identifies the different positions taken by different ethnic groups relative to each other, and then examines ethnic minorities' forms of capital (accessible resources) relative to their position. After confirming their positions and forms of capital, the researcher further examines their strategies.

The study found that Pakeha (New Zealanders mostly British descent) take the most advantageous positions; migrants from China and East Asia take the most disadvantageous positions; sitting between them, are ethnic minorities who grew up in New Zealand, and migrants from the Indian subcontinent and South Asia.

Ethnic minorities are potentially discriminated against on eight subtle factors including English proficiency (oral proficiency in particular), understanding of local New Zealand culture, accounting work experience in New Zealand, personality traits (appearances and manners in particular), their New Zealand accounting degree, country of origin (and associated accent and surname), cultural stereotype (work ethic in particular), and any weakness in their social networks with local New Zealanders.

To overcome such potential discrimination, ethnic minorities have been observed to use seven strategies; including adopting an English surname, meeting the employer faceto-face, cutting down the CV (removing overseas accounting qualifications and experiences), accepting an undesirable job offer, seeking a niche in the accountant job market, "knitting the web" (building up social networks with New Zealanders), and transforming the self (changing their habitus and adapting to New Zealand norms).

This study shows that discrimination is suffered not only by Chinese and Indians (as identified in previous accounting research), but also by many other ethnicities. It supports the view that accounting is not just a recording technique; it is also a tool which is used to produce and reproduce economic and cultural domination in the society. Some seemingly meritocratic attributes, such as accounting knowledge, skills and personality traits, are in fact perceived to be inherently connected to an accountant's social and cultural background. 


\section{Table of Contents}

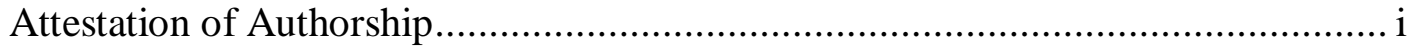

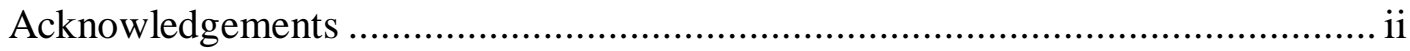

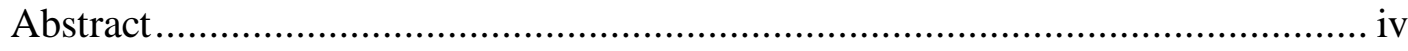

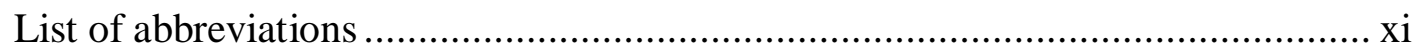

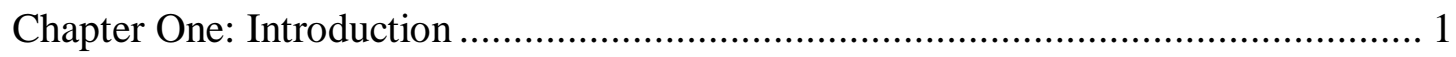

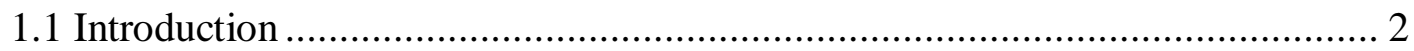

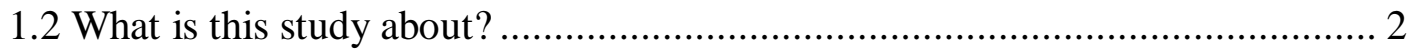

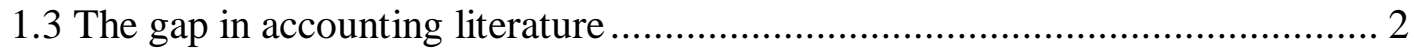

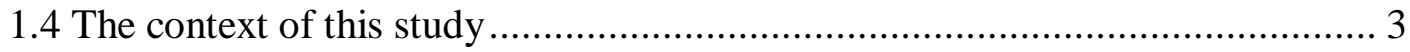

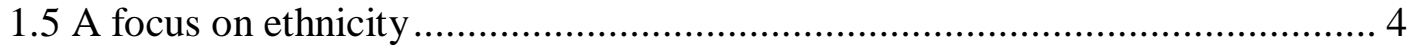

1.6 The theoretical foundation ................................................................. 4

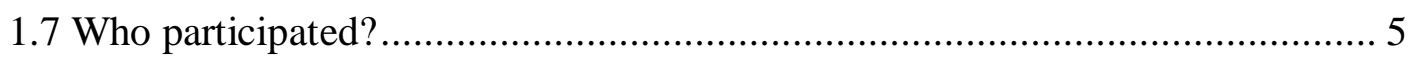

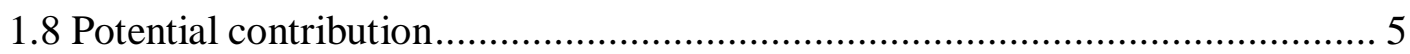

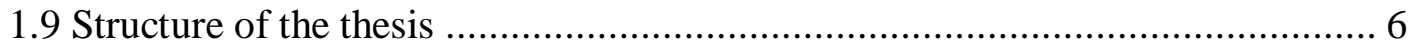

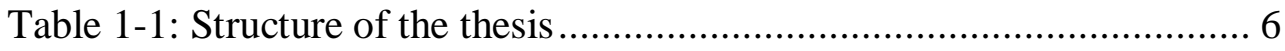

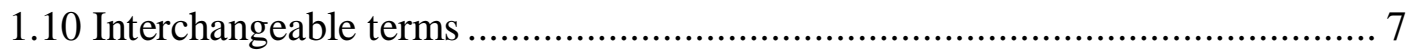

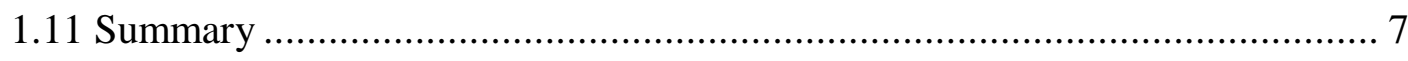

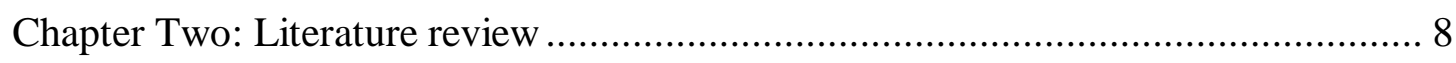

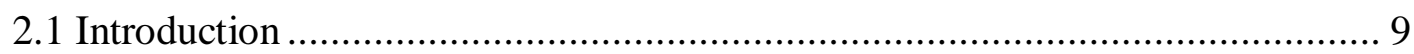

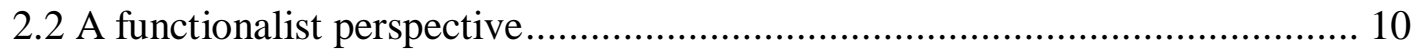

2.2.1 Accounting knowledge and skills .................................................... 10

2.2.2 Communication and socialisation skills ........................................... 11

2.2.3 Information technology (IT) skills ............................................... 12

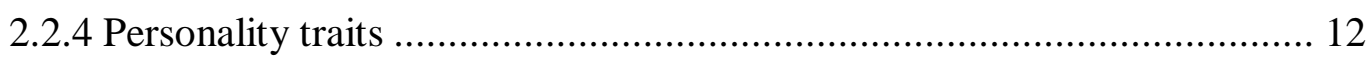

2.2.5 Accounting work experience ........................................................ 13

2.3 The functionalist perspective: a weakness .................................................. 14

2.4 The socially-constructed perspective ....................................................... 14

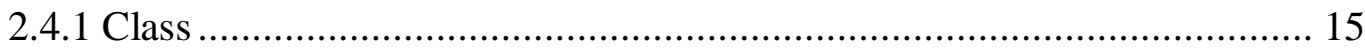

2.4.2 Country of origin, race and ethnicity ............................................. 15

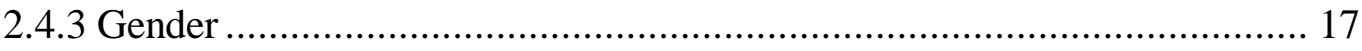


2.4.4 Age

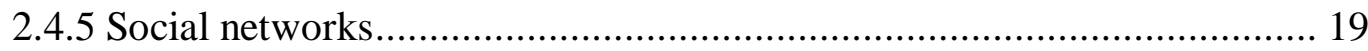

2.5 The gap in the socially-constructed perspective....................................... 19

2.6 The Focus on Ethnicity ............................................................................... 20

2.6.1 The choice of ethnicity as the focus.............................................. 20

2.6.2 The problem narrowed down........................................................ 21

Figure 2-1: The literature review process and finding the gap................. 22

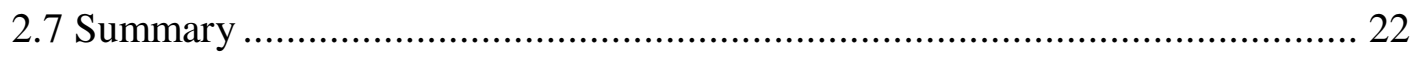

Table 2-1: A summary of potential exclusion factors as identified by accounting researchers

Chapter Three: Bourdieu's Theory of Practice …................................................. 25

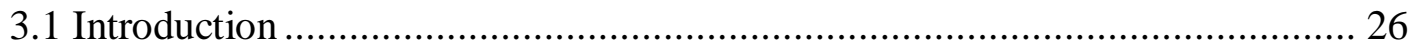

3.2 The choice of Bourdieu's Theory of Practice ............................................ 26

3.3 Key concepts of Bourdieu's Theory of Practice ........................................ 27

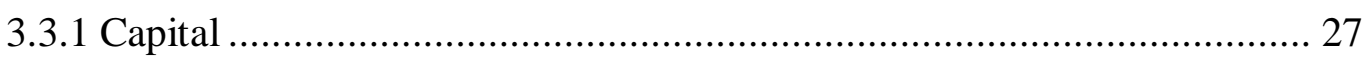

Table 3-1 Categorisation of the potential exclusion factors into Bourdieu's

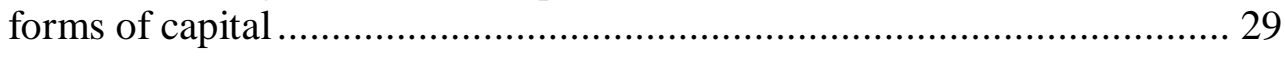

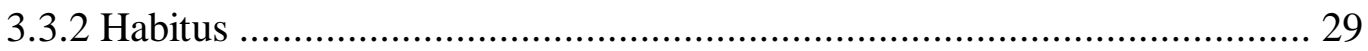

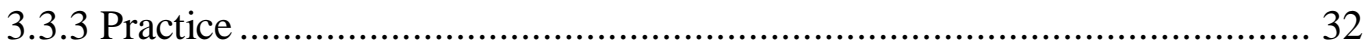

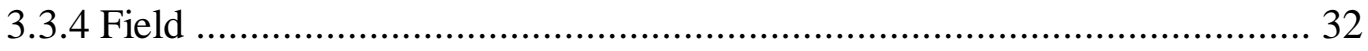

3.4 Applying Bourdieu's epistemological insights in the field .......................... 33

3.4.1 The symbolic nature of capital ....................................................... 33

3.4.2 Use people with diverse backgrounds as sample................................. 33

3.4.3 Map out the field and explain people's different positions in capital and

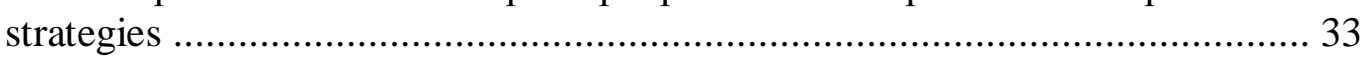

3.4.4 Pay much attention to the voices of those disadvantaged ...................... 34

3.5 How Bourdieu's Theory of Practice is used by accounting researchers........... 34

3.6 How Bourdieu's Theory of Practice is used to set up the research questions for

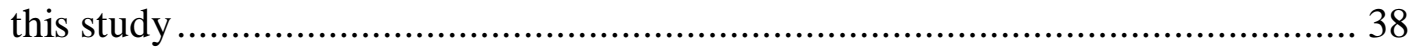

Figure 3-1 Specific research questions set through applying Bourdieu's theoretical framework ......................................................................... 40

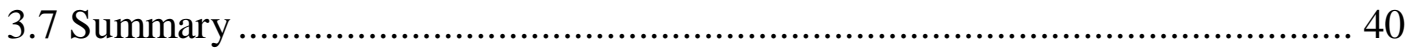

Chapter Four: Research Methods ..................................................................... 41

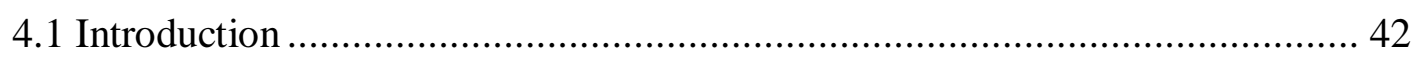

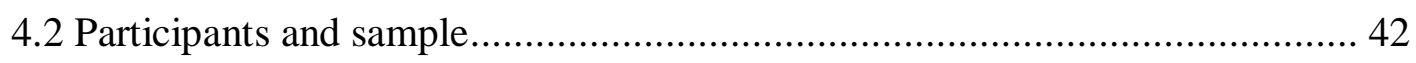


Table 4-1: Ethnic, national and other background demographics of the participants ............................................................................. 43

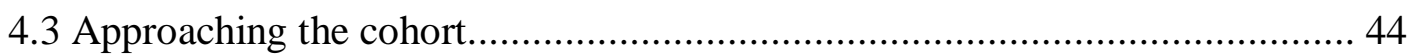

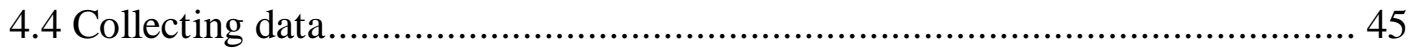

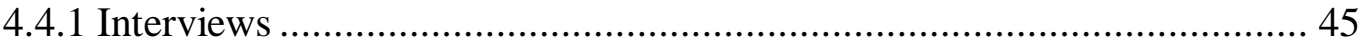

4.4.2 Ethnic background and other personal information validation ................ 47

Figure 4-1: A sample note for interviewee 22 .................................... 48

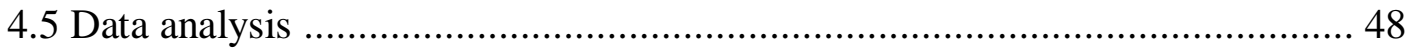

4.5.1 Divide the interviewees into different ethnic groups ........................... 48

Figure 4-2: Major steps of data analysis ............................................. 49

4.5.2 Eliciting the forms of capital and strategies ........................................ 50

Figure 4-3: Elicitation of the forms of capital and strategies from interview

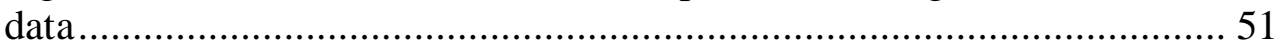

4.5.3 The shared forms of capital and strategies .......................................... 51

4.5.4 Assigning values to the forms of economic and cultural capital ............. 51

Figure 4-4: How a value for a form of capital is assigned ...................... 52

Table 4-2: The forms of capital and their values obtained from interviewees' self-perceptions ........................................................ 54

4.5.5 Identify the spaces occupied by different ethnic groups........................ 54

Figure 4-5: Positioning an interviewee in a space of economic and cultural

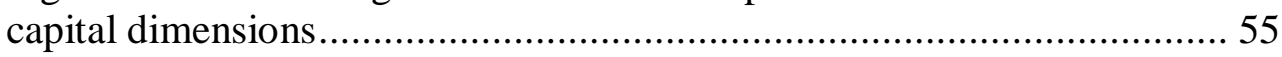

4.5.6 Forms of capital lacking in ethnic minority aspirant accountants ............ 55

4.5.7 Strategies used to overcome discrimination ......................................... 56

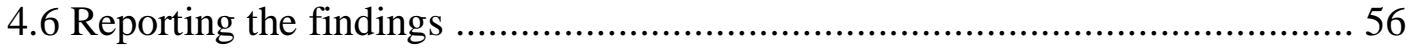

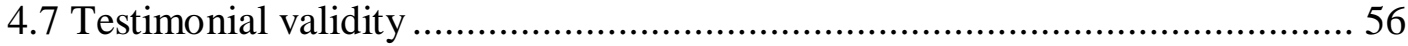

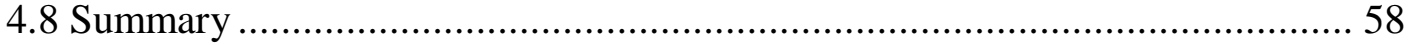

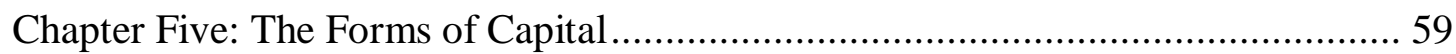

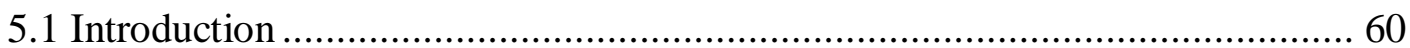

5.2 Different positions taken by different ethnic groups .................................. 60

Figure 5-1: Spaces of ethnic groups in the economic capital and cultural

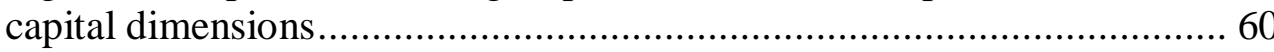

5.3 Forms of capital that are lacking in ethnic minority aspirant accountants ...... 61

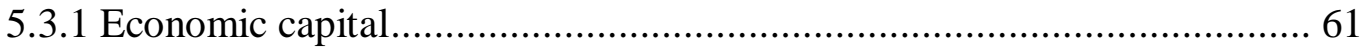

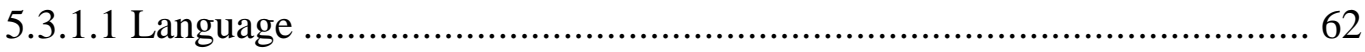

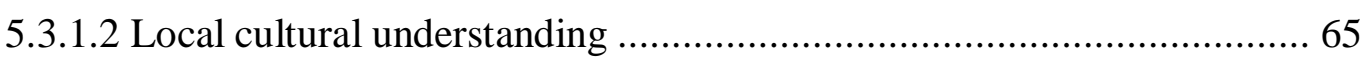

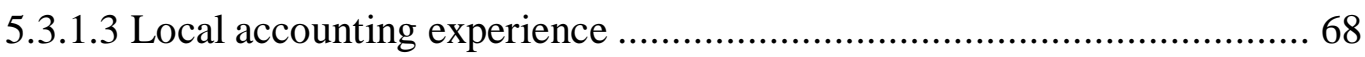

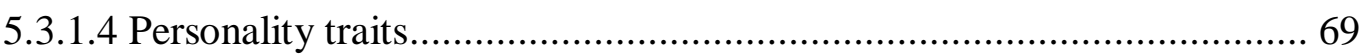


5.3.2 Cultural capital.... 73

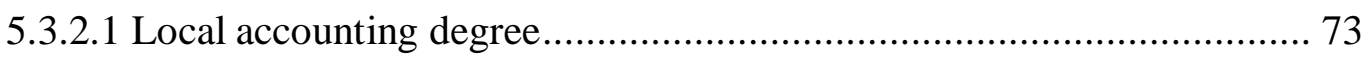

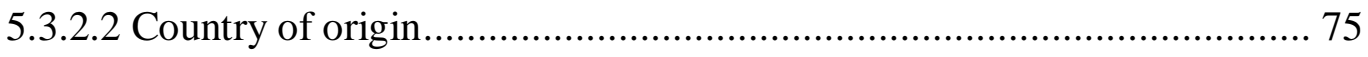

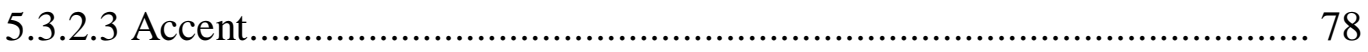

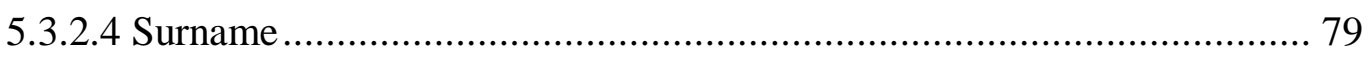

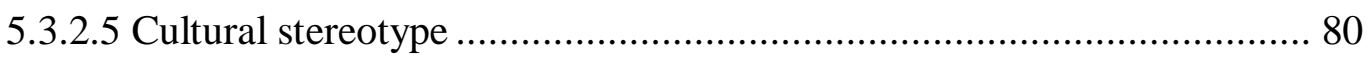

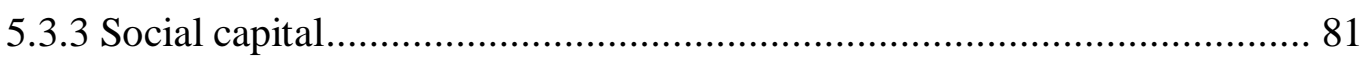

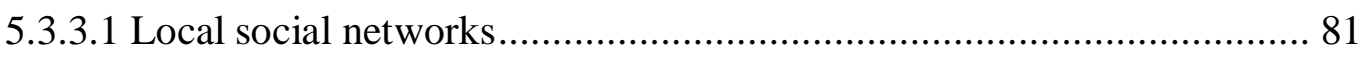

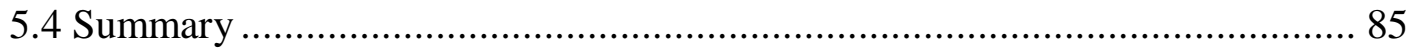

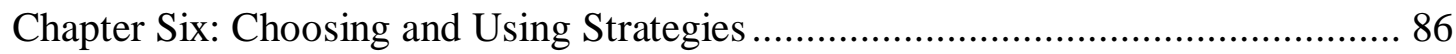

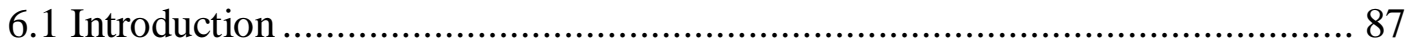

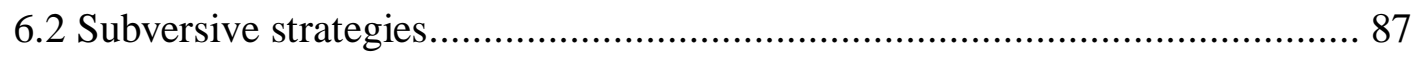

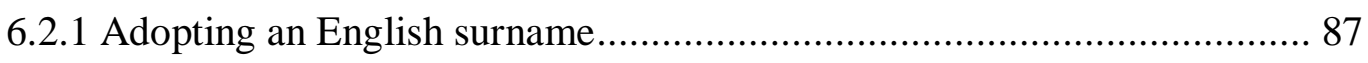

6.2.2 Meeting the employer face-to-face .................................................. 89

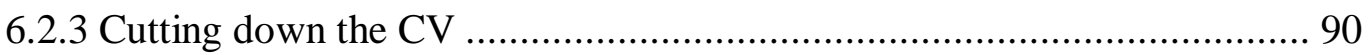

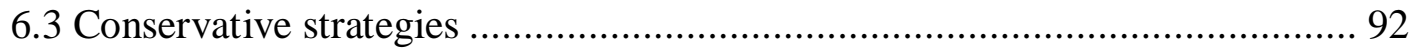

6.3.1 Accepting an undesirable offer ........................................................ 92

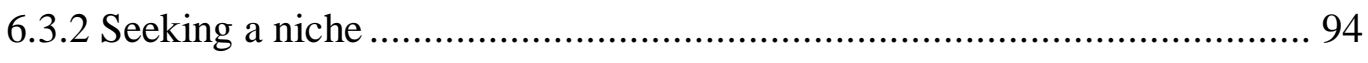

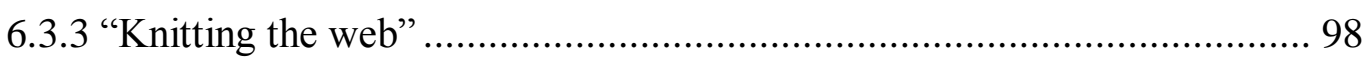

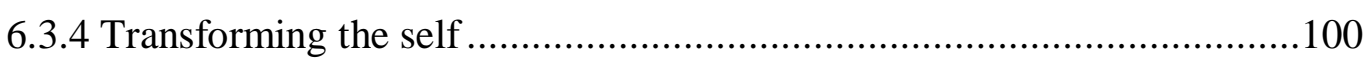

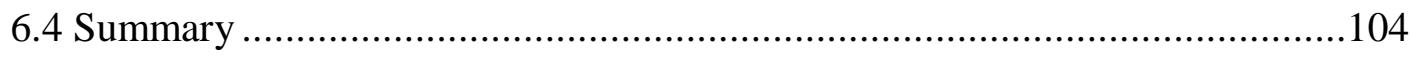

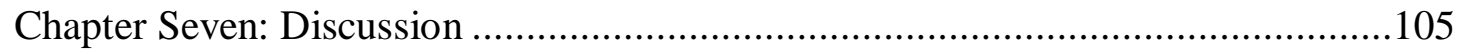

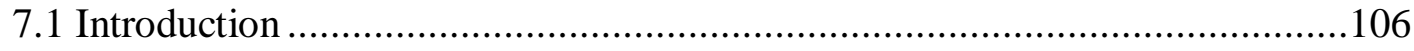

7.2 Bourdieu's field, and insights of accounting scholars ................................106

7.3 The "taken for granted" ideologies that impact on the accountant employment

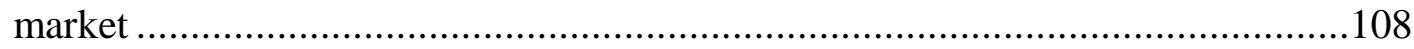

7.4 Groups who may suffer discrimination on the basis of ethnicity..................109

7.5 How skills and attributes may be integrated into social and cultural

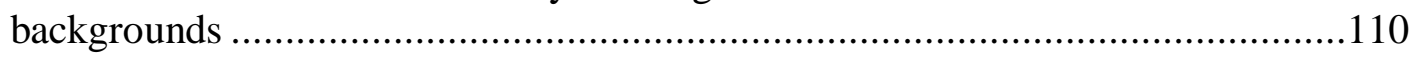

7.6 The function of hegemony in the processes of discrimination....................1111

7.7 Making use of dynamics between capital and field ....................................111

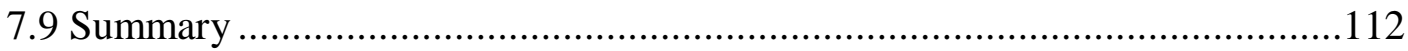

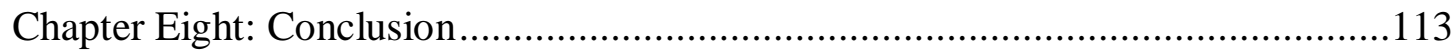

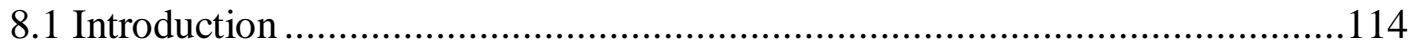


8.2 Review of the study

8.3 Answers to research questions

8.3.1 Research question one: the forms of capital

8.3.2 Research question two: the strategies

8.3.3 Additional Insights.

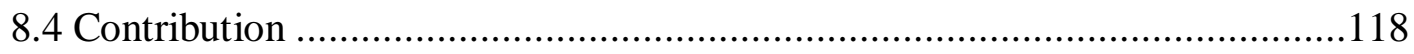

8.4.1 Contribution to the accounting literature .............................................118

8.4.2 The benefits of Bourdieu ...................................................................119

8.4.3. The contribution of the validation exercise .........................................120

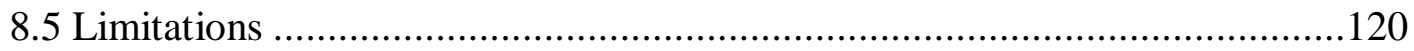

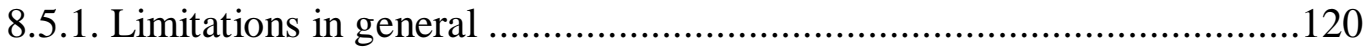

8.5.2. Limitations specific to the researcher ............................................. 121

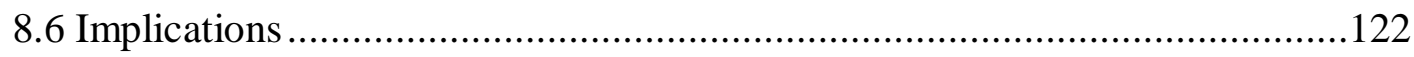

8.6.1 Implications for the accounting profession ........................................122

8.6.2. Implications for aspirant accountants ............................................. 122

8.7 Directions for further research .................................................................. 123

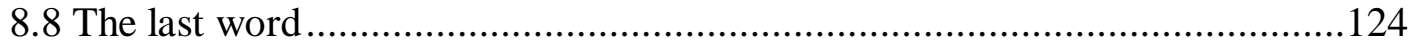

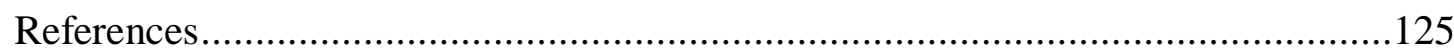

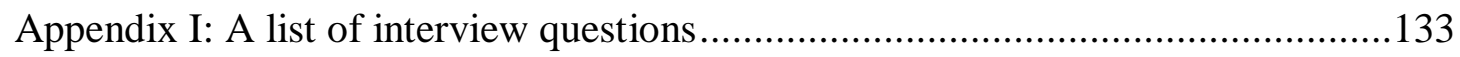

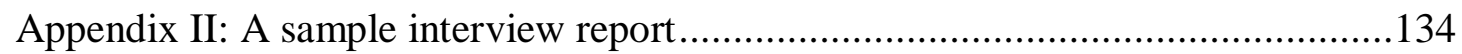

Appendix III: Report of Testimonial Validation...............................................141

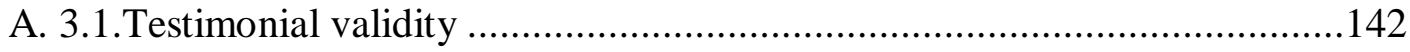

A 3.1.1 Validating the overall findings.....................................................142

3.1.2 Validating specific quotations, themes and other interpretations .............142

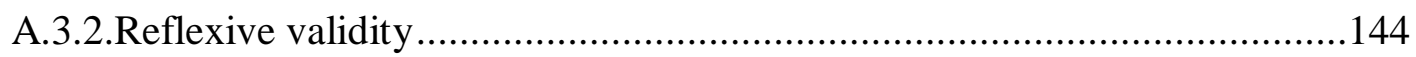

A.3.2.1 Deeper understanding about New Zealand society and accountant employment market

A.3.2.2 Additional thoughts about the New Zealand accounting profession ....146

A. 3.3.Catalytic validity.

Appendix IV: The epistemology of Pierre Bourdieu ........................................... 148

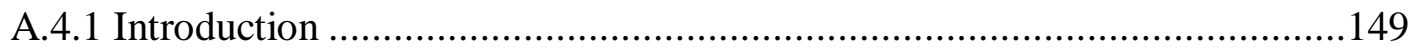


Table A 4.1 Books examined for analysing Pierre Bourdieu's epistemology

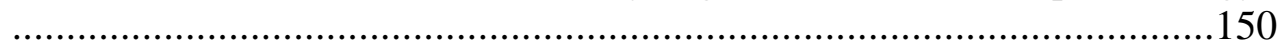

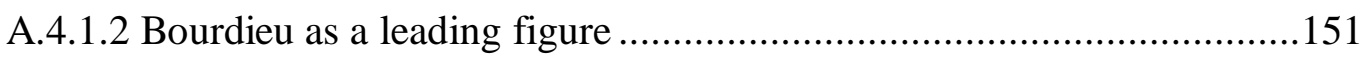

A.4.1.3.Bourdieu's world view for social research .......................................152

A.4.1.4.Social classes are symbolic and relational.......................................153

A.4.1.5 How Bourdieu's social world is created..........................................154

A.4.1.6 The social fact is won, constructed and confirmed by social scientists'

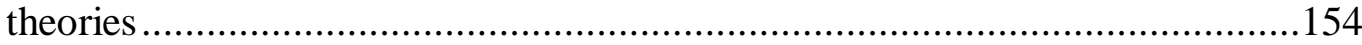

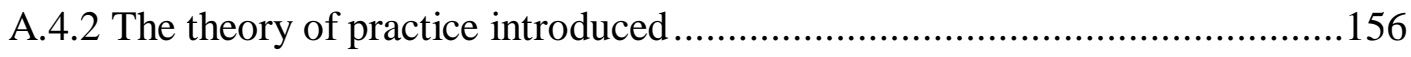

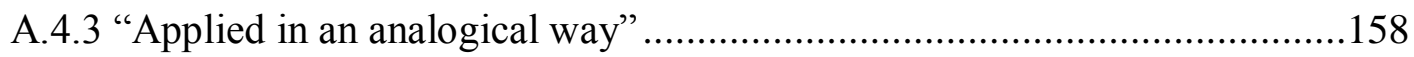

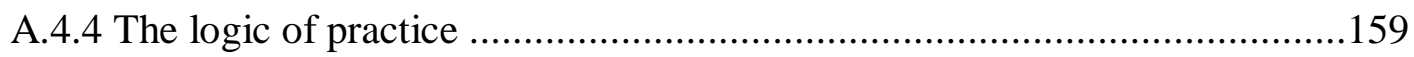

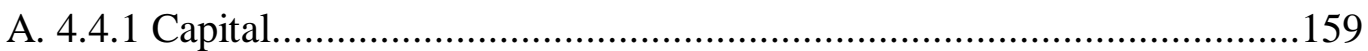

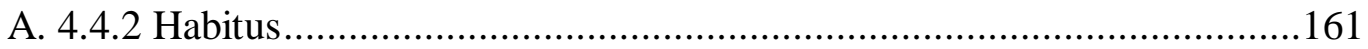

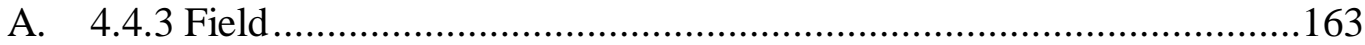

A.4.5 The inter-relationship between capital, habitus and field: logic of practice 165

A. 4.6 Operationalising social research using Bourdieu's Theory of Practice ......166

A.4.7 Concluding a social research project .................................................170 


\section{List of abbreviations}

$\begin{array}{ll}\text { ATO } & \text { Approved Training Organisation } \\ \text { BCom } & \text { Bachelor of Commerce } \\ \text { CA } & \text { Chartered Accountant } \\ \text { CPA } & \text { Certified Public Accountant } \\ \text { CV } & \text { Curriculum Vitae } \\ \text { EEO } & \text { Equal Employment Opportunity } \\ \text { ESL } & \text { English as a Second Language } \\ \text { GST } & \text { Good and Services Tax } \\ \text { HR } & \text { Human Resources } \\ \text { IT } & \text { Information Technology } \\ \text { NZICA } & \text { New Zealand Institute of Chartered Accountants } \\ \text { MPA } & \text { Masters of Professional Accounting } \\ \text { UK } & \text { The United Kingdom } \\ \text { USA } & \text { The United States of America } \\ \text { VUW } & \text { Victoria University of Wellington }\end{array}$


Chapter One: Introduction 


\subsection{Introduction}

This chapter provides a general overview of the thesis. It describes what the study is about, which gap in the accounting literature it fills, the context on which it focuses, how the study is carried out, the potential contributions, and other important framing questions. The last section of this chapter describes how the thesis is structured and outlines the interchangeable terms used in the thesis.

\subsection{What is this study about?}

This thesis sets two research questions: (1) What forms of capital do ethnic minority aspirant accountants perceive they lack for successful entry into the accounting profession? This question may be abbreviated to: "What forms of capital are perceived as lacking for successful entry into the accounting profession" (when represented in the figures in this thesis)? The second question which directly follows on from this is: (2) What strategies have these aspirant accountants used to overcome any potential discrimination? These questions fill some of the gaps in accounting research, in that they will explain how aspirant accountants are often excluded from the accounting profession when they come from certain social and cultural backgrounds, and how certain factors that potentially exclude these people become manifest in mobilising their strategies to overcome such exclusion. The notion of forms of capital is taken from Bourdieu's Theory of Practice, which is core to this study. The forms of capital represent the variety of resources that can be used by these aspirant accountants to gain entrance to the accounting profession.

\subsection{The gap in accounting literature}

In discussing what determines entry into the accounting profession, there are generally two perspectives: a functionalist perspective and a socially-constructed perspective. The former emphasizes an accountant's functional attributes, such as knowledge, skills and personality traits; and the latter, their social and cultural backgrounds, such as class, race and gender. The former is used to inform those studies focusing on the formation of the accounting profession (inter alia Richardson, 1989; West, 1996) and the 
accountant identity (inter alia Anderson-Gough et al., 1998; Wells et al., 2009); the latter, discrimination in the profession (inter alia Hammond, 1997a; Annisette, 2003; Kim, 2004a; Sian, 2006, 2007).

While both perspectives are useful, the socially-constructed perspective is seen to better explain extant exclusion mechanisms (Jacobs, 2003; Sidhu \& West, 2014). It explains why some aspirant accountants seemingly in possession of the appropriate knowledge, skills and personality traits, cannot, or find it hard to, enter the accounting profession.

The explanation provided from such a socially-constructed approach, however, is not complete. It has not answered how those who come from certain social and cultural backgrounds are potentially discriminated against and, furthermore, what they have done to overcome potential discrimination. These questions, if answered, will not only permit an improved understanding about the actuality of discrimination mechanisms in New Zealand, but will also inform how such factors mobilise people in their real-life strategies.

\subsection{The context of this study}

In addressing the determinants of entry into the accounting profession, this study focuses on the first step an aspirant accountant takes in getting a job in the accountant employment market. It is probably the most crucial step for those who aspire to obtain membership of the accounting profession.

This step is intertwined with the dynamism of the accountant employment market which, when compared with research into the accounting professional bodies, accounting education systems and accounting firms, receives little attention. The New Zealand accountant employment market is used in this study. 


\subsection{A focus on ethnicity}

Among the factors such as class, ethnicity and gender that represent social and cultural backgrounds, this researcher has chosen ethnicity as the focus. The reasons for this choice are:

(1) Ethnicity is rarely addressed as an issue in the accountant employment market, an exception being Firth (1981), and has mostly been ignored by accounting researchers; and

(2) Ethnicity has recently emerged as a salient issue for the accounting profession in New Zealand, Australia and Canada, and such salience is observed as part of a response to larger and ongoing influxes of ethnic minority migrants into these countries (Kim, 2004a; James \& Otsuka, 2009; Annisette \& Trivedi, 2013).

\subsection{The theoretical foundation}

As with all $\mathrm{PhD}$ theses, it was necessary to determine the best-fit foundational theoretical approach to answer the research questions in this study. This then benefits from the direction and insights that are brought by the chosen theory. Bourdieu's Theory of Practice was chosen as the foundational theory for this thesis. It is believed to best reflect the hidden and subtle nature of exclusion in the accounting profession today (Chua \& Poullaos, 1998; Jacobs, 2003; Lee, 2004; Malsch et al., 2011).

The theory is first used to shape the research questions. The forms of capital and strategies, corresponding to the first and second research questions respectively, are the two instruments Bourdieu $(1972,1980,1984)$ suggested may be used to reveal mechanisms of exclusion in professions.

The theory is then used in analysis of the data. For studying exclusion, Bourdieu suggested that one should first map out the field and then explain people's different positions in terms of their capital and strategies. Such 'mapping out' reveals the 
positions of ethnic minority aspirant accountants relative to others; and the explanation which follows suggests not only why they are positioned where they are in the 'map', but also what they can actually do to change their positions.

\subsection{Who participated?}

This study uses a cohort of accounting graduates from Victoria University of Wellington (VUW). These graduates had all experienced seeking work in the New Zealand accountant employment market and therefore will provide first-hand narrations, or raw material for analysis. They also offer diverse profiles with multiple ethnic and national backgrounds. They are used as the sample for this study.

This sample comprises 45 accounting graduates with ethnic backgrounds from 20 countries. It is ethnically more diverse and inclusive than the samples used by James and Otsuka (2009) or Annisette and Trivedi (2013), or other studies close to the topic of this thesis.

The sample used in this study is also noteworthy as it includes members of ethnic minorities as well as the dominant ethnic majority, those who are employed and also those who failed to gain employment.

\subsection{Potential contribution}

The study contributes to the current debate as to key factors that determine entry into the accounting profession; whether they are functional attributes, such as knowledge, skills and personality traits, or social and cultural background, such as class, ethnicity, race and gender (Jacobs, 2003). This study demonstrates that both are potentially key factors, with some functionalist attributes interlinking with an accountant's social and cultural background.

The study addresses whether accounting comprises only technical skills to fulfil special tasks, or is it also a tool used to produce and reproduce economic and cultural 
domination within society (Richardson, 1987)? It indicates that accounting is such a tool.

The study further determines whether it is only a few large ethnic minority groups, such as Chinese and Indians, who suffer discrimination, or if it is also encountered by others from many diverse backgrounds. Whatever the focus, it is an issue that must be taken seriously and addressed by those in the accounting profession.

This study has practical implications. In particular, it will inform accountant employers who are potentially involved with hiring ethnic minority accountants. Further, it will educate accountant employers and allow them to anticipate which of those in their offices are likely to suffer discrimination because of ethnicity and other social backgrounds, and act accordingly.

\subsection{Structure of the thesis}

The thesis of this study is structured as in Table 1-1 below.

\begin{tabular}{|c|l|l|}
\hline Chapters & \multicolumn{1}{|c|}{ Title } & \multicolumn{1}{c|}{ Content } \\
\hline 1 & Introduction & $\begin{array}{l}\text { The research objective, literature gap, theoretical } \\
\text { position, methods, context, and potential } \\
\text { contributions }\end{array}$ \\
\hline 2 & Literature review & $\begin{array}{l}\text { What is known already in the literature, and how } \\
\text { the unknown is to be revealed }\end{array}$ \\
\hline 3 & Bourdieu's Theory of Practice & $\begin{array}{l}\text { What the key elements of the theory are and how } \\
\text { the theory is used in this study }\end{array}$ \\
\hline 4 & Research methods & $\begin{array}{l}\text { Sampling, data collection, data analysis, } \\
\text { testimonial validation, and other procedures }\end{array}$ \\
\hline 5 & The forms of capital & $\begin{array}{l}\text { Identifying the forms of capital which are } \\
\text { perceived as lacking for successful entry into the } \\
\text { accounting profession }\end{array}$ \\
\hline 7 & Choosing and using strategies & $\begin{array}{l}\text { Determining what strategies these aspirant } \\
\text { accountants have used to overcome any potential } \\
\text { discrimination. }\end{array}$ \\
\hline 8 & Discussion & $\begin{array}{l}\text { Additional insights which may be derived from } \\
\text { the findings in Chapters Five and Six }\end{array}$ \\
\hline Conclusion & $\begin{array}{l}\text { Answers to research questions, additional insights } \\
\text { including the implications and contributions, } \\
\text { limitations and directions for further research }\end{array}$ \\
\hline
\end{tabular}

Table 1-1: Structure of the thesis 


\subsection{Interchangeable terms}

In this thesis the following terms are used interchangeably.

- Aspirant accountant, accounting graduate, applicant, candidate, job seekers.

- Pakeha, Kiwi, "New Zealanders, mostly of British descent", "European New Zealanders".

- New Zealander, local people, locals.

It is worth noting that "Pakeha" and "Kiwi" are not defined consistently in different dictionaries. In The New Zealand Oxford Dictionary (2005), "Pakeha" is "a lightskinned non-Polynesian New Zealander, esp. one of British birth or ancestry as distinct from a Maori”, and “Kiwi” is "a New Zealander." In Collins English Dictionary (2009), Pakeha" is "(in New Zealand) a person who is not of Māori ancestry, esp. a White person.", and "Kiwi” is “(informal) a New Zealander". In this study, both "Pakeha” and "Kiwi" are used to denote New Zealanders who are mostly of British descent.

\subsection{Summary}

This chapter provides a general overview of the study. It describes what this study is about, where there are gaps in the accounting literature it covers, the approach it takes to carry out the research, the potential contributions and other framing questions. It also advises how the thesis is structured and the lexicon of terms that are used interchangeably in this thesis.

Chapter Two will present the literature review for this study and reveal the gaps in that literature. 
Chapter Two: Literature review 


\subsection{Introduction}

This chapter presents a review of the relevant accounting research literature, some of which explores the factors that may affect an aspirant accountant's entry into the accounting profession. At the end of this review, the gaps in the literature are revealed. Such gaps offer an opportunity to identify and scope the problem addressed by this study.

The review pays particular attention to those factors that affect an aspirant accountant's employability in the accountant employment market. This is because:

1) Getting an accounting job is the first step towards becoming a member of the accounting profession, and

2) Compared with other contexts, such as accounting education systems, accounting firms and accounting professional bodies, the accountant employment market receives little attention from accounting researchers.

Evetts (2003), in her sociological analysis of professionalism and occupational change, divided approaches into two categories: value systems and ideologies. Value systems are inherent in the understanding that a profession can be identified by certain professional values, such as specialist knowledge, skills and personality traits. Those who possess such values are suitable to represent, or to be a member of, that profession. Ideologies, on the other hand, are a belief that a profession is socially constructed, based on certain ideologies. These ideologies tend to favour one group over another. People with certain social and cultural backgrounds, such as being from a middle-class family, 'British whites' and males, are favoured; and people without such backgrounds, disfavoured. Evetts (2003) further identified that the value systems approach was the predominant one used by studies before the 1970s, but since then there has been an increase in studies taking an 'ideology' approach. 
Evetts' value systems and ideologies correspond to the identification by Willmott (1986) of the functionalist perspective and critical perspective, these being two dominant perspectives in professionalisation studies in accounting. The functionalist perspective emphasizes that it is the functional attributes that exclude people from the accounting profession, and the critical perspective emphasizes that it is aspirant accountants' social background that determines or inhibits entry.

The literature review below uses the terms 'functionalist perspective' and 'sociallyconstructed perspective' to accommodate both Evetts' and Willmott's distinctions.

\subsection{A functionalist perspective}

The functionalist perspective is mostly adopted by those who study accountantemployer expectations. From this perspective, an accountant is a package of functions that are traded in the labour market (Willmott, 1986; West, 1996; Gammie, 1996). Behind this perspective is the ideology of economism, which sees the relationship between accountants and their employers as overwhelmingly economic. Those who possess the functions that help employers make money are highly appreciated, and those who do not, devalued. Associated with economism, is practicum (Velayutham \& Perera, 2008). Practicum suggests that some accounting functions are only fulfilled by "soft" or non-technical skills, and these skills cannot be acquired in universities but only in 'real' workplaces. Those who have accounting work experience are therefore much more highly appreciated by potential accountant employers.

The five factors that are found from the functionalist perspective are: accounting knowledge and skills, communication and socialisation skills, information technology skills, personality traits and accounting work experience. Each of these is discussed below.

\subsubsection{Accounting knowledge and skills}

Richardson (1989), in his Canadian's Accounting Elite 1880 - 1930, suggested that accounting knowledge and skills played an important role in excluding people from the 
accounting profession, and this was particularly visible in the early years of accounting professionalisation. Richardson's opinion was supported by Dezalay (1995) who broadly examined the history of accounting professionalisation in the U. S. Dezalay (1995) held the view that accounting knowledge and skills were the 'pillars' to support the accounting profession.

Accounting knowledge and skills are so important that they are used to identify an accountant today. When employers select an accountant, they emphasize that a candidate must possess an accounting qualification, diploma, degree or certification by a professional body, to prove that he or she possess accounting knowledge and skills (Kavanagh \& Drennan, 2008; Chillas, 2010). For entry into the largest accounting firms and mainstream corporations, a candidate must have at least an accounting degree before applying for an accountant position (Anderson-Gough et al., 1989; Chillas, 2010). As Chillas (2010) observed:

Employers assume that degrees automatically signal greater productivity.... Degrees are, or can be, a proxy for occupational knowledge and skills. (ibid, pp. 158-160)

\subsubsection{Communication and socialisation skills}

Tempone et al. (2012), in their study of accountant employer expectations in Australia, divided an accountant's skills into two categories: technical and generic (non-technical). They were of the view that in today's accountant employment market, graduates with an accounting degree are seen as oversupplied, and in this situation it is the generic skills rather than technical skills that affect the employability of an accounting graduate. Amongst the generic skills they described, communication and socialisation skills are the two basic skills which underpin others. These two skills are of the most concern to accountant employers, especially when they are facing a pool of culturally-diverse candidates (Keneley \& Jackling, 2011).

Unsurprisingly, communication and socialisation skills are closely related to a candidate's first language, with all the norms and behaviours which are distinctive to particular cultures. In an English-speaking country, such as Australia or New Zealand, 
Chinese and other Asians for whom English is not their first language often find it very hard to access a position in the accountant employment market. Their English proficiency has been observed to be a major impediment (Kim, 2004a; Birrell \& Healy, 2008). A number of researchers have identified that with English proficiency, it is the oral proficiency which is the most difficult to master (Kennedy \& Sorensen, 2006; Birrell \& Healy, 2008; Gray, 2009; Johns, 2010; Gray \& Murray, 2011; Sugianto \& Johns, 2011). Such research suggests this is an important factor when employers are selecting a trainee accountant.

Communication and socialisation skills are also related to how well an accountant understands the local New Zealand culture. As found by Holmes and Riddiford (2009, 2010), migrant professionals including accounting professionals often violate New Zealand norms because they either are not aware of the local norms, or do not understand them very well. They may annoy their teammates and clients, and such an experience by an employer will mean that in future such migrant applicants are avoided.

\subsubsection{Information technology (IT) skills}

Oliver and Que (1996), in their study of the views of American accountant employers, highlighted the importance of a candidate's IT skills. They emphasized that accounting systems have now shifted from traditional manual processes to computerised processes, and to meet this change, accountants are expected to be proficient in using information technologies.

Oliver and Que's view from the U. S. was confirmed by Velayutham and Perera (1996), who describe some radical changes in the accounting profession in New Zealand: accountants are required to possess more skills than accounting, and IT skills are the most essential of these additional skills.

\subsubsection{Personality traits}

Anderson-Gough et al. (1998), in their observation on how a trainee accountant is selected and trained in the biggest accounting firms in the U. K., identified personality traits as being of particular relevance. A trainee accountant is selected not only based 
on "a good degree" (ibid, p. 58) but also on the basis of personality traits. In their view, personality traits are appearances and manners that are likely to please or even entertain clients. Appearance and manners, such as a friendly persona, smart dress and intelligent presentation, are what accounting firms emphasize in their choices, and then use to further train and assess a trainee accountant on an ongoing basis. As they saw it, professionalism is reflected in outward mannerisms.

Such research findings are confirmed by others: Courtis and Zaid (2002), in their study of accounting graduate employability in Australia, conveyed that employers pay much attention to personality traits and they also use a personality performance test to select an accountant. Wells et al. (2009) showed that in New Zealand, what matters to employers is an accounting graduate's emotional intelligence (EQ) because those possessing such intelligence have the potential to better associate with clients. Kim (2004a) provided an explanation based on psychological 'types': those who may be called Type A (which is characterised by aggressive, ambitious and assertive traits) are preferred in accounting firms; whereas those who are Type $B$ (which is characterised by relaxed and easy-going behaviours) are less favoured.

\subsubsection{Accounting work experience}

Accounting work experience was found by Cheng et al. (2009) to also be an important factor that is used to distinguish or give preference to one candidate over another. Those who are employed in an accounting job, even a part-time job, are identified as possessing certain attributes that are preferred by employers. It is therefore much easier for those who have accounting work experience to find an accountant job when compared to those who have no experience.

The importance of accounting work experience is explained by accounting researchers in different ways. For example, Oliver and Que (1996) explained that certain IT knowledge and skills, which are essential for an accountant, cannot be acquired in textbook study but in doing 'real' accounting jobs. Tempone et al. (2012) described that some skills, such as teamwork, critical thinking and self-management, can better be developed in the workplace than in universities. 


\subsection{The functionalist perspective: a weakness}

The above review presents the potential exclusion factors that have been identified in research with a functionalist perspective. This perspective may well enhance people's understanding about what technical or functional attributes an accountant should ideally possess. However, it fails to explain or fully explain all the exclusion mechanisms presently in operation (Chua \& Poullaos, 1998; Jacobs, 2003). It cannot answer why some aspirant accountants, with the required accounting degree, skills and work experience, are not being appointed to an accounting job.

That question has been answered from a different perspective, the socially-constructed perspective. This perspective emphasizes that an aspirant accountant who comes from a less-favoured social and cultural background will find it difficult to enter the accounting profession, and this occurs irrespective of whether he or she has the appropriate accounting degree, skills and work experience. This perspective was employed by Jacobs (2003) who, using Bourdieu's Theory of Practice, argued that some accounting graduates lack the cultural habitus that is associated closely with middle-class families (whose habitus is more akin to the employer). It was also part of Richardson's (1987) hegemonic accounting theory approach, where he purported that accounting is a tool which is used by the ruling class or elite to exclude others from joining, so that their economic and cultural domination can be perpetuated. Such exclusion may be found to apply across the business community, as well as in the accounting profession (ibid). The socially-constructed perspective is discussed in-depth in the next section as it deserves a further in-depth review.

\subsection{The socially-constructed perspective}

The socially-constructed perspective is adopted principally by those who study the situations of disadvantaged or marginalised people in the accounting profession. The potential exclusion factors they have identified are: class, country of origin, race and ethnicity, gender, age and social networks. Each of these will be discussed below. 


\subsubsection{Class}

Class has been a focus of accounting professionalisation studies for a considerable time. During the late 19th to mid-20th centuries, the biggest accounting firms in Scotland, Canada and the U. K., were dominated by those who came from upper or middle-class family backgrounds. The employers appeared to favour those candidates who came from the same family backgrounds as their own (Willmott, 1986; Richardson, 1989; West, 1996; Anderson et al., 2005; Lee, 2009).

Maltby (1997) associated class with elitism in the 19th century. In her article, Accountant and the Soul of the Middle Class, Maltby claimed "[a]ccounting is not simply a set of techniques, but an attitude of life" (ibid, p. 79). Aristocrats are not suitable for accounting because they do not worry about money; equally, 'the mob' is not suited for accounting because they lack orderliness and rationality; and "when they join forces, they will bring the roof down" (ibid, p. 75). This situation calls for a class in the middle tier, can act in a stereotype both "as a staid but incorruptible bore and as a crafty financial wizard" (ibid, p. 82). In Maltby's view, accountants are those who serve the aristocratic group and, because they serve this group, they can also claim some category of elite status in society.

Class mindfulness is still with us today; and is perceived to be a factor that potentially excludes candidates from working-class families from entering the accounting profession (Jacobs, 2003). Such exclusion is now less visible and more subtle than hitherto, when accent or schooling was a useful class identifier. It is embedded in the so-called "transferrable skills", such as charisma, interpersonal and leadership skills, which are emphasised by accountant employers. These skills are harder to gain in working-class families than in upper and middle-class families (Jacobs, 2003; Anderson, Edwards \& Chandler, 2005; Spence \& Brivot, 2011).

\subsubsection{Country of origin, race and ethnicity}

Hammond (1997a), in her study of professional employment opportunities for black Americans in the American accounting profession, raised race as an issue. She demonstrated that black Americans were racially marginalised or discriminated against 
when entering the profession; such discrimination was very visible from the 1920 s to 1960 s.

Research by Miranti (1998) introduced the concept of nativism. In his study of the American accounting profession in late $19^{\text {th }}$ Century, he found those who migrated from East and South European countries were prevented from accessing the American public accountancy market. He described this as follows.

The language, religions, customs, and even physical appearances of these new groups seemed at variance with the norms to which the socially predominant white Anglo-Saxon Protestant middle classes had long been accustomed. To some, these immigrants seemed to lack the correct combination of personal qualities of 'character' believed essential in professional life. This apparent dilemma motivated some professional and political leaders to try to preserve the social leadership of the nativist middle class by establishing government structures to regulate entry into the new and promising profession of public accountancy (ibid, pp. 362-363).

Miranti further observed that while Eastern and Southern Europeans suffered such objections from the American accounting profession, those from what is now called the United Kingdom, in particular England, found it easier to be accepted. Nativism is thus not really about whether an accountant is of European origin in preference to other groups; it is about whether the accountant is of a particular European race or ethnicity, with preference being shown for those of Anglo-Saxon/British origins.

Both Kim (2004a), and James and Otsuka (2009) associated nativism with racism. They argued that there is racist ideology in the accountant employment market in New Zealand and Australia, and such ideologies may partly be traced back to racism which originated during the gold-mining periods in Australasian economies from the mid- to late $19^{\text {th }}$ Century. In those days, Asian migrants were harshly discriminated against at times, and many settlers and colonial officials were particularly racist, treating the migrants as inferior to British and other 'whites', such as diggers arriving in Australasia after gold rushes on the West Coast of America. Such perceptions of co-workers that 
Asians are inferior are still experienced by many these migrants, who comprise a major group of new migrants to New Zealand and Australia. Kim, and James and Otsuka's arguments are supported by Annisette and Trivedi (2013), who have recently identified that the same situation is being experienced by new migrants from the Indian subcontinent to Canada.

Annisette (2003), in her article The Colour of Accountancy, linked race with ethnicity. In her view, race and ethnicity work together, and they are proxies for each other. They work together to exclude those who are both ethnic minorities and migrants, from the accounting profession. Ethnicity is further examined by Baskerville et al. (2014). They identify several identifying features of ethnicity which may be used by researchers, among which country of origin and 'first language' are the most significant. The significance of these two factors is confirmed by other researchers. Country of origin had been earlier confirmed by Miranti (1998), in his study of "Professionalism and nativism: the competition in securing public accountancy legislation in New York during the 1890s". He observed that if there were two Europeans, one from an AngloSaxon country and another not, they will be treated differently by the American public accountancy employment market. Language and accent have been confirmed by Spence and Brivot (2011) as important signifiers, in that when there are two employees, one Francophone (French-speaking) and the other Anglophone (of English-speaking origin), these will be distinguished from each other by some members in the Canadian accounting profession.

\subsubsection{Gender}

Gender and its related concept of 'sexism' have been long discussed in the accounting research literature. Ciancanelli et al. (1990), Loft (1992) and Lehman (1992) were among the first to focus on this aspect. Such studies offered a glimpse of long-existing levels of sexism in the British accounting professional body, as well as women being discriminated against when pursuing an accounting job. Women were overlooked because they were perceived as being inferior to men, who were also the majority of business owners. In the extensive debate around the time of World War I in the UK, it appeared that men were not comfortable with their work being accounted for and/or reported on by women. Men believed that: 
[B]y nature, women were impulsive, full of sentiment and hasty in judgment failings which condemned her against entry into the professions where justice, stern and unbending, but not sentiments, had a place (Lehman, 1992, p. 269).

Perhaps this is changing in the $21^{\text {st }}$ Century, especially for women privileged by education and class. Ikin et al. (2012) found that sexism had not been an issue for women entering the accounting profession (circa 1940s in Australia), but it was seen by Kim (2004b), and Fearfull and Kamenou (2006) to still be an issue for ethnic minority women.

\subsubsection{Age}

Lehman (2012) also described ageism when her research presented the sexism issue in her in-depth review of practices which have restricted women's entry into the accounting profession since the early 1900s. Ageism was found to be a factor that potentially excludes from the accounting profession those who are older, and its impact may not be any less severe than the impact of the other more widely researched 'isms' (ibid, p. 257), such as classism, racism and sexism. Lehman's perception of ageism was acknowledged in the article Overcoming Ageism in the Accountancy World, which was published in Insight, of the Chartered Institute of Management Accountants (Anon, 2012).

In interpreting what age is seen as unacceptably old for new entrants to the accounting profession, Gringart and Helmes (2001) suggested that, in the Australian accountant employment market,

Minimal interest was shown in hiring persons over 45 years of age and there was no interest in hiring persons over 56. (ibid, p. 23)

They further established that ageism potentially amplifies the impact of sexism, and women are further disadvantaged when accessing the accountant employment market; as far as employability is concerned, a woman's age 'counts against' them at a younger age than for men (Anon, 2012). 


\subsubsection{Social networks}

Social networks or social connections are slightly different from the sociallyconstructed factors such as race, gender and age, mentioned above. They are different because these networks or connections do not pertain to each individual, but groups of people with whom the individual associates. Such an associated group of persons has the capacity to signal to 'outsiders' a particular individual's social status and cultural affiliation.

Baskerville (2006b) held this to be a salient issue in the accounting profession in New Zealand. Social networks surfaced in oral-history evidence of nepotism in accounting partnerships with (principally) sons following fathers into the partnership. Thus those who had blood relationships with the partners used to be favoured. Baskerville was discussing the development of widespread support for anti-nepotism rules in New Zealand partnerships, thereby favouring a pure meritocratic approach. But this does not preclude the lack of social connectivity/networks remaining a potential issue in the accountant employment market today.

\subsection{The gap in the socially-constructed perspective}

The socially-constructed perspective, as reviewed above, offers several factors that may exclude an aspirant accountant, even one with the required accounting degree, skills and work experience, from the accounting profession. An aspirant accountant may be excluded on the basis of any or all of these factors. In this sense, the socially-constructed perspective has further explained some factors, which were not to be found if solely adopting a functionalist perspective.

However, the socially-constructed perspective has not provided a completely satisfactory or comprehensive explanation. In particular:

a) it has not answered how, or in what way, particular individuals experience discrimination, on the basis of certain ethnic/ cultural backgrounds; 
b) if such potential exclusion factors have been experienced, how do these factors mobilise these individuals into developing their own 'real-life' strategies to combat the discrimination? and

c) What are such strategies?

With these questions as yet largely unanswered, the arguments that the accounting profession is socially constructed based on certain ethnic or cultural preferences (Jacobs, 2003) and that accounting is a tool used to segregate society (Richardson, 1987) are still not satisfactorily proved. This suggests that there remains a research 'gap'; a gap this study aspires to fulfil by asking or addressing:

1) How aspirant accountants are potentially excluded on the basis of certain cultural factors when entering the accounting profession; and

2) What strategies have aspirant accountants used to overcome any potential or experienced discrimination?

\subsection{The Focus on Ethnicity}

\subsubsection{The choice of ethnicity as the focus}

The research gap that occurs, after considering the socially-constructed research perspective, can be closed by choosing one of the social and cultural factors (identified in Sections 2.4 and 2.5) as the focus for this research. Choosing one factor as the focus is a common approach adopted by accounting researchers. For example, Kim (2004a) chose race as the focus to probe the racism issue; while Maltby (1997) focused on class, and Fearfull and Kamenou (2006) on gender.

Among the available social and cultural factors, ethnicity is chosen as the focus for this study. Ethnicity has already been raised as an issue pertaining to discrimination in the accountant job market by Firth (1981). He reported that in the British accounting labour market in mid-1970s, those who were of Britain, Australia and France were advantaged, and those who were from India and Pakistan were disadvantaged. Firth did not offer further explanations for this discrimination.

Following Firth, Hammond (1997a; 2002) provided evidence that black Americans were discriminated against when entering the "white-collar" American accounting 
profession and that this was particularly visible between the 1920s and the 1960s. She determined that the Civil Rights Act 1964 and governmental incentives to encourage accounting firms to employ black Americans played an important role in increasing the number of blacks in the American accounting profession. Nonetheless, Hammond's focus was not on the mechanisms of discrimination. Similarly, in another study already described above, James and Otsuka (2009), claimed racism exists in the Australian accountant employment market, and Chinese are racially discriminated against when entering the accounting profession. Their study, however, focused only on the Chinese and did not include other ethnicities such as those from the Indian sub-continent.

More recently, Annisette and Trivedi (2013) found Indian migrant accountants encountered different challenges when entering the Canadian accountant employment market. It was suggested that Indians have a somewhat different 'moral order' from those of local Canadians and that it is hard for them to present a sufficiently 'Canadian' accountant identity. Like James and Otsuka (2009), Annisette and Trivedi reported on a sample which consisted of a group from only one area, i.e. the Indian migrants.

\subsubsection{The problem narrowed down}

With ethnicity as the focus, the research questions (related to the gap identified in Section 2.5) are further narrowed down to:

(1) How ethnic minority aspirant accountants are potentially discriminated against when entering the accounting profession, and

(2) What strategies have aspirant accountants used to overcome any potential or experienced discrimination?

Figure 2-1 below summarises the process of the literature review towards finding the gap that this study addresses. 


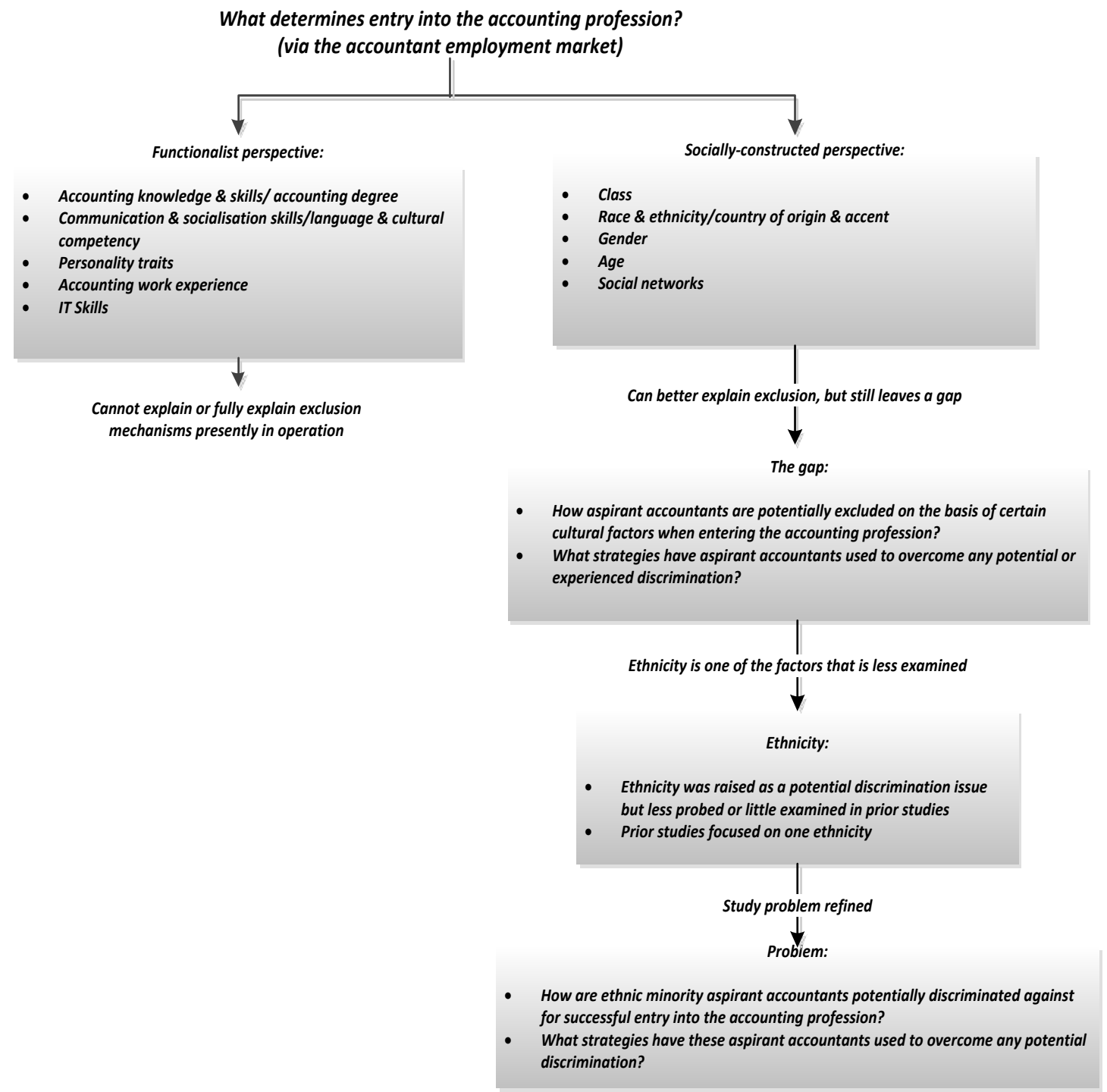

Figure 2-1: The literature review process and finding the gap

\subsection{Summary}

This chapter has presented the literature review focusing on the factors that potentially exclude aspirant accountants from the accounting profession via the accountant employment market. The purpose of this review is to make explicit these factors and to reveal the gap for this study. The review examined two perspectives: the functionalist perspective and the socially-constructed perspective. The factors that are identified in these two perspectives are summarised in Table 2-1 below. 


\begin{tabular}{|c|c|c|c|}
\hline Perspectives & Exclusion factors & $\begin{array}{l}\text { Accounting researchers who identified the } \\
\text { factors }\end{array}$ & $\begin{array}{l}\text { Countries where the } \\
\text { factors are found }\end{array}$ \\
\hline \multirow[t]{5}{*}{ Functionalist } & $\begin{array}{l}\text { Accounting degree/ } \\
\text { accounting knowledge \& } \\
\text { skills }\end{array}$ & $\begin{array}{l}\text { Dezalay (1995); Richardson (1989); Anderson- } \\
\text { Gough, Grey \& Robson (1998); Kavanagh \& } \\
\text { Drennan (2008); Chillas (2010) }\end{array}$ & $\begin{array}{l}\text { The U. S., Canada, } \\
\text { Australia, the UK }\end{array}$ \\
\hline & $\begin{array}{l}\text { Language \& cultural } \\
\text { competency/ } \\
\text { communication \& } \\
\text { socialisation skills }\end{array}$ & $\begin{array}{l}\text { Kim (2004a); Kennedy \& Sorensen (20060; } \\
\text { Birrell \& Healy (2008); Gray (2009); Johns } \\
\text { (2010); Holmes \& Riddiford (2009 2010); } \\
\text { Keneley \& Jackling (2011); Gray \& Murray } \\
\text { (2011); Sugianto \& Johns 2011); Gray \& Murray } \\
\text { (2011); Tempone et al (2012). }\end{array}$ & $\begin{array}{l}\text { Inter alia New Zealand, } \\
\text { Australia; Canada }\end{array}$ \\
\hline & IT skills & $\begin{array}{l}\text { Oliver \& Que (1996); Velayutham \& Perera } \\
\text { (1996) }\end{array}$ & $\begin{array}{l}\text { The U. S., New } \\
\text { Zealand }\end{array}$ \\
\hline & Personality traits & $\begin{array}{l}\text { Anderson-Gough, Grey \& Robson (1998); } \\
\text { Courtis \& Zaid (2002); Kim (2004a)); Wells, } \\
\text { Gerbic, Kranenburg \& Bygrave (2009) }\end{array}$ & $\begin{array}{l}\text { The U. K., Australia, } \\
\text { New Zealand }\end{array}$ \\
\hline & $\begin{array}{l}\text { Accounting work } \\
\text { experience }\end{array}$ & $\begin{array}{l}\text { Oliver \& Que (1996); Cheng, Hoebuck \& } \\
\text { Simnett (2009); Tempone, Kavanagh, Segal, } \\
\text { Hancock, Howieson \& Kent (2012) }\end{array}$ & The U. S., Australia \\
\hline \multirow[t]{5}{*}{$\begin{array}{l}\text { Socially- } \\
\text { constructed }\end{array}$} & Class & $\begin{array}{l}\text { Willmott (1986); Richardson (1989); West } \\
\text { (1996); Maltby (1997); Jacobs (2003); Anderson, } \\
\text { Edwards \& Chandler (2005); Lee (2009). }\end{array}$ & $\begin{array}{l}\text { The U. K., Scotland, } \\
\text { Australia }\end{array}$ \\
\hline & $\begin{array}{l}\text { Country of origin, race \& } \\
\text { ethnicity, and accent }\end{array}$ & $\begin{array}{l}\text { Hammond (1997a); Miranti (1998); Kim } \\
\text { (2004a); James \& Otsuka (2009); Spence \& } \\
\text { Brivot (2011); Annisette \& Trivedi (2013); } \\
\text { Baskerville et al (2014) }\end{array}$ & $\begin{array}{l}\text { The U. S., New } \\
\text { Zealand, Australia, } \\
\text { Canada }\end{array}$ \\
\hline & Gender & $\begin{array}{l}\text { Ciancanelli, Gallhofer, Humphrey \& Kirkham } \\
\text { (1990); Loft (1992); Lehman (1992); Ikin, Johns } \\
\text { \& Hayes (2012); Kim (2004b); Fearfull \& } \\
\text { Kamenou (2006) }\end{array}$ & $\begin{array}{l}\text { The U. K., Australia, } \\
\text { New Zealand }\end{array}$ \\
\hline & Age & Lehman (2012); Gringart \& Helmes (2001). & The U. K., Australia \\
\hline & Social networks & Baskerville (2006b) & New Zealand \\
\hline
\end{tabular}

Table 2-1: A summary of potential exclusion factors as identified by accounting researchers

The functionalist perspective identifies what is required by accountant employers; however, it fails to explain or fully explain why some aspirant accountants, with the required accounting degree, skills and work experience, cannot find an accountant job. The socially-constructed perspective provides part of the explanation, but falls short of explaining specifically how aspirant accountants experience exclusion, especially when 
based on certain social and cultural backgrounds. This leaves a gap to be filled by this study.

Ethnicity was raised as an issue in the accountant employment market, but it is infrequently probed or interrogated by accounting researchers. It is therefore chosen as a focus for this study.

Chapter Three presents Bourdieu's Theory of Practice, the theoretical framework which is adopted in this study. It also explains how the answers to the specific research questions are to be determined through applying this theoretical framework. 
Chapter Three: Bourdieu's Theory of Practice 


\subsection{Introduction}

This chapter presents the theoretical framework, Bourdieu's Theory of Practice, which is adopted for this study. In studying Bourdieu's theory, and in particular his epistemology, the author made an extensive examination of current writings, as further detailed in The Practical Epistemology of Pierre Bourdieu in Appendix IV. Reference may also be made to this Appendix if further cross-referring to the concepts, described below, is required. The chapter explains why his theory is chosen, the key concepts of the theory and the epistemological elements associated with applying the theory. It also examines how Bourdieu's theory is used by accounting researchers. All of these contribute towards a clear understanding of the context of the specific research questions for this study.

\subsection{The choice of Bourdieu's Theory of Practice}

In social research, there are generally two categories: quantitative research and qualitative research. The former, largely statistics-based, is often most suitable for description and exploration of large amounts of data; the latter is more suitable for deeper description and explanation (Patton, 2002). As this study focuses on explaining when, where, and how individuals are discriminated against, the qualitative approach is taken.

Qualitative research can be further divided into two types: theory oriented and nontheory oriented (Patton, 2002). The former studies a problem following the framework set by a theory, the latter studies a problem using the more generic methods such as grounded theory, phenomenology and case study. The former theory oriented type has also been used by accounting researchers who study discrimination in the accounting profession. For instance, Jacobs (2003) used Bourdieu's theory to study class discrimination in the process of recruitment of trainee accountants in the Scottish accounting firms; James and Otsuka (2009) used Engels' reserve army theory to study racial discrimination in the Australian accountant employment market; and Sidhu and West (2014) used Weber's social status theory to study caste systems in the Indian 
accounting profession. The theories they adopted have contributed towards the enlightened findings, revealing particular times or areas of discrimination in-depth.

The theory that this study adopts is Bourdieu's Theory of Practice. The reasons for adopting this theory are: first, Bourdieu's Theory of Practice, and in particular his concept of habitus, is well appreciated by accounting scholars such as Jacobs (2003), Haynes (2008) and Spence and Brivot (2011). They perceive Bourdieu's habitus has enabled them to reveal factors which would otherwise be harder to identify if other theories, such as Marx's class theory, Weber's social status theory, and Giddens structuration theory, had been used.

Second, the research questions in this study have been developed from a sociallyconstructed perspective. This perspective aligns with Bourdieu's view: that professions are constructed from, and perpetuate, certain ideologies which favour one social group over another (Bourdieu, 1984, 2001; Wacquant, 1989). The key concepts of Bourdieu's Theory of Practice will now be described.

\subsection{Key concepts of Bourdieu's Theory of Practice}

Bourdieu's Theory of Practice (Bourdieu, 1972; 1980; 1984; 1991; 2001; Bourdieu, in Biggart, 2002, pp. 280-291) is built on four key concepts: capital, habitus, practice and field.

\subsubsection{Capital}

Capital is any resource, both material and symbolic, that is controlled and can be used by an individual to compete with others in a social field. Capital has three fundamental forms: economic, cultural and social. In addition, symbolic capital is the symbolic form of those other fundamental forms of capital.

Economic capital consists of assets of many forms such as tangible and intangible property and cash under the control of an individual. These may be used, for example, to monopolise a market for personal wealth maximisation and other money-making 
activities. In the market for professional accountancy services, economic capital relates to those capabilities and human capital that the professional firm controls, and uses to gain and maintain clients and make money for the firm or partnership.

In contrast, cultural capital is not generally used directly to monopolise a market niche or to make money, although the term encompasses significant and valuable resources. Cultural capital has three generic sub-forms:

- artefacts, such as paintings, novels and music;

- institutionalised credentials, such as certificates, citizenships and awards, and

- habitus, the internalised dispositions of thinking and behaving that is embedded within an individual.

In the professional employment market, the highest valued cultural capital relates to those credentials and symbols that signify or identify the most valued social and cultural background of a professional.

Finally, social capital relates to the social networks or social connections of individuals, and these may be used by an individual to advantage himself or herself over others. Such networks and social groups are particularly relevant to any professional market for employment, and will be discussed in relation to the accountant employment market. Further references to the sources and nature of these categories are fully described in Appendix IV.

According to the above descriptions, some of the factors that may exclude aspirant accountants from the accounting profession, presented earlier in Table 2-1, can be realigned into the framework of Bourdieu's forms of capital, as shown in Table 3-1 below. 


\begin{tabular}{|c|c|c|}
\hline $\begin{array}{l}\text { Potential exclusion factors } \\
\text { identified in research to date }\end{array}$ & $\begin{array}{c}\text { Proposed forms of } \\
\text { Bourdieusian capital }\end{array}$ & Justification \\
\hline $\begin{array}{l}\text { - Language/verbal/oral fluency } \\
\text { - Cultural } \\
\text { - } \text { competency/understanding } \\
\text { - } \text { Personality traits } \\
\text { - } \text { Accounting work experience }\end{array}$ & Economic capital & $\begin{array}{l}\text { These skills can directly be used by an } \\
\text { accountant on behalf of their employer to } \\
\text { gain and retain clients and create revenue } \\
\text { for his or her employer. }\end{array}$ \\
\hline $\begin{array}{ll}\text { - } & \text { Accounting degree } \\
\text { - } & \text { Accent }\end{array}$ & Cultural capital & $\begin{array}{l}\text { These factors signify an accountant's social } \\
\text { status and cultural background. They are } \\
\text { not directly related to money- making } \\
\text { activities. }\end{array}$ \\
\hline - $\quad$ Social networks & Social capital & $\begin{array}{l}\text { Social networks can be used by an aspirant } \\
\text { accountant to obtain a professional } \\
\text { employment position quickly }\end{array}$ \\
\hline $\begin{array}{ll}\text { - } & \text { Country of origin } \\
\text { - } & \text { Gender } \\
\text { - } & \text { Age }\end{array}$ & $\begin{array}{l}\text { Immutable characteristics, } \\
\text { but may be a component of } \\
\text { any of the above }\end{array}$ & \\
\hline
\end{tabular}

Table 3-1 Categorisation of the potential exclusion factors into Bourdieu's forms of capital

These forms of capital and individual attributes will be later used by the researcher to inquire of aspirant accountants, in particular accountants from an ethnic minority, how they may gain or compensate for the resources they perceive that they lack.

\subsubsection{Habitus}

Habitus, as abovementioned, is a form of cultural capital, but it is the internalised part of thinking and dispositions towards behaviours. Bourdieu (1972) described habitus as follows.

[T] he strategy-generating principle enabling agents to cope with unforeseen and ever-changing situations... a system of lasting, transposable dispositions which, integrating past experiences, functions at every moment as a matrix of perceptions, appreciations, and actions and makes possible the achievement of infinitely diversified tasks, thanks to analogical transfers of schemes permitting 
the solution of similarly shaped problems, and thanks to the unceasing corrections of the results obtained, dialectically produced by those results. (ibid, pp. 82-83)

Habitus applies to a group of individuals as well as to each individual, and can be applied to shared beliefs and values of a profession. When applied to a professional group, habitus means certain "taken for granted" (Bourdieu, 1972, p. 80) ideologies that are constructed by members of that profession; these may be eventually partially articulated in a Code of Ethics or Membership Rules but are more often less explicit, although shared between members. Because they are "taken for granted", they may be consciously or subconsciously used by those people within the profession on a daily basis.

Such ideologies that underpin a profession may appear to be neutral and impartial but will in fact favour the dominant social group within that profession. Bourdieu (1989) perceived this as follows.

The notion of profession is dangerous because it has all appearances of false neutrality in its favor. Profession is a folk concept which has been uncritically smuggled into scientific language and which imports in it a whole social unconscious. It is a product of historical work of construction and representation of a group which has slipped into the very science of this group. (Bourdieu, in Wacquant, 1989, p. 38)

Because of such ideologies, entry to a profession is determined not only by what a person can do, but also by who the person is in terms of age, gender, ethnicity and other social factors. When referring to such entry event decisions, Bourdieu described the judgment.

[I]t takes into account not only the nature of the job and the income, but those secondary characteristics which are often the basis of their social value (prestige or discredit) and which, though absent from the official job description, function as tacit requirements, such as age, sex, social or ethnic origin, overtly or 
implicitly guiding co-option choices, from entry into the profession and right through a career, so that members of the corps who lack these traits are excluded or marginalized. (Bourdieu, 1984, p. 97)

To elaborate the impacts of an ideology in a profession, Bourdieu took gender as an example. Professions are dominated by what he saw as the masculine ideology, which favours men.

To succeed completely in holding a position, a woman would need to possess not only what is explicitly demanded by the job description, but also a whole set of properties which the male occupants normally bring to the job - a physical stature, a voice, or dispositions such as aggressiveness, self-assurance, 'role' distance, what is called natural authority, etc., for which men have been tacitly prepared and trained as men. (ibid, p. 62)

Since women cannot 're-design' their genetically-determined traits of womanhood to comply with the masculine ideal type:

Their chances of access (and rate of representation) decline as one moves towards the rarest and most sought-after position.... They are proportionally more affected by redundancies and insecurity of employment and more often relegated to part-time posts - which has the effect, among other things, of almost invariably excluding them from access to decision-making and career prospects. (ibid, pp. 91-92)

Furthermore,

The dominated apply categories constructed from the point of view of the dominant to the relations of domination, thus making them appear as natural. (ibid, p. 35)

In other words, it is conjectured that some women thought themselves incapable or unsuitable if the dominant men perceived them as such. Any such process of 'selling 
themselves short' will inevitably reinforce masculine dominance and gender inequality within professions.

Translating Bourdieu's masculinity logic to ethnicity also, ethnic minorities may suffer an ideology such as 'British White' xenophobia, a norm of believing in a superiority which is "taken for granted" by society. Such an ideology may inhibit those outside 'the Establishment' from finding a job in many parts of society, such as the professions. Their experience may further lead them to 'sell themselves short' and give up on their aspiration to enter into a profession.

\subsubsection{Practice}

Habitus, as mentioned above, is often unconscious to the people who hold it. However it will be reflected in their practice or practical strategies. People will apply different practical strategies according to the forms of capital they have and the habitus within the field. In this sense, practice is where the interrelationships among capital, habitus and field are manifested.

This may further be observed in two distinctive strategies: conservative strategies and subversive strategies. Conservative strategies are used by the dominant group to reinforce the habitus in the field. Conservative strategies may also be used by a minority group to align the appearance of their habitus to that preferred by the dominant group. Subversive strategies may also be used by either group; subversive strategies will be adopted with the purpose of undermining the habitus of the field.

\subsubsection{Field}

Capital, habitus and practice all exist and may be observed in a field. A field is the social context which attracts people to compete with each other for success, such as economic and social benefits. Professions are such a field. People may be distinguished from each other in a field because they have different forms of capital, both in types and in values. Those whose forms of capital align with the habitus of the field most closely may expect the most favourable outcomes. 
Those who are thus successful will find themselves positioned most favourably in a space of two dimensions: economic capital and cultural capital, and those who are less successful may be observed at lower positions in such a space. Those in lower positions are potentially discriminated against when next competing with others within the field.

\subsection{Applying Bourdieu's epistemological insights in the field}

To ensure the proper operationalisation of his key concepts in social research, Bourdieu and his colleagues (Bourdieu et al., 1991) provided some valuable epistemological insights. Those that are applicable to this study are presented next.

\subsubsection{The symbolic nature of capital}

Capital, as mentioned in Section 3.3.1, is both material and symbolic. For capital to be accessible to those competing in a field, or even behaving with what Bourdieu called "symbolic violence" (Bourdieu, 1991, p. 170), it must be both recognised and appreciated as such (ref. Appendix IV). In this sense, all the capital is symbolic. It may be consciously perceived by people in terms of what they have or lack, and how much they have, or how much they are lacking in such attributes/resources.

\subsubsection{Use people with diverse backgrounds as sample}

Bourdieu always described fieldwork which was composed of people with diverse backgrounds (Bourdieu, 1980; 1984; 2005). Only by using this kind of sample can habitus be reflected and understood, because habitus is a kind of "consensus" (Bourdieu, 1991, p. 164) that is shared by all the members within the field.

\subsubsection{Map out the field and explain people's different positions in capital and strategies}

Bourdieu suggested a researcher should map the field in the early stages of a research 
project. The mapping out is to identify different positions for different people in the field (Bourdieu, 1984, 1996, 1998; Swartz, 1997). This enables the researcher to see how people are stratified, who has been a winner, and who 'the losers' are. Then the researcher further explains people's different positions with identification of the forms of capital they have (or do not have), and their corresponding strategies. The forms of capital and strategies are thus both the causes and results of each person's different positions.

\subsubsection{Pay much attention to the voices of those disadvantaged}

To identify what forms of capital are the bases for distinguishing between people in a field, Bourdieu paid much attention to the voices of those who are disadvantaged or marginalised. In his view, there is more awareness of the range of varieties and forms of capital by those who are lacking in them, rather than by those who have them (Bourdieu, 1972).

\subsection{How Bourdieu's Theory of Practice is used by accounting researchers}

Bourdieu's Theory of Practice is used by accounting researchers in many different research areas (Malsch et al., 2011). The following review is focused on the area of accounting professionalisation, which is the area closest to the context of this study.

Malsch, Gendron and Grazzini (2011), three Canadian accounting scholars, provided an extensive analysis of Bourdieu's influence on the accounting literature. They found that Bourdieu's theory, as compared with Foucault, Latour and Giddens, is less used by accounting researchers (ibid, p. 201), and if it is used, it is used in a piecemeal manner rather than as a holistic framework that utilises the three key concepts: capital, habitus and field, and their dynamic interrelationship. Among the three concepts, habitus is at the core but is given less attention (ibid, p. 217). This means many accounting researchers may have missed the opportunity to use Bourdieu's theory as a whole, rather than some dislocated ideas; and to fully harvest the benefits that may be brought about with the application of his theory. 
The Canadians examined three highly-ranked journals in the critical paradigm: Critical Perspectives on Accounting, Accounting, Organizations and Society and the Accounting, Auditing and Accountability Journal over a ten year period from 1999 to 2008.They found 18 articles that used Bourdieu's theory substantively. Among these, two articles are related to the topic of this study. The first is Jacobs' (2003) examination of the hidden processes of accounting firms when recruiting trainee accountants. Using Bourdieu's concept of habitus, he argued that the recruitment criteria, while giving lipservice to using meritocracy, are in fact based on class and status. This recruitment process is camouflaged by the so-called 'transferable skills' that are reiterated by the employers; and such skills are more likely to be acquired by the children of middleclass families. They are a kind of habitus that are passed on through generations within middle-class families and so the 'best-fit candidates for the profession are prepared on an ongoing basis. This 'underground' class preparation invalidates the claim for equality on the surface. The way Jacobs uses Bourdieu's theory is impressive as he uses it at the core (Malsch et al., 2011). His focus is on habitus, and he addresses it logically. To enhance his logic, Jacobs (2003) also employed Marx's class concept and Weber's status power to lay the foundation for the use of Bourdieu's habitus.

The second work is Haynes' (2008) study on how a female accountant's professional identity may be conceived, retained and compromised by pregnancy. It is related to this study in that it revealed a particular criterion by which a professional accountant is identified. Starting with Giddens' agency and structures dichotomy, Haynes (2008) presented Bourdieu's theory as the theory that best reflects the dialectic relationship between the biological body and the professional identity. In Bourdieu's view, the body is socially constructed and is a social entity (Bourdieu, 2001, p. 64). Haynes (2008) integrated all the attributes which are formed in the professional social context, as found by Grey (1998), Anderson-Gough et al. (1998) and others, into a female's selfconsciousness. The way Haynes used Bourdieu's theory, as judged by Malsch et al. (2011), would be appropriate. Her focus is on the habitus and, more specifically, on the internal conflicts within the habitus. As such, she was able to present insights that are both enlightening and sensitive. 
As mentioned above, Malsch et al. (2011) identified that it is rare that Bourdieu's triad is used as a whole set. This situation has not improved since 2008, the last year of the examination in their study. Among more recent accounting literature, there are two articles which have used Bourdieu's theory substantively. One was Ikin, Johns and Hayes' (2012) historical study that explained how women entered the Australian accounting profession; the other was Spence and Brivot's (2011) examination of the social exclusion of Francophone accountants from the Canadian accounting profession. Ikin et al. (2012) opened their argument by presenting the profession as a field of hierarchies and suggested that the hierarchical order is determined by the capital that social actors possess. Their focus is on capital. They treated accounting expertise and its social recognition as a form of symbolic capital which, before World War II, was traditionally attached to male accountants. The male symbolism was inherent in the habitus that dominated the profession since its inception in the $19^{\text {th }}$ Century. It was challenged by the accountancy labour market when men were in short supply as they were leaving the local employment field to fight. This created an urgency for employers to employ people from the 'reserve army' pool. Women took up the roles which were left by men and proved equally suitable. The male dominance of the profession has since changed, and women continue to increase in numbers entering the profession and taking leadership roles (Ikin, et al., 2012).

The manner in which Ikin et al. (2012) applied Bourdieu's theory, as compared with Jacobs (2003) and Haynes (2008), is less convincing. This is because of their premise that the profession is a field of hierarchies determined by capital, and the driver to increasing numbers of women entering the profession was not directly related to the outbreak of war (World War II, WWII). Ikin et al. (2012) provided an avenue by utilising symbolic capital, which in their view, contains the 'maleness' habitus. The fact that women entered the profession thus changed the collective habitus (doxa) and therefore the symbolic capital; they were to achieve positions more easily at higher hierarchical levels. The premise which underpins their logic is that habitus is changeable and it is changed by a shift of the social environment. This might be seen as different to the habitus proposed by Bourdieu who, in his The Logic of Practice, to which Ikin et al. (2012) referred, made it clear that habitus is an historical impetus, a regenerative scheme of history (Bourdieu, 1980, p. 54). If this were not true, it would 
not become the key to producing and reproducing the social and cultural domination for the profession - the premise which supports Jacobs (2003), Haynes (2008), and others' arguments. Ikin et al. (2012) may argue that the entry of women into the profession is a gradual process, taking years to become a phenomenon, but, in the end, their study leaves the reader with more questions than answers. The problem lies with the way they use Bourdieu's theory. They could have focused primarily on habitus; how women have attempted to enter the profession and how they have overcome societal barriers and those within themselves, to better advance their hypothesis. If they had given primacy to Bourdieu's habitus as the research focus, they might have presented different findings (Malsch et al., 2011). For example, they might have pointed out more directly that it is the habitus that operationalises accounting as social practice, and the accounting skills were well within the capacity of women long before WWII, or that the habitus which favours the male is but an illusion.

Another problem underlying the study of Ikin et al (2012) is that they highlighted all forms of capital except the economic one. They treat accounting expertise and its social recognition as a category of symbolic capital rather than economic, and they appeared to overlook that Bourdieu's theory is largely developed from Marx's economic class and Weber's social status theories (Biggart, 2002; Jacobs, 2003). Such a study may fit with Bourdieu's theory better if the accounting expertise and its social recognition were treated as economic capital. Such human capital would be identified by the employers as 'production forces' and also by the accountants themselves as important means to monopolize the market (Schultz, 1961; Weber, 1987[1947]).

In comparison with Ikin et al. (2012), Spence and Brivot (2011) used Bourdieu's theory in a more robust manner. Although they used Bourdieu's socio-linguistic theory, rather than his theory of practice, they retained the habitus focus. Language is a category of habitus which is inculcated in one's early life. It is a product of culture and symbolizes an individual's social and economic background. In the professional arena, language becomes a commodity to trade (Bourdieu, 1991), and because there are two official languages in Canada (English and French), Anglophones and Francophones were distinguished from each other. Francophones find it hard to be accepted by the Anglophones, who dominate the accounting profession. This process of discrimination 
is not overt and may not even be felt by the French themselves, but is ongoing.

The effect of Spence and Brivot (2011) utilising the habitus concept is that one can clearly observe another dimension (that of language) in closure mechanisms in addition to those that are more widespread, such as class, gender, and race. Documenting the importance of this dimension was what Spence and Brivot (2011, p. 168) intended to achieve. The key to their success is their treatment of language (i.e. first language) as habitus. It is a habitus that cannot be changed. As a result, fearing that Francophones would set up a separate profession in competition, Anglophones changed their language rules to accommodate the French members of the profession.

The above examination has covered four articles in the accounting literature that have used Bourdieu's theory as the major informing theory. Although the manner of their application of Bourdieu's theories is different, they have all produced important insights and discoveries pertaining to the application of Bourdieu in accounting research. However, even putting aside Spence and Brivot (2011) as they used Bourdieu's sociolinguistic theory (which is slightly different from Bourdieu's Theory of Practice used by the other three), none has used Bourdieu's Theory of Practice as a completely holistic framework. In particular, it is that 'theory of practice' which manifests the dynamic interrelationship between capital, habitus and field. In this sense, their applications of Bourdieu's Theory of Practice to the accounting professional field may be less than satisfactory, and many of the criticisms of Malsch, Gendron and Grazzini (2011) remain relevant to accounting research.

\subsection{How Bourdieu's Theory of Practice is used to set up the research questions for this study}

Informed by Bourdieu's key concepts, his epistemological insights and how his theory of practice is used by accounting researchers, this researcher further divides the study problem developed in Chapter Two into two specific research questions. This process is explained as follows.

Habitus is important. It is what a profession is about, and therefore it is also what a 
study of a profession is about. It is habitus, the "taken for granted" ideologies, which validate people's forms of capital and hence discriminate against those whose forms of capital does not comply with habitus. Habitus, therefore, must be set as the central focus for this study.

This focus, however, is hard to operationalise because habitus is most often held unconsciously by people; this habitus may be hard to isolate and harder to prove. For example, racism, a potential ideology, is unlikely to be acknowledged by a racist employer. It may be identified by an ethnic minority accountant but it is hard for the latter to prove. While habitus is hard to prove, it can be reflected in people's capital and in their practice. Habitus is interrelated with capital and practice; it is hoped that each interviewee in this study may offer a reflection (explicitly or implicitly) on this interrelationship. Although forms of capital are symbolic, for these to become manifest they must be acknowledged. Strategies are used with a purpose, that is, to overcome the potential discrimination; therefore it is hoped that these will also be part of the responses by interviewees.

The above arguments enable the researcher to set the research questions as:

1) What forms of capital do ethnic minority aspirant accountants perceive they lack for successful entry into the accounting profession? and

2) What strategies have these aspirant accountants used to overcome any potential discrimination?

Figure 3-1 outlines the logic of the above process. 


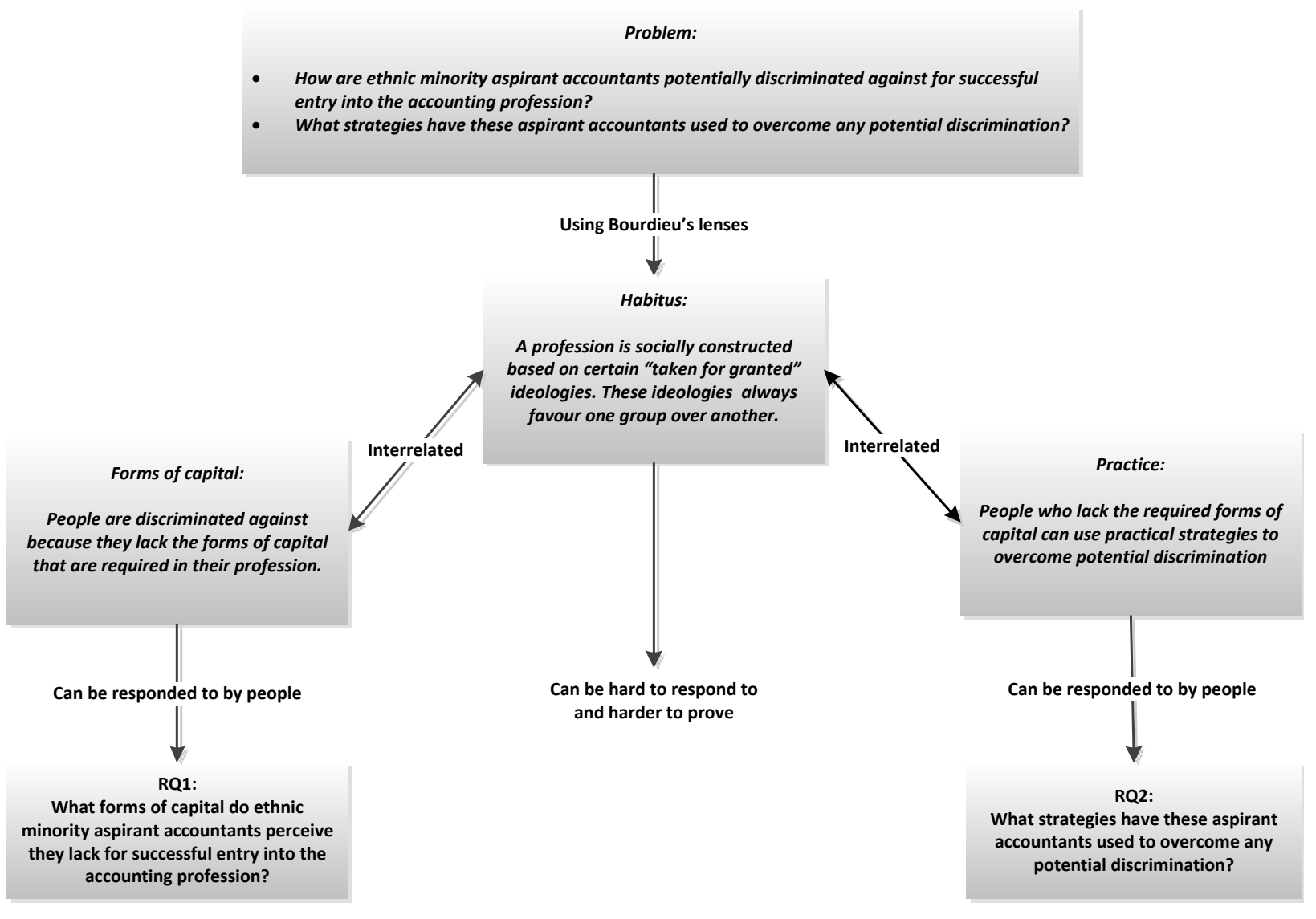

Figure 3-1 Specific research questions set through applying Bourdieu's theoretical framework

\subsection{Summary}

This chapter has presented Bourdieu's Theory of Practice, which is the theoretical framework for this study. His key concepts and their interrelationships are explained. His epistemological insights for operationalizing his key concepts in social research are also introduced. Furthermore an examination was offered of how his theory has been applied by accounting researchers to date. Lastly the specific research questions are restated as based on the core concepts of Bourdieu's Theory of Practice, his epistemological insights and how his theory is applied.

Chapter Four will explain the research methods and other procedures used in this study to provide the answers to these research questions. 
Chapter Four: Research Methods 


\subsection{Introduction}

This chapter presents the research methods and other major procedures used to provide answers to the research questions of this study. It explains what sample is used, how the cohort was approached, the data collection and analysis, the ultimate validation of the findings and the process for reporting the findings.

\subsection{Participants and sample}

This study uses a purposive sampling method. Compared with the random sampling method, purposive sampling directs attention to the selection of participants whom the researcher believes will make a more valuable contribution towards answering the research questions (Marshall, 1996; Patton, 2002). To this end, this study uses participants with a diversity of ethnic backgrounds. As shown in Table 4-1, the sample comprises 45 participants who have national and ethnic backgrounds from 20 countries.

\begin{tabular}{|c|c|c|c|c|c|c|c|c|}
\hline $\begin{array}{l}\text { Ref } \\
\text { No. }\end{array}$ & $\begin{array}{l}\text { Name in } \\
\text { report }^{1}\end{array}$ & $\begin{array}{c}\text { Self-identified } \\
\text { Ethnicity }\end{array}$ & Country of origin & Gender & Age & $\begin{array}{c}\text { A new } \\
\text { migrant }\end{array}$ & Found a job & $\begin{array}{c}\text { Had employer } \\
\text { experience }\end{array}$ \\
\hline P1 & Shada & Iraqi & New Zealand & $\mathrm{F}$ & $20-29$ & No & Yes & No \\
\hline P2 & Judy & British & UK & $\mathrm{F}$ & $40+$ & Yes & Yes & No \\
\hline P3 & Kasim & Iraqi & Iraq & M & $40+$ & Yes & Yes & Yes \\
\hline P4 & Ling & Malaysian Chinese & New Zealand & $\mathrm{F}$ & $20-29$ & No & Yes & No \\
\hline P5 & Javana & Malaysian Chinese & Malaysia \& UK & $\mathrm{F}$ & $40+$ & Yes & Yes & Yes \\
\hline P6 & Jacob & Dutch & Netherland & $\mathrm{M}$ & $40+$ & No & Yes & Yes \\
\hline P7 & Anna & Russian & Russia & $\mathrm{F}$ & $30-40$ & Yes & No & No \\
\hline P8 & John & Pakeha & New Zealand & $\mathrm{M}$ & $40+$ & No & No & No \\
\hline P9 & Issur & Israeli & Israel & $\mathrm{M}$ & $40+$ & Yes & Yes & No \\
\hline P10 & Aryan & Indian & New Zealand & $\mathrm{M}$ & $20-29$ & No & No & No \\
\hline P11 & Edward & Pakeha & New Zealand & M & $20-29$ & No & Yes & No \\
\hline P12 & Ishan & Indian & New Zealand & M & $20-29$ & No & No & No \\
\hline P13 & Justin & Pakeha & New Zealand & $\mathrm{M}$ & $20-29$ & No & No & No \\
\hline P14 & Lubna & Pakistani & Pakistan & $\mathrm{F}$ & $30-40$ & Yes & No & No \\
\hline P15 & Nimra & Malaysian Indian & Malaysia & $\mathrm{F}$ & $30-40$ & Yes & Yes & Yes \\
\hline P16 & Thanhha & Vietnamese & Vietnam & $\mathrm{F}$ & $20-29$ & Yes & No & No \\
\hline P17 & Aamir & Sri Lankan & Sri Lanka & $\mathrm{M}$ & $20-29$ & Yes & No & No \\
\hline
\end{tabular}

\footnotetext{
${ }^{1}$ These are fictitious names.
} 


\begin{tabular}{|c|c|c|c|c|c|c|c|c|}
\hline $\begin{array}{l}\text { Ref } \\
\text { No. }\end{array}$ & $\begin{array}{l}\text { Name in } \\
\text { report }^{1}\end{array}$ & $\begin{array}{l}\text { Self-identified } \\
\text { Ethnicity }\end{array}$ & Country of origin & Gender & Age & $\begin{array}{c}\text { A new } \\
\text { migrant }\end{array}$ & Found a job & $\begin{array}{l}\text { Had employer } \\
\text { experience }\end{array}$ \\
\hline P18 & Biscero & Tongan & Tonga & M & $30-40$ & Yes & No & No \\
\hline P19 & Fan & Chinese & China & $\mathrm{F}$ & $20-29$ & Yes & No & No \\
\hline $\mathrm{P} 20$ & Aleena & Sri Lankan & Sri Lanka & $\mathrm{F}$ & $20-29$ & Yes & Yes & No \\
\hline P21 & Usman & Sri Lankan & Sri Lanka \& UK & M & $30-40$ & Yes & Yes & No \\
\hline P22 & Ming & Chinese & China & M & $20-29$ & Yes & Yes & No \\
\hline P23 & Chris & Pakeha & New Zealand & M & $20-29$ & No & Yes & No \\
\hline P24 & Kiki & Tongan & New Zealand & $\mathrm{F}$ & $20-29$ & No & No & No \\
\hline P25 & Bella & Pakeha & New Zealand & $\mathrm{F}$ & $20-29$ & No & Yes & No \\
\hline P26 & Druv & Indian & India & M & $30-40$ & Yes & Yes & No \\
\hline P27 & Wei & Chinese & China & $\mathrm{F}$ & $40+$ & Yes & Yes & No \\
\hline P28 & Qing & Chinese & China & $\mathrm{F}$ & $40+$ & Yes & No & No \\
\hline P29 & Nicole & European & South Africa & $\mathrm{F}$ & $30-40$ & Yes & Yes & Yes \\
\hline P30 & Jiayi & Chinese & China & M & $40+$ & Yes & Yes & Yes \\
\hline P31 & Aadi & Indian & India & M & $40+$ & Yes & Yes & Yes \\
\hline P32 & Nina & Nepali & Nepal & $\mathrm{F}$ & $30-40$ & Yes & No & No \\
\hline P33 & Hasan & Indian & India & M & $20-29$ & Yes & No & No \\
\hline P34 & Lai & Chinese & China & $\mathrm{F}$ & $20-29$ & Yes & No & No \\
\hline P35 & Ansh & Indian & India & M & $30-40$ & Yes & Yes & Yes \\
\hline P36 & Uche & Nigerian & Nigeria & $M$ & $30-40$ & Yes & No & No \\
\hline P37 & Nishat & Bangladeshi & Bangladesh & $\mathrm{F}$ & $20-29$ & Yes & No & No \\
\hline P38 & Jonah & Kenyan & Kenya \& UK & $\mathrm{M}$ & $40+$ & Yes & Yes & Yes \\
\hline P39 & Hua & Chinese & China & $\mathrm{F}$ & $40+$ & Yes & Yes & No \\
\hline $\mathrm{P} 40$ & Ji-eun & Korean & South Korea & $\mathrm{F}$ & $40+$ & Yes & Yes & No \\
\hline P41 & Tomoko & Japanese & Japan & $\mathrm{F}$ & $30-40$ & Yes & No & No \\
\hline P42 & Diya & Indian & India & $\mathrm{F}$ & $30-40$ & Yes & No & No \\
\hline P43 & Sophia & Philipino & Philippine & $\mathrm{F}$ & $40+$ & Yes & Yes & No \\
\hline P44 & Dominika & Russian & Russia & $\mathrm{F}$ & $30-40$ & Yes & Yes & No \\
\hline P45 & Liang & Chinese & China & $\mathrm{F}$ & $30-40$ & Yes & Yes & No \\
\hline
\end{tabular}

Table 4-1: Ethnic, national and other background demographics of the participants

It is noted that no Maori graduates participated in these interviews. In Table 4-1, ethnicity is determined based on each participant's own identification (Baskerville et al., 2014). Country of origin refers to where a participant had their childhood. It includes: New Zealand, the UK, the Netherlands, Russia, South Africa, Kenya, Algeria, Israel, Iraq, Tonga, India, Sri Lanka, Nepal, Bangladesh, Philippines, Malaysia, China, South Korea, Japan, and Vietnam.

This sample includes both ethnic minorities and the NZ ethnic majority (Pakeha). This is to achieve a well-balanced representation of people of different ethnic backgrounds. 
Of this group, 40 have ethnic minority backgrounds and five have the ethnic majority background. Also, the sample includes those who have succeeded in entering the accounting profession via the accountant employment market and those who failed. This, again, helps to achieve a comprehensive yet focussed sample. Of these 45, 26 succeeded in entering that market and 19 failed. This sample also includes nine who have experiences as accountant employers in New Zealand, although that was very much an unexpected feature. This is further referred to in Chapter Five.

\subsection{Approaching the cohort}

The researcher approached graduates from the MPA (Masters of Professional Accounting) and BCom (Bachelor of Commerce) accounting programmes at Victoria University of Wellington. These graduates have diverse ethnic backgrounds and their multinational profiles enables the researcher to compose a sample which is ethnically more inclusive than the samples used by James and Otsuka (2009), and Annisette and Trivedi (2013). Most importantly, these graduates have experienced seeking an accountant job in New Zealand and therefore will be able to provide first-hand data.

The researcher first approached a cohort of accounting graduates who had participated in an online survey conducted by the researcher's supervisors regarding employment prospects. This resulted in 36 participants who expressed their willingness to be interviewed. They were then contacted to arrange an interview but, because there was a lapse of time between the online survey and subsequent interview period, only 34 of them were eventually available in New Zealand. The other two did not respond for reasons unknown. The available participants were interviewed face-to-face and, following each interview, were asked if they would like to introduce others who they thought would be suitable for this study. By using this snowballing technique, the researcher was able to recruit another 11 interviewees. The process of recruiting new interviewees stopped when the researcher was confident that no new factors were likely to emerge from any additional interview. 


\subsection{Collecting data}

\subsubsection{Interviews}

To collect the data, an interview method was used. Interviews are highly valued for collecting rich, in-depth and multi-variant data (Patton, 2002) and are suitable for studying people's experiences and perceptions.

The interview questions were semi-structured: structured in terms of inquiring about the research questions; unstructured in terms of allowing the participants to fully express themselves without any limitation or hesitation in answering the questions. A list of the interview questions is included in Appendix I. Reference is made to some of these in the following paragraphs.

Before conducting the interviews, the researcher applied to Victoria University of Wellington and obtained approval for the study from the Pipitea Human Ethics Committee. The researcher then started interviewing graduates in accordance with the conditions of this ethics approval, as follows.

Before each interview, an information sheet and a consent form were sent to the interviewee. The information sheet highlighted the aim and scope of the research. The consent form reiterated the voluntary nature of the interview, emphasized the interviewee's rights to withdraw from this research at any time they wished and also their right to request both feedback about the interview and a copy of the interview transcription, albeit partial.

At the start of the interview, the interviewee was asked to introduce him or herself in terms of ethnic, national and education backgrounds, employment history and current situation. Particular attention was paid to how the interviewee identified his or her ethnic identity and country of origin. This step not only enabled the researcher to acquire the interviewee's personal data but also further engaged the interviewee with the topic. 
The researcher then moved to general questions, inquiring about the interviewee's past experience seeking an accountant job in New Zealand and whether or not it was difficult. This line of questioning helped the researcher determine whether the interviewee was a disadvantaged candidate.

The researcher then asked the first research question, but using the terminology that was most appropriate for each interviewee to understand and respond to. For identifying the forms of capital, questions such as, "What do you think were your advantages or disadvantages when applying for an accountant's job in New Zealand?" and "What do you think were the reasons you were employed or not employed in an accountant's job?" were asked.

After the researcher was satisfied with the interviewee's answer to the first research question, he moved on to ask questions based around the second research question. Again, he used terminologies that were the most appropriate for each interviewee to understand and respond to. Questions such as, "How have you attempted to distinguish yourself from others when applying for an accountant job?" and "What methods have you used to avoid being ignored by employers?" were asked.

At the end of an interview, the interviewee was asked to evaluate the appropriateness of the interview questions and whether they would like to add more information for the researcher to consider. To close an interview, the researcher also reminded the interviewee that he or she was welcome to contact the researcher at any time if he or she felt a need to add information.

During the whole interview process, from time to time the researcher checked if the interviewee understood the interview questions and also checked back as to a shared understanding of what the interviewee intended to mean. If there was anything that might prove to be unclear in the analysis stage, the researcher would break the interview for clarification. 
Each interview had a flexible timeframe. On average, an interview took 45 minutes but the longer ones went up to 70 or 80 minutes. All the interviews were voice-recorded with the interviewees' consents.

\subsubsection{Ethnic background and other personal information validation}

On the same day, after each interview was finished, the researcher prepared a note which recorded the interviewee's ethnic background, education, employment history and current situation. This was prepared based on the researcher's reflection. A sample note is shown in Figure 4-1 below.

The researcher then sent the note via email to the interviewee to achieve two purposes: (1) to validate whether the interviewee's ethnic background, employment history and situation are captured correctly; and (2) to provide general feedback, because many of them were very interested to know how their ethnic identities and employment situations were understood by others. There was no material correction request from the interviewees concerning the validation.

\footnotetext{
Field note22

Interviewer: George Huang Interviewee: Ming Date:26/01/2012 Place: Interviewer’s office

1.General reflection

Ming is a first generation Chinese migrant. He started off his NZ adventure from studying at a language school, and then completed his accounting degree at uni. He then found an entry-level accounting job at a small private company. After 2 years, he had to quit that job and came back to uni. to finish his professional accounting diploma. He had a very hard time finding a professional employment after he completed his PG Dip in Professional accounting. After struggling for a half year, he got an entry level accounting job at an ATO. There he quickly got a position which recognised by NZICA for taking PCE2, and now he is a CA.
}

Ming's professional progression seems to be very successful, however behind the success, are his high work ethic, sociable personality, and his strong initiative to mingle with local people. As he perceives, good personality and fitting in are the real catches for understanding language, communication and cultural barriers. He stresses that the communication is about how you can use simple English words and sentences to talk with people, and the culture is about whether you share the same interest and behaviour with locals. He encourages international students to step out of their language comfort zone and force them to interact with local people. He also thinks university should attempt to create more chances in their academic activities to engage international students with local students.

While he admits that there is racial filing (prejudice) and social networks which disadvantage foreigners in the employment market, he thinks NZ society in general is open and not very discriminative against them.

2.Professional trajectory and current position

Background and past experience

Chinese, first generation migrant, male, started with language school in Auckland and then completed his BCA at Vitoria in Wellington

After graduation, got an accounting job at a small company (non ATO)

After 2 years, went back to Victoria to complete PG Diploma in professional accounting. 


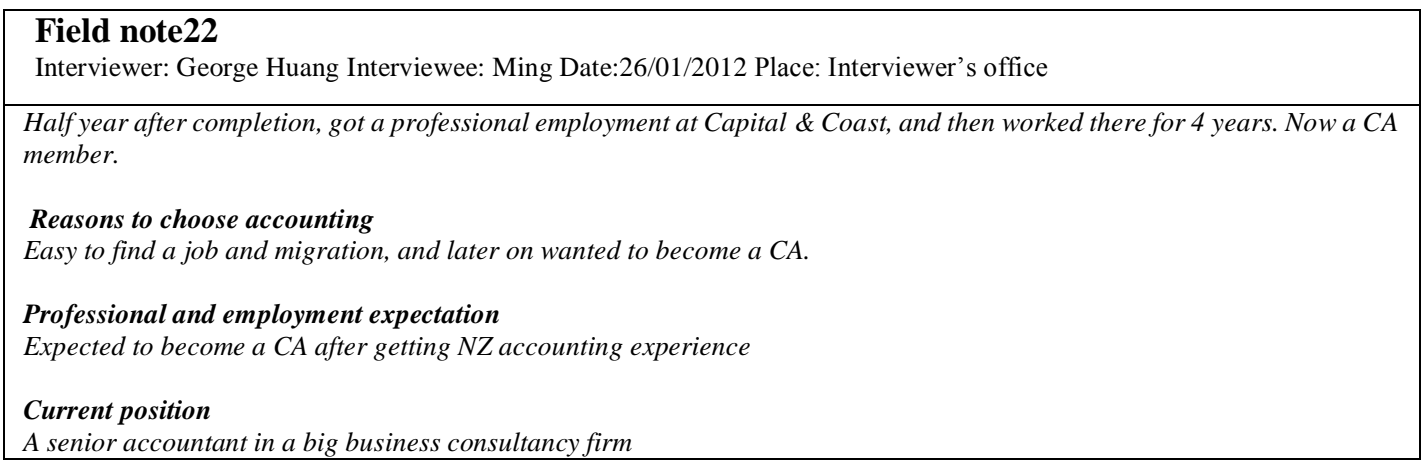

Figure 4-1: A sample note for interviewee 22

\subsection{Data analysis}

To address the two research questions, the process was to map out the field first and then explain people's different positions concerning their capital and strategies (Ref: Section 3.4.3). These steps are shown in Figure 4-2 on the next page. The steps are explained as follows.

\subsubsection{Divide the interviewees into different ethnic groups}

For the ethnicity analysis, the researcher first divided the interviewees into different ethnic groups according to their own identifications. The ethnic groups were as follows.

- Group 1: "Chinese \& East Asian migrants". Group 1 consists of those who have identified themselves as having ethnic backgrounds from China and East Asia and who recently migrated to New Zealand.

- Group 2: "Indian \& South Asian migrants". Group 2 consists of those who have ethnic backgrounds from the Indian subcontinent and South Asia and who recently migrated to New Zealand.

- Group 3 consists of those who grew up locally in New Zealand.

- Group 4: all those not in the first three groups. Group 4 consists of ten interviewees: one Briton from the UK (P2), one Iraqi (P3), one Dutch respondent (P6), one Israeli (P9), two Russians (P7 \& P44), one Tongan (P18), one 'European' from South Africa (P29), one Nigerian (P36), and one Kenyan from the UK (P38). These were not included in the analysis which now follows, because this further analysis is seeking to identify commonalities of the experiences of those within the three major 
ethnic groups as already described above. This leaves 35 in the cohort for analysis as follows.

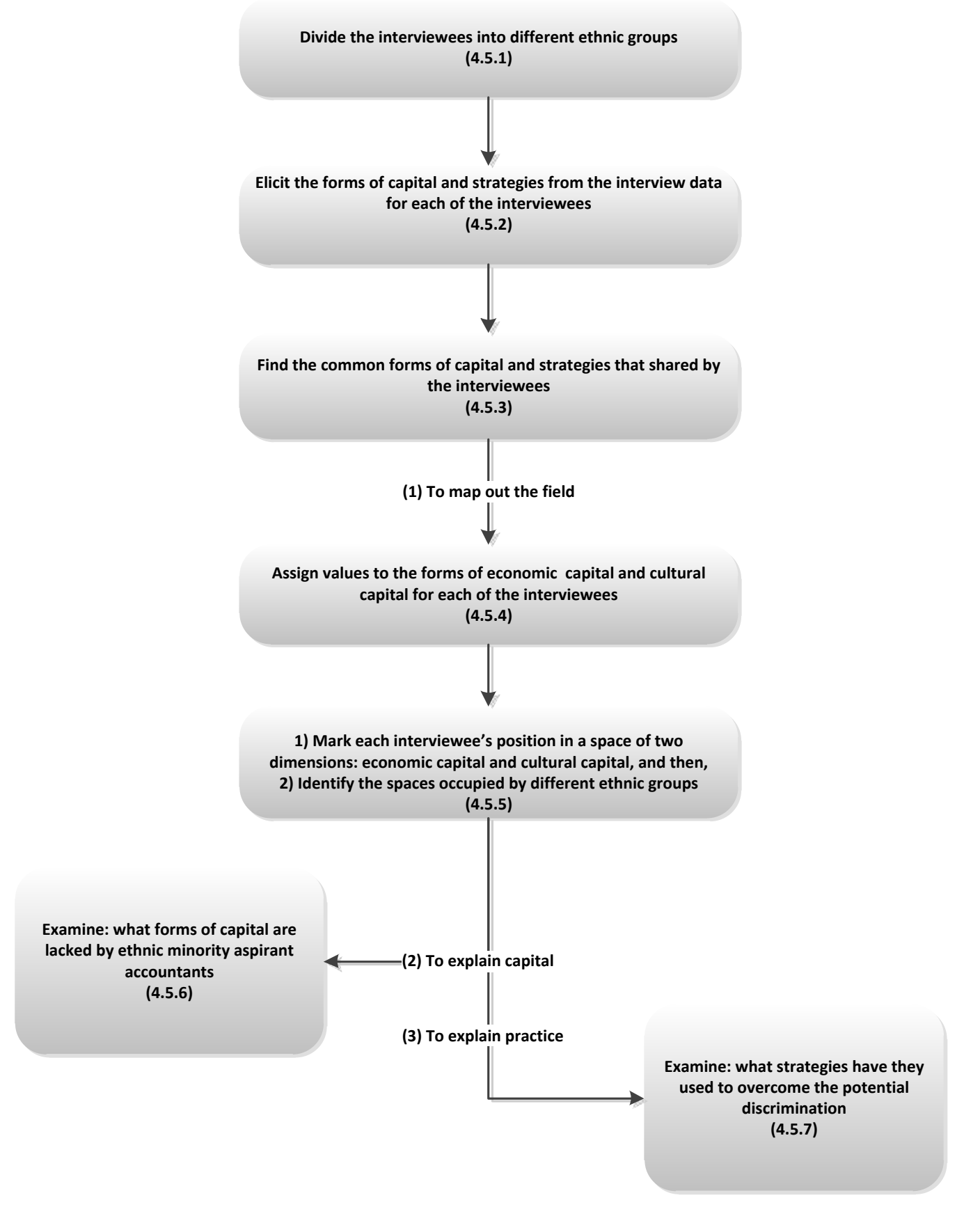

Figure 4-2: Major steps of data analysis

In terms of their different language and British colonization history, it did not make sense to combine these into one cluster for the purposes of the group ethnicity analysis. However, their 'voices' are included in the individual analyses of capital and strategies in Section 5.3 and Chapter Six respectively. 
Group 3 was further divided into two subgroups:

- Sub-group 1, "Ethnic minority New Zealanders", who are in an ethnic minority; and

- Sub-group 2, Pakeha, who are New Zealanders (mostly of British descent), the ethnic majority.

Note that Group 3 did not include any tangata whenua (Maori) as already noted.

Following this division of Group Three, there were four ethnic groups for the analysis as further offered in this and the next chapter. They are: "Chinese \& East Asian migrants" (Group 1), "Indians \& South Asian migrants" (Group 2), "Ethnic minority New Zealanders" (Subgroup 1 of Group 3) and "Pakeha" (Subgroup 2 of Group 3). The detailed information for who the interviewees are in each of these four groups is shown in Table 4-2 in Section 4.5.4.

\subsubsection{Eliciting the forms of capital and strategies}

The researcher first listened to all the interviews, reviewed notes and then undertook a partial transcription of each interview into a Word document, based on "data relevance" (McLellan et al., 2003, p. 67). All data that were related, either closely or remotely, to addressing the research questions were transcribed. Second, the researcher elicited the forms of capital and strategies for each interviewee. An excerpt screenshot of this elicitation process is shown in Figure 4-3 on the next page.

Third, the researcher prepared a summary for the forms of capital and strategies that were elicited from each interviewee. A sample summary is attached in Appendix II. Preparing this summary would enable an interviewee to validate how his or her responses were captured and analysed by the researcher, not only at the textual level but also at a level which enabled the interviewee to confirm his or her forms of capital and strategies. This procedure was carried out with all 45 interviewees except for nine who did not want the summary. One interviewee decided to withdraw from the study after this procedure. According to the proviso of the Ethics Approval, all the files related to this interviewee have been destroyed. There were two errors in spelling and 
one omission of words identified by two other interviewees. These errors did not affect the content analysis and they have been corrected.

Interview data transcribed
Elicitation details

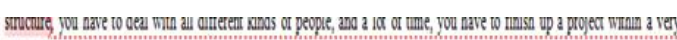
limited time. Tha means, you are on the more al the ime. For example, there is a meting going on, suddenly you bave to cancel it. You bare to let all the attendance how why you are learing and a so pou have to make poople feel confortable for the change, That comes to that you havet to commericate vith people with a stratey. Also, some times, to ge the project done, you have to persade people to do the things in your way. So, wou have to build a good reationship, ant jus like a working

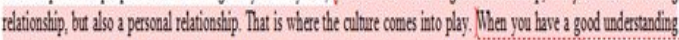
about kivi alture, the it is essier for rou to buld a personal redtionship on top of the roorkng reationship, which will make

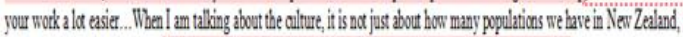
or those kinds of basic things It is more like a shared expenence about past, about your ralue proposition For example, when sometody sad, in my chilchood, what I had done, bla bla bla, and those hinds of things. IfI come foum China, my dilabood would betcally differer from ther childhood. Then we talk about somehing about that $t$ is very hard to join the converstion to build a very guick and dose reationship with tem I guess, one ting we can mprove, as imigrants, they ted to get the common topic which mosly people are talling about for example, for guss, it might be Rugby, for guils, it masjo shopping on something, if you relly want to join ther culture, go to the stret and find out some fastions or shops, just for later on when you

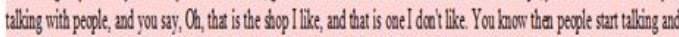
stan to bow you Because the bes way the will boor you is through some basic and daly kind of things. It is na like the

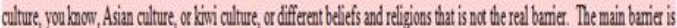

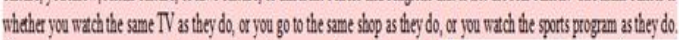
Then you got some common topic then culture will beeome a less and less bamien It is the same comminication reference and

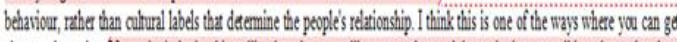
close to the ative. lf you dont do the things like they do, you will never understand the topic they are taling about, then hor

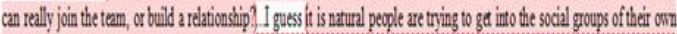
ethricty. One thing is that they feel more comfotable, What someone comes to a foreign wuntry, we here, they are soot of in

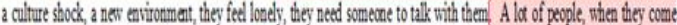
bee, ther English is vey basic. It is very had for them to communicate with uatives. They wat to express, they want to find

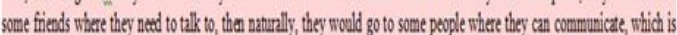
using Chinese to conmunicate with Chinese people. So, neturlly they come together. It is not like that they dont want to

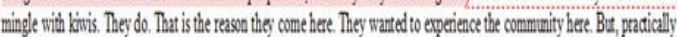
it is very hard for them So, I think, sometimes, faris t take it wrong way. They look at Chinese poople, hey, all of your Chinese become a group and come together and talling Bimg, Bing, Bang, Bang, and you dont undessad, so they think they punposely

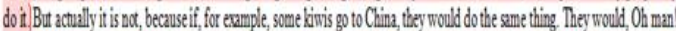

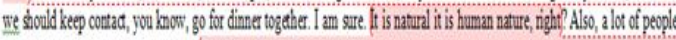

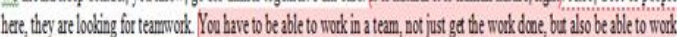

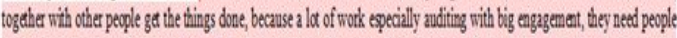
wokking together, everybdy works on litle piecs, but you have to work togethe as a whole team to deliver some big project.

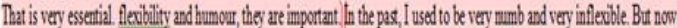
I tad to have a little joke with othe people Enjoy the work, athe than, just like do the rook. People wait to see you happy. If

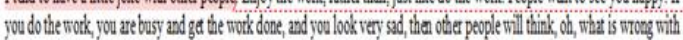

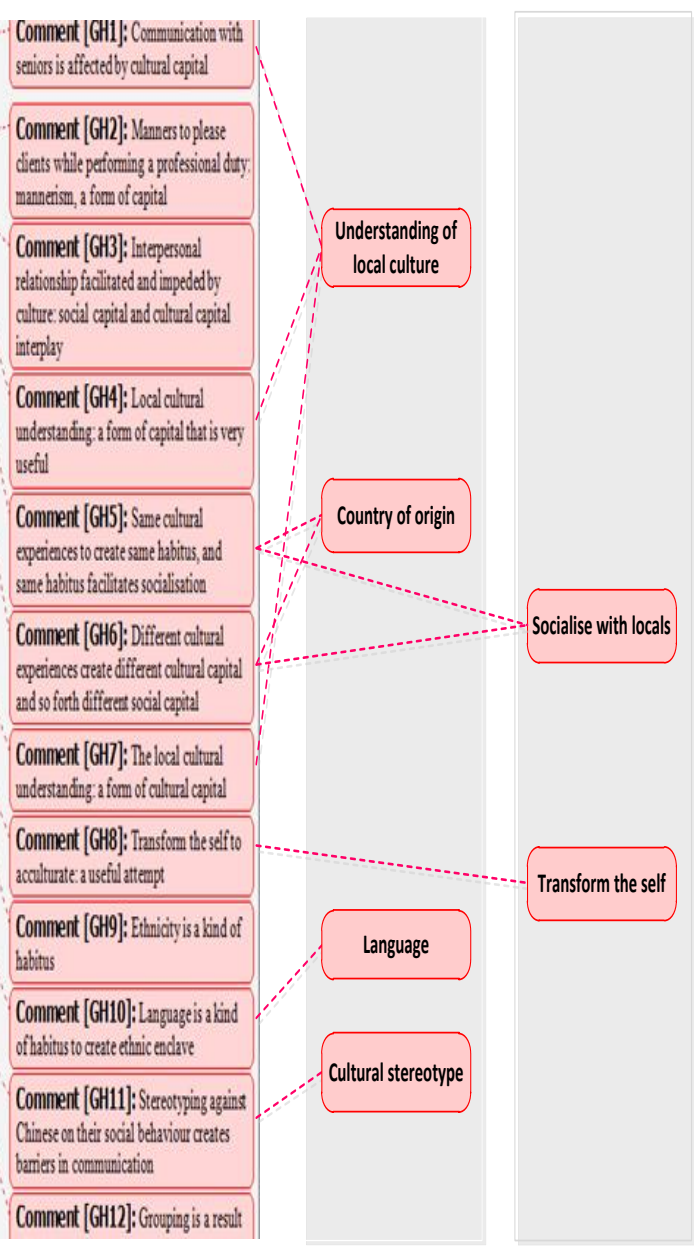

Figure 4-3: Elicitation of the forms of capital and strategies from interview data

\subsubsection{The shared forms of capital and strategies}

After the researcher had completed the preliminary analysis for all interviewees, he counted the occurrences for each form of capital and each strategy. He then identified those that were occurring most often. The most frequent forms of capital and strategies were used in the following analysis and later to address the research questions.

\subsubsection{Assigning values to the forms of economic and cultural capital}


The researcher divided the most frequent forms of capital into economic capital and cultural capital according to the categorisation in Table 3-1.He then assigned values to each. This step was carried out for each interviewee in Groups 1 to 3. Figure 4-4 indicates how a value is assigned.

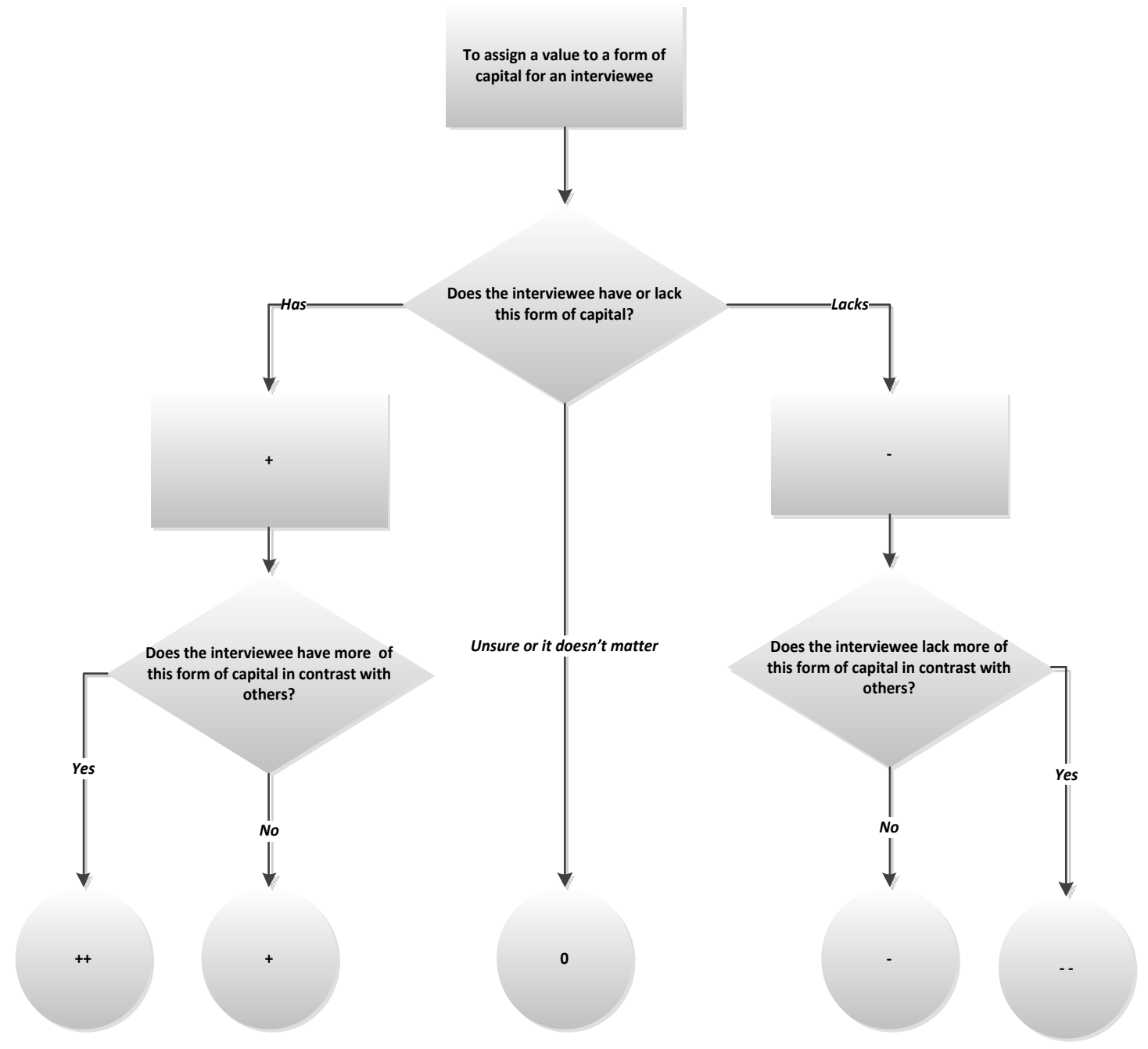

Figure 4-4: How a value for a form of capital is assigned

In explanation of these steps, the researcher first identified whether the interviewee perceived they possessed or lacked a form of capital, such as language, personality traits and country of origin. If it was possessed, a positive sign was assigned; if it was lacking, then a negative sign was assigned. If it was neither possessed nor deemed lacking, a zero sign was assigned. 
Second, the researcher assigned a value, either one or two signs, to the form of capital. This value was based on the interviewee's self-perception about how much he or she perceived they possessed or lacked that capital in contrast with others. For example, a Pakeha interviewee assessed that he had more language capital than others because he had a double major degree in both accounting and law. The law programme made his English writing and business communication skills superior to one who might have completed only the programme in accounting. Another Pakeha interviewee thought she possessed the language capital and her capital was useful when competing with those who had immigrated. In this case, the first Pakeha was assigned "++" and the second, “+”. On the other hand, an Indian migrant interviewee thought he lacked language capital when competing with locals because he did not know the local slang; however, he felt his English was much better than Chinese migrants who, he believed, would lack not only the local slang but also the grammar. Corroborating what the Indian thought, a Chinese migrant interviewee felt not only that she lacked language capital but she lacked it the most. When competing with locals, she suffered from both the lack of local slang and other lexical knowledge of New Zealand English. The Indian was assigned "_" and the Chinese, ". -.".

The forms of capital and their values obtained from these two steps are shown in Table 4-2 below.

\begin{tabular}{|c|c|c|c|c|c|c|c|c|c|c|c|}
\hline Group & $\begin{array}{l}\text { Ref } \\
\text { No. }\end{array}$ & Language & $\begin{array}{l}\text { Local cultural } \\
\text { understanding }\end{array}$ & $\begin{array}{r}\begin{array}{r}\text { Personality } \\
\text { traits }\end{array} \\
\end{array}$ & $\begin{array}{c}\text { Local } \\
\text { accounting } \\
\text { experience }\end{array}$ & $\begin{array}{c}\text { Local } \\
\text { accounting } \\
\text { degree }\end{array}$ & Accent & $\begin{array}{c}\text { Cultural } \\
\text { stereotype }\end{array}$ & $\begin{array}{c}\text { Country } \\
\text { of } \\
\text { origin } \\
\end{array}$ & Surname & $\begin{array}{c}\text { Local } \\
\text { social } \\
\text { networks }\end{array}$ \\
\hline \multirow{11}{*}{ 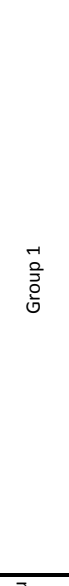 } & P16 & - & - & .. & - & - & 0 & 0 & 0 & - & 0 \\
\hline & P19 & -. & 0 & -. & .. & -. & 0 & 0 & - & 0 & - \\
\hline & P22 & -. & -. & - & 0 & 0 & 0 & 0 & - & - & - \\
\hline & P27 & -. & - & - & 0 & 0 & 0 & 0 & - & 0 & 0 \\
\hline & P28 & -. & -. & - & - & 0 & 0 & 0 & - & - & 0 \\
\hline & P30 & - & - & 0 & - & 0 & 0 & ++ & - & 0 & - \\
\hline & P34 & -. & 0 & - & - & 0 & 0 & + & 0 & 0 & 0 \\
\hline & P39 & -. & -. & 0 & - & 0 & 0 & ++ & - & 0 & 0 \\
\hline & P40 & - & 0 & 0 & - & - & 0 & + & 0 & 0 & 0 \\
\hline & P41 & -. & - & -. & 0 & - & - & ++ & 0 & 0 & - \\
\hline & P45 & -. & - & - & 0 & 0 & 0 & + & 0 & 0 & 0 \\
\hline $\begin{array}{l}z=0 \\
\text { oํํ }\end{array}$ & P05 & - & - & - & 0 & 0 & - & + & 0 & 0 & 0 \\
\hline
\end{tabular}




\begin{tabular}{|c|c|c|c|c|c|c|c|c|c|c|c|}
\hline Group & $\begin{array}{l}\text { Ref } \\
\text { No. }\end{array}$ & Language & $\begin{array}{c}\text { Local cultural } \\
\text { understanding }\end{array}$ & $\begin{array}{r}\text { Personality } \\
\text { traits }\end{array}$ & $\begin{array}{c}\text { Local } \\
\text { accounting } \\
\text { experience }\end{array}$ & $\begin{array}{c}\text { Local } \\
\text { accounting } \\
\text { degree }\end{array}$ & Accent & $\begin{array}{c}\text { Cultural } \\
\text { stereotype }\end{array}$ & $\begin{array}{c}\text { Country } \\
\text { of } \\
\text { origin }\end{array}$ & Surname & $\begin{array}{c}\begin{array}{c}\text { Local } \\
\text { social } \\
\text { networks }\end{array} \\
\end{array}$ \\
\hline & P14 & 0 & -- & 0 & 0 & - & - & + & 0 & 0 & 0 \\
\hline & P15 & 0 & -- & - & - & - & 0 & 0 & 0 & 0 & 0 \\
\hline & P17 & 0 & - & 0 & -- & - & - & 0 & -- & - & 0 \\
\hline & P20 & 0 & - & 0 & 0 & 0 & 0 & 0 & 0 & 0 & 0 \\
\hline & P21 & 0 & 0 & 0 & - & - & 0 & 0 & -- & 0 & 0 \\
\hline & P26 & 0 & - & 0 & -- & - & - & 0 & - & - & - \\
\hline & P31 & 0 & - & 0 & - & - & - & 0 & - & 0 & 0 \\
\hline & P32 & 0 & 0 & 0 & - & - & 0 & + & -- & 0 & 0 \\
\hline & P33 & - & - & 0 & - & 0 & 0 & 0 & - & 0 & 0 \\
\hline & P35 & 0 & - & 0 & - & 0 & 0 & ++ & - & 0 & 0 \\
\hline & P37 & - & -- & - & 0 & 0 & 0 & 0 & - & - & 0 \\
\hline & P42 & 0 & - & 0 & - & 0 & 0 & 0 & - & 0 & 0 \\
\hline & P43 & - & - & - & - & 0 & - & + & 0 & - & 0 \\
\hline \multirow{3}{*}{ 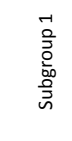 } & P01 & 0 & + & + & 0 & 0 & 0 & + & 0 & - & 0 \\
\hline & P04 & 0 & + & + & 0 & 0 & + & 0 & + & - & 0 \\
\hline & $\mathrm{P} 10$ & 0 & + & + & + & - & + & 0 & - & 0 & + \\
\hline \multirow{4}{*}{$\begin{array}{l}m \\
\text { mo } \\
0 \\
0 \\
0\end{array}$} & $\mathrm{P} 12$ & 0 & 0 & 0 & ++ & 0 & 0 & 0 & 0 & - & + \\
\hline & P24 & 0 & 0 & 0 & + & 0 & 0 & 0 & 0 & 0 & 0 \\
\hline & P08 & 0 & 0 & ++ & + & 0 & 0 & 0 & 0 & 0 & 0 \\
\hline & P11 & + & 0 & + & + & + & + & 0 & 0 & 0 & 0 \\
\hline \multirow{3}{*}{ 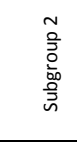 } & $\mathrm{P} 13$ & 0 & 0 & ++ & + & 0 & 0 & 0 & 0 & 0 & + \\
\hline & $\mathrm{P} 23$ & 0 & 0 & + & 0 & 0 & 0 & 0 & 0 & 0 & 0 \\
\hline & P25 & 0 & 0 & ++ & + & 0 & 0 & 0 & 0 & 0 & 0 \\
\hline
\end{tabular}

Table 4-2: The forms of capital and their values obtained from interviewees' self-perceptions

\subsubsection{Identify the spaces occupied by different ethnic groups}

The researcher then calculated the total values for economic capital and cultural capital for each interviewee. In calculating the total values, a value of "+" was assigned 1; “++", 2; “-”, -1; “- -", -2, and “0”, 0. For example, P39, an interviewee, has the following values for her different forms of economic capital: “- _" for language, “- -" for local cultural understanding, "0" for personality traits, and “_" for local accounting experience: she therefore received -5 for the total value of economic capital. In her cultural capital value calculation, she has " 0 " for accounting degree, " 0 " for accent, "+ + " for cultural stereotype, "_" for country of origin, and " 0 " for surname: she therefore received 1 for that total value. An economic capital value of -5 and a cultural capital value of 1 put her in the position as shown in Figure 4-5. 


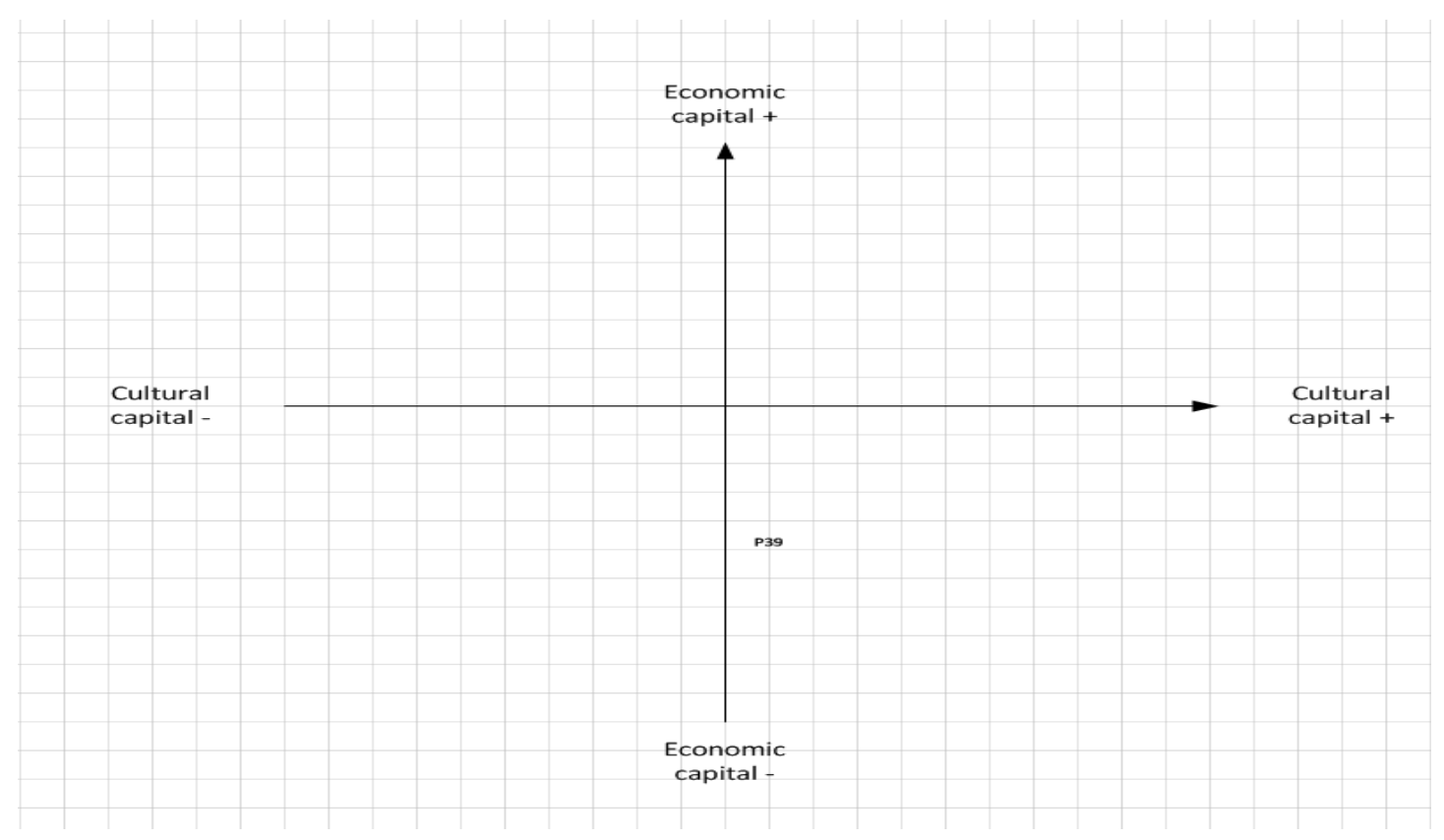

Figure 4-5: Positioning an interviewee in a space of economic and cultural capital dimensions

This process was carried out for each of the 35 interviewees (ref to Section 5.4.1) so that their respective positions could be identified. By delineating the positions of all the interviewees who belong to one of the first three ethnic groups, the spaces occupied by these groups were identified.

After the spaces for all three major ethnic groups were identified, the researcher was able to compare their spaces and see which group took the most advantageous space, which group sat in the middle and which group could be observed to occupy the most disadvantageous space. The mapping out of the field was thus completed.

\subsubsection{Forms of capital lacking in ethnic minority aspirant accountants}

To explain the spaces occupied by the ethnic minority groups, the researcher examined their forms of capital. The examination focused on finding the forms of capital they deemed lacking, and how these forms of capital affected their entering the accounting profession via the current New Zealand accountant employment market. This examination enabled the researcher to provide the answer to the first research question, 
that is: "What forms of capital do ethnic minority aspirant accountants perceive they lack for successful entry into the accounting profession? "

\subsubsection{Strategies used to overcome discrimination}

After examining their forms of capital, or lack thereof, the researcher examined their strategies. These strategies were used to cope with the forms of capital they lacked and to avoid their being discriminated against. This examination enabled the researcher to provide the answer to the second research question, that is, what strategies have been used to overcome the potential discrimination? The data analyses were finished with the completion of the above steps.

\subsection{Reporting the findings}

In reporting the findings, this thesis offers a large number of direct quotations from the interviewees' narratives. This is in the belief that it will help a reader enter into the situations or world-view of the aspirant accountants to better understand their reactions. To offer a sufficiently balanced view, the quotations include not only those from ethnic minorities but also those from the ethnic majority. Also, the narratives supporting the research argument, as well as the narratives against it, are both presented.

After the findings are presented, a discussion on the findings is provided in an effort to offer additional insights that will enhance the understanding of the accounting audience about the discrimination of ethnic minorities.

\subsection{Testimonial validity}

After the findings were written up, a procedure of testimonial validation was carried out. This procedure was conducted by the $\mathrm{PhD}$ supervisors independently without involvement of this researcher. In this procedure, all 45 interviewees were invited to participate in the validation; 24 participants responded. The supervisors then sent the drafts of three chapters, Four, Five and Six to them, seeking feedback in any form (email, notation, telephone call). These draft chapters, either sent by PDF or hard copy 
depending on the interviewee's preference, included the research methods and procedures which were carried out by the researcher and, most importantly, the findings of the study.

The above procedure is similar to "member checking", as suggested by Creswell and Miller (2000) for ensuring validity in qualitative research. As they describe,

Throughout this process, the researchers ask participants if the themes or categories make sense, whether they are developed with sufficient evidence, and whether the overall account is realistic and accurate. In turn, researchers incorporate participants' comments into the final narrative. In this way, the participants add credibility to the qualitative study by having a chance to react to both the data and the final narrative. (ibid, p. 127)

The 24 participants were allowed 20 days to provide feedback; nine did so. At the close of this validation period, the supervisors sent all the feedback to the researcher.

The results of validation are confirmative and positive in general. A detailed report of the feedback is provided in Appendix III. They are also classified into three categories: testimonial validity, reflexive validity and catalytic validity (Stiles, 1999) as explained in Appendix III. There were some problems identified in the feedback. These included: (1) two interviewees thought the fictitious names used were not sufficiently anonymous enough to avoid their being identified ; (2) one thought a small town's name that was used in a quotation should be changed, again, to avoid her being identified; (3) one was unsure that a quotation was hers. These problems are minor in that they do not affect the findings, interpretations and other substantial parts of this study. However, they were resolved by the researcher, as follows. First, all the fictitious names were reinvented, to ensure they are very different from the real ones. Second, the small town's name was changed to another which is distant from it, but this is not perceived to affect understanding by the reader as it is similar in nature. The third problem was resolved by double-checking the voice recordings to make sure the quotations, and who was being quoted, match exactly. 


\subsection{Summary}

This chapter presents the research methods and other major procedures that were used by the researcher. It explains what sample is used, how the cohort was approached, how data were collected and analysed, and how the findings are reported. At the end of the chapter, the testimonial validity check, which was carried out by the $\mathrm{PhD}$ supervisors to validate the findings, is explained.

Chapter Five is the first chapter to present the findings. It will describe where each ethnic group is situated and explain what forms of capital ethnic minority aspirant accountants perceive they lack, for successful entry into the accounting profession. 
Chapter Five: The Forms of Capital 


\subsection{Introduction}

This chapter reports the findings in order to answer the first research question; that is, what forms of capital were found lacking by ethnic minority aspirant accountants? It first presents a diagram to show the different positions taken by different ethnic groups as they relate to each other. This chapter then offers a more detailed description and examination of the forms of capital in the sample that the ethnic minority accountants perceived to be lacking. The narratives explaining or justifying their perceptions are also presented.

\subsection{Different positions taken by different ethnic groups}

In Chapter Four, the steps to identify the spaces occupied by different ethnic groups are explained (Ref: Section 4.5.5). These steps resulted in a diagram as shown in Figure 51 below.

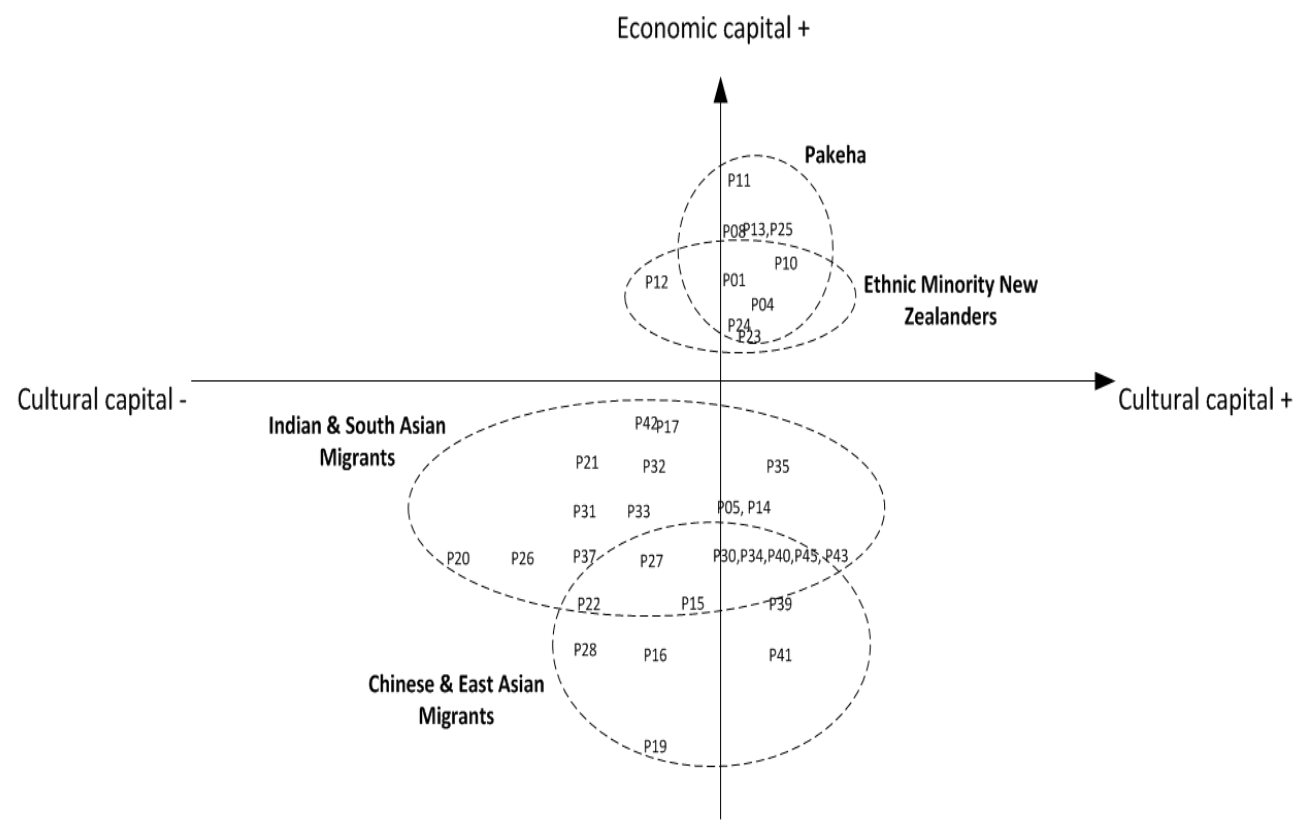

Economic capital -

Figure 5-1: Spaces of ethnic groups in the economic capital and cultural capital dimensions 
In this diagram, the spaces of different ethnic groups are identified in two dimensions: economic capital and cultural capital.

This diagram shows that:

- Pakeha, the ethnic majority group, take the most advantageous positions;

- migrants from China and East Asia take the most disadvantageous positions; and located between them are

- ethnic minorities who grew up in New Zealand; and those who migrated from the Indian subcontinent and South Asia.

\subsection{Forms of capital that are lacking in ethnic minority aspirant accountants}

Bourdieu $(1972 ; 1980 ; 1984)$ believed that people are disadvantaged or discriminated against because they lack the forms of capital that are required in the field. Their forms of capital are in three fundamental categories: economic capital, cultural capital and social capital.

The factors in the category of economic capital that are found by the participants of this study are: language (English proficiency such as oral fluency), local cultural understanding, local accounting experience, and personality traits. The factors in the category of cultural capital that are found in this study are: local accounting degree, and accent (as identified in other research - refer Table 2-1) as well as country of origin, surname, and cultural stereotype. These last three are in addition to those listed in Tables 2-1 and 3-1; thus these form an important part of the findings in this analysis. Social capital has only one form in this study; that is, local social networks. The above mentioned factors or forms are explained as follows.

\subsubsection{Economic capital}

Economic capital enables an accountant both to gain clients and prevent loss of clients, and to derive revenues from accounting services for his or her employer more directly (Ref: Section 3.3.1). 


\subsubsection{Language}

Language means English proficiency, in particular oral proficiency, which is mastered by an aspirant accountant (Gray \& Murray, 2011). Nishat, a Bangladeshi, presents a contrast between those who speak good English and those who do not.

In Bangladesh, there is one thing that the schooling has been divided into two: you go either to an English-medium school or to a Bangla-medium school. . . I had the privilege having [gone] to an English medium school, and because of that my English is quite all right... It helped me to integrate with the culture. But at the same time, I know a lot of people who have come from Bangla medium schools; although they are very friendly, because there is a language barrier, they tend to become different people within [the] New Zealand context.

Hua, who majored in English in China, sees herself as standing out from others of her ethnicity in competing for a professional employment position.

I think my advantage, compared with other immigrants here, was that I had [an] English education background, so my communication in the local language has been at a higher level than an average Chinese immigrant here.

Within language skills, oral /verbal proficiency is probably the hardest part. Ji-eun, a Korean who migrated to New Zealand 15 years ago, reflects that:

I think my language is still not good enough. Although I have worked for more than six years, still sometimes when I want to explain my opinions to people, it is like, "Ooh, how can I say it?" I was really stuck there.

Ji-eun's self-evaluation concurs with the view of a local participant. Edward, a Kiwi, perceives it is the oral language which may prevent his Taiwanese accounting classmate from performing well in a job interview.

I know she does find it difficult finding a job...I suppose there is a lot of New Zealanders who aren't pre-disposed to a non-Kiwi accent...Her written 
communication is really good. Most of the time, her oral communication is fine but I just think over the phone it would be quite difficult. Maybe there is a problem when a lot of employers do it over the phone, [a screening interview] before they will go onto the person-to-person interview.

Even if they are employed, migrant accountants from non-English speaking countries, especially those countries outside what was the British Empire, are likely to be apprehensive in oral communications. Qing (Chinese) describes her feelings when she approaches a phone call.

Before I pick up the phone, Oh, what kind of question would they ask? I don't feel confident with my language.

Oral communication apprehension may also be suffered by those who spoke English in their home countries. Sophia, a Filipino now working at a CA firm, feels nervous every time she takes a call.

Taking the telephone [call] is my big problem. It is very hard for me to understand them [clients] and I don't know ... maybe they cannot understand me either... [The] Kiwi accent is very difficult to understand for me... It seems that the accent of New Zealanders is very different from the English that I knew in Philippines...I cannot get what is the spelling, so that is the number one barrier for me...I prefer emails rather than telephone conversations; it is easier for me to communicate. When they [clients] have urgent queries, they will ring me and I need to talk to them. I can do that but I am not that comfortable.

Oral proficiency may have a negative impact on the work performance of a professional accountant. Wei (Chinese) works in a CA firm and recalls the following.

Every time at my half year review, my manager was very happy with my performance. I did my job within the timeframe and met the clients' requirements. When she asked me where I should improve? I always said oral 
language. The written [language] is not a big issue. . I still think this is an issue for me, and she agreed.

Lai, (Chinese) who is currently unemployed, further identifies the problem as an expression problem rather than a listening problem.

Maybe I can't express myself clearly. Maybe my spoken English is not very good, but I can hear and understand what other people are saying. So the employers will think about me: that I can understand and I can do the job properly.

Because of her limited ability in English expression, Lai's communication with her employer is likely to be one-directional, which means she can only play a 'do-as-told' role.

Anna (Russian) brings another issue associated with oral proficiency. She sees the issue as involving dialects which are 'localised' linguistically:

Sometimes, like people, especially in remote areas, they've got used to their language [dialects], and if I am as a foreigner, speaking to them, they themselves get lost, and they'll, oh, get frustrated as well.

Language proficiency, and oral proficiency in particular, as mentioned above, is a factor which hinders migrant accountants in their performance of a successful accountant's role. This is especially true for those from non-English speaking countries. Language proficiency, however, is a barrier that can be overcome. Wei, Chinese, who has worked in an accounting firm for two years, recalls the following.

When I was first employed in this firm, my boss talked to clients and I just did the paperwork. When I received a query, I wrote the query down and gave it to him. Currently I [now] manage everything. I talk to clients. 
Comparing herself with her Kiwi counterparts who entered the firm in the same year,

I cannot see any difference. We do the same in terms of dealing with clients.

Wei's experience is shared not only by Ming and Tomoko, the two East Asians, but also by Anna and Dominika, the two Russians. It is further supported by Jonah and Jacob, the two senior accountants who have experienced employing accountants from non-English speaking countries. Jonah expressed this issue as follows.

It was just an assumption issue, not a real issue. It is just a domestic situation [as] they were not having many occasions to practice it a lot. Verbal is a lot more challenging if you were not using it. For migrants, once they've joined the organisation, they start picking and picking, and within a short period of time, they will pick it up with you.

\subsubsection{Local cultural understanding}

Language does not work alone. It is often intertwined with an understanding of local New Zealand culture (Kim, 2004a; Gray \& Murray, 2011). The impact of local cultural understanding is first reflected in job interviews. Biscero, a Tongan, highlights that it is important to be aware of the norms used by New Zealanders.

Because the first thing in the interview process in [the] New Zealand protocol, they want to see you eye to eye. Even in shaking hands, we don't see the point why you [are] squeezing the other else's [sic] hand unless you want to do some harm to that person, but here you signify your confidence or stuff like that...I see it is an obstacle at the entry of an interview, how you present yourself like shake hands, all of these small things are added up in terms of when somebody [is] deciding to hire this person versus that person.

Liang (Chinese) finds it hard to give her natural performance in a job interview because she is not sure about the norms of local culture. 
Although your English may be pretty good, but the way they talk will be different from the native speaker, and the culture. For example, you cannot make a joke. You don't want to offend or to be offensive to other people. That is a good example of a cultural barrier. So that would reflect on your communication. When dealing with locals, it is not flexible at all, especially in job interviews. Every time I tried to remember what I should say and what I shouldn't. Just be careful to answer the questions. It is not a natural performance.

Hasan (Indian) also worries about his behaviour.

At least we need support in how to plan, how to dress, how to behave in an interview.

Ling, a Malaysian Chinese who grew up in New Zealand, perceives that migrant accountants may not perform well in the psychometric test in the recruitment process, because they do not comprehend the added meanings of the terms used by local New Zealand people.

If English is your second or third language, or you have learnt it somewhere else along the way, your comprehension isn't as high as somebody whose English is their first language. You will be missing the innate understanding of the language, the hidden part, and extra things. If you can't speak a language with the same level of understanding, it might be a huge detriment to the applicant.

Understanding local culture not only affects a migrant accountant's performance in job applications and interviews, but also their communication and socialisation with local people. Qing, a Chinese, reveals that she has much difficulty socializing with locals, other than at a superficial level, as follows.

If you are from China, you don't share the same back knowledge or background with people here. When you talk to people, you kind of just say 'How are you'; you don't really get into deep conversation for things. 
Thanhha (Vietnamese) echoes what Qing says.

Even [when] you know English is not a problem, some of the jobs are...kind of things they will talk about, [but] you are not familiar with... Local Kiwi people [have] got interests in different kinds of stuff we cannot match.

Aadi, an Indian, sees the impact of cultural understanding from both sides: the employers and migrant accountants.

So, it is two ways: the perceptions in the minds of New Zealand employers, that these people [migrant accountants] are a different kind of thing, and a little bit of a lack of cultural awareness on the part of people [migrant accountants] who come into this country also, from both sides. I think it takes a little bit of time, for that gap to be bridged.... People from here come closer [to the migrants], the immigrants come closer [to the locals]. They understand, 'Oh, this is the way we do things here. '... This is how they interact, so it comes to closer and closer. Once it is there, they get employment, I think.

Wei (Chinese) echoed that statement.

Communication includes lots of things. Language is one thing, and another is a cultural thing. Such as sometimes I email to my clients and talk about something. I just focus on the job, but for my manager, she will write some other things, for example, How about your family? just to make clients feel, oh, each time it is not serious. I am very serious, each time I just talk about the job. But my manager talks about something else [to] make the clients feel very relaxed.

Jiayi (Chinese) further explains this.

For the job itself, my English is very proficient. But I found that in most of the workplace, work-related interaction is not enough. You also need to have other interaction outside the work...It is that area I found that being a new migrant, I 
lack confidence. When people talk about news, literature, sports or other things, I found it hard to be part of the conversation.

Nimra, a Malaysian Indian, enhances Jiayi's view by highlighting the notion of social communication.

Now the social side of communication, this is where when you are sitting in a coffee room having morning tea or having a lunch catch-up; people need to feel they are comfortable dealing with you. You know when you are coming, "Oh gosh, I don’t really want to talk to her, or I have nothing to talk to her [about]."

Hua (Chinese) reveals her difficulty when communicating with people at a senior level.

In that level, the communication is very difficult. I mean, accurate and also political, diplomatic expressions in English.

\subsubsection{Local accounting experience}

Accounting experience in this context means a candidate has already had work experience in accounting or an accounting-related role in New Zealand. Edward, a Kiwi who received job offers from two of the Big 4 firms before graduation, emphasizes that accounting experience is much appreciated by accountant employers when selecting a candidate:

There was an officer who said that was a big plus. He said that they've got a lot of graduates who have very little, poor or no experience.

Ishan, an Indian who grew up in New Zealand, failed to find an accounting job. $\mathrm{He}$ explained this in the following terms.

I don't have prior experience in accounting. A lot of my classmates used to work in like the payroll office and that helped them to get into the firms. For me, I never had that, those types of roles. I've just found these days employers are looking for people at least to have some relevant experiences. 
Kasim, an accounting manager who has experienced employing accountants in New Zealand, reveals this also.

I don't want to spend time to train this person to do work for me. If I am hiring a person now, which I am going to do that next year, I need that experience, I need a person who has experience already.... So what I will ask this person, please go and do some work on your own accommodation.

Accounting experience, to be valid, must be verified by a local referee. This is a common practice in New Zealand. Sophia, a CPA from the Philippines, finds it hard to get an accountant's job in New Zealand because she cannot provide a local referee:

CPA of Philippines is not recognized here. A reference here is very important.

In comparison to Sophia, Fan, a Chinese who has successfully acquired an accountant's position, reflects:

I've got a good reference from a reputable accounting professor: because I have been working with her, she knows me very well.

Aadi (Indian) believes that the requirement of a local referee comes from uncertainty:

Because the testimonials they bring, you know, the certificate they bring, the reference checks, for example, for locals, it would be easy to make reference checks, but for people who are coming from overseas, you cannot really rely on the reference checks. So, the uncertainty, the element of uncertainty, makes you discriminate, isn't it?

\subsubsection{Personality traits}

Personality traits mean the appearance, manners and behaviours that are most favoured by clients (Anderson-Gough et al, 1998). Bella, a Kiwi who was offered a trainee accountant position soon after her graduation, perceives her personality traits were the reason why she was employed. 
Personality was huge. They really went for that. They weren't so concerned with marks. Everyone else had put four years at university and I only had three. My work experience within accounting was zero, but I have been a gym coach for five years...I put that into my CV just to show that I can stick at something... so it was quite easy for me because as a gym coach I definitely deal with the appearance and clients. So you can kind of relate that to what it could be like in a professional situation.

Justin, another Kiwi who started his cadetship in a CA firm when he was 17, shows a personable character:

I think I was just a quite approachable person and I can come up with the answers on the spot.

He further explains:

It is important, I mean, whom we deal with on a day to day basis, chief executives, chief financial officers, top managers...You've got to convey yourself in a manner that people will listen to you and respect you, because your first impression is how you look and how you come across. So if you come across professionally, you get a better outcome.

Chris (Kiwi) also sees personality traits as key to gaining employment.

If they are happy with dealing with you as a person and they like you as a person, they'll probably not go for another accountant...It is a lot like any sales, building personal relationship, and get that link so people want to deal with you and enjoy dealing with you.... I mean, grades help you to get an interview, but at the end of the day, if you are a boring plank, they will not hire you. 
Chris's view is supported by Uche, a Nigerian:

If I am an employer, I want to employ someone [with whom] I am more comfortable to talk to and to be around, rather than someone who just wants the job.

In terms of pleasing clients, migrant accountants, limited by their linguistic proficiency and local cultural understanding, cannot offer a good performance. Qing, Chinese, describes the impact of language on her personality trait.

I would think, first of all, the language. When I spoke English, I myself was not confident.

Jiayi, another Chinese, associates his personality traits to his limited knowledge of local culture.

Apart from asking for the data, I don't know what else I should talk to them [about]. There is nothing relaxed, warm and interpersonal...I cannot always say [sic] about today's weather is good or bad, you know. The moment I thought about that, I started feeling not good and not confident [in] myself.

Unsure about what kinds of joke can be accepted by locals, Liang (Chinese) chooses not to use them. For Liang, being perceived as "jokeless" is better than offending local people. Liang's self-protective stance is similarly adopted by Wei (Chinese). Her communication with clients focuses on completing the accounting task rather than socialising with them.

Communication in this area, I am not confident. I don't know what I should talk about, and what I shouldn't and I should avoid it.

Lubna, Pakistani, further reveals the shallowness and boring nature of conversations between Pakistanis and local Kiwis. 
That is my question: "Are you able to talk to them and discuss and think at the same level, or are you always one, here I always feel one step lower, so, 'yes', 'ok', 'thank you'?'

Migrant accountants' performance in pleasing clients is impaired not only by their limited language proficiency and cultural understanding, but also by their own cultural make-up (habitus). Tomoko, Japanese, perceives that:

How I behave might not be acceptable here. I am a little bit shy. I am not appearing [projecting] myself better, because in our culture, we don't do like "me, me, me", and "pick me", that kind of stuff.

Nimra (Malaysian Indian) agrees with Tomoko. She described her experience:

Because I had worked in Malaysia, the very first interview I went for was in Wellington, and the guy was really good. I didn't get the job. So I rang him up and I said I would really appreciate if you can give me some feedback. He said, "You have a lot of talents, but you were not really selling yourself." I think, being a Malaysian or Asian, I am sort of like an underdog. I wasn't selling myself really well. That was just a cultural transition, working in Kuala Lumpur and coming to Wellington.

Nishat (Bangladeshi) further identifies a preference to "clam-up" or to keep silence, possibly to be found within many different Asian ethnicities, which may shut them out from getting close to local New Zealand people.

As an international especially from Asian background, you tend to have that shield, which sometimes may stop you from going to have a conversation. But I've noticed that for a Kiwi here, especially whites, it is very easy to go and have a conversation with a random person. 


\subsubsection{Cultural capital}

Cultural capital signifies the social and cultural background of an accountant (Ref: Section 3.3.1).

\subsubsection{Local accounting degree}

An accounting degree signifies that an aspirant accountant possesses a certain level of accounting knowledge and skills. Judy, British, perceives that:

My employability is based on my accounting degree.

A Kiwi graduate, Bella, also believes that an accounting degree is a kind of precondition an aspirant accountant has to have when seeking an accounting job. Jacob, Dutch, further suggests that holding only a Bachelor's degree in Accounting may not be enough.

Some of them [candidates] have to go for a longer [period of] study for Honour's Degree or Master's Degree, and then they'll have more chances to get the position.

Fan, a Chinese graduate, has a different view. She sees having a higher accounting degree may put an international student in an awkward situation when seeking a job in the job market.

I am an international student and I don't have related New Zealand experience, so I was trying to find some very basic work related to accounting. But the problem is I got a Master's degree ${ }^{2}$, which is a higher degree, but I have no New Zealand experience. So I had tried to figure out what kind of position (that) suited me well, because they [employers] have to pay me more. But I don't have

\footnotetext{
2 However, the 'Masters' is the Master of Professional Accounting degree. This may be thought of by some employers to be the equivalent of undergraduate papers, although it is positioned as a higher degree than the BCom. International students consider this to be a higher degree than a B.Com.
} 
any experience, you know, a higher education with no experience is a quite weird combination for me to [find] work in New Zealand.

Ansh, Indian, acknowledges that an accounting degree is important, but it has to be a New Zealand degree, rather than a degree obtained in India.

Employers here are quite particular on New Zealand qualifications, having a bachelor degree of New Zealand, doing a graduate diploma in accounting, or an honour's qualification.

Diya, another Indian, who got her accounting degree in India, corroborates what Ansh says:

After I arrived in New Zealand, I realized my degree was not recognized here: they prefer people who have a degree from here.

Uche, Nigerian, encountered the same problem as Diya.

My Nigerian accounting degree was not recognised here. I have to study a New Zealand qualification ... [to be] accepted by the New Zealand employers.

Druv, Indian, provides a further elaboration using his life story.

I have got a very recent example. I had applied for a job. I spoke to the [human resource] manager and he was very keen for my application. He recommended me to make that application as soon as possible but later I did not hear back from him for quite a while. Then I phoned him up for the feedback and he said initially the criterion was quite different from [what] it is now. It was changed to someone who has completed studies in New Zealand and based on that I was not considered any more.

The fact that overseas qualifications are not appreciated by New Zealand employers creates a situation in which Asian accountants are deemed "over-qualified" because of 
their 'home' degrees, and yet not seen as suitable for entry-level accountant positions. Ansh, an Indian, perceives that:

Most Asians, when they come to New Zealand, they are overqualified for entrylevel accounting positions such as accounts payable, accounts receivable and transaction processing roles.

Aadi, another Indian, explains this further.

So the question is that all the [overseas] qualifications also become hindrances. If they find the people are 'over qualified', they think this guy got lots of degrees and academic qualifications, whether this kind of job, the entry-level accounting job will interest this person, they will think about it, right?

\subsubsection{Country of origin}

Country of origin means the country an aspirant accountant comes from (Miranti, 1998). Uche, a Nigerian, introduces the concept of a "comparable labour market" 3 during his interview; being a list of countries where university degrees are recognised by the New Zealand government when considering an application for immigration. As Uche perceives, an accountant who comes from a comparable market will find it much easier to find a job than those who do not. Generally, the list contains many developed countries of Anglo-Saxon origin, such as the UK and Canada, as well as EU states such as Germany, but none of those jurisdictions which have more recently developed a capitalist or market economy, such as India, Russia and China.

Uche's perception is corroborated by Nicole, a European who migrated from South Africa.

We [she and her husband] made the decision to migrate to New Zealand in 2008, and I got my first job in November 2008. That was a telephone conversation,

\footnotetext{
${ }^{3}$ For checking which countries are in the comparable markets, see: http://www.immigration.govt. nz/opsmanual/30570.htm
} 
and I did not need to come over...Yes. Definitely, South African accounting experience is definitely recognized here.

But for Aadi, from India, it was a different story.

I directly applied to the companies. I directly applied through the consultants. The consultants, as usual, they take copy of my CV, they gave me an accounting test and all, you know. I got close to a hundred per cent in all the accounting tests, but still I couldn't get a job.

Issur (Israeli) shared Aadi’s experience.

I would like to work for a CA firm because I had that experience in India as well as in Israel. But every time I introduced myself, they said, 'Oh, you don't have the experience in a CA firm in New Zealand'...It is a very difficult situation.

Jonah, a former CFO of a large company, makes a further distinction between Asian countries.

If a candidate is from Hong Kong, Singapore and so on, then they would be fairly comparable to Indians because they both have British context in them, because they were former colonies. If they come from China where they haven't had that, then they would be different, because they would not be very familiar initially with the British kind of Western culture.

Nina (Nepali) has a similar perception.

They don't prefer those from East Asian countries because their English is a bit lower as compared to other countries, South Asian countries, especially from India, Nepal and those countries. 
Hua, a Chinese, echoes this:

Language wise or communication wise, Chinese will find it difficult as compared to people from India or South Asian countries.

From Jonah, Nina and Hua's narrations, it is seen that the country of origin is intertwined with British colonisation history and language. However, it is also important to note that country of origin does not equate to race. Non-whites, if "gilded" by accounting experience in the UK or any other Anglo-American country, are unlikely to be rejected. Usman, a Sri Lankan trained in England, encountered no difficulty entering into the accountant employment market in New Zealand.

I am not going to tell my Sri Lankan experience because that is useless...I didn't find any difficulty finding a job in New Zealand. I see the reason for that is the UK experience which I had, and so apparently the academic qualification which was from UK again...

Javana, a Malaysian Chinese, agrees with Usman.

I do not see there was any issue at all, partly because of my education, because I had a UK degree, and also 2 years audit training in London.

Jonah, a Kenyan, has a similar experience. All three, although with "coloured" skins, are still appreciated in the New Zealand job market. That said, Jonah makes a cynical comment.

It is like a big-brother syndrome, isn't it? If you have experience in North America or UK, it is valued no matter where you go. It is traditionally thought [that] you've been fairly advanced, because you are ahead in terms of application of a lot of these tools and techniques in [the] day-to-day accounting world, because industries are bigger, population bases are bigger, competition is bigger. 
The three participants mentioned above share an opinion that the country of origin is an important factor that distinguishes aspirant accountants in the job market. Their opinions, however, are not universally agreed by the research participants in this project. Ji-eun, a Korean who works in a government organisation, states:

It does not matter whether you are a Korean, or Chinese, or Malaysian: I don't think they have discrimination between countries.

\subsubsection{Accent}

Accent is different from language as presented in Section 5.3.1.1. In the study of Francophones in Canada, it was seen as different to language, as it signifies an aspirant accountant's ethnicity (Spence \& Brivot, 2011). In the UK, accent may be used as a primary signifier of class (Crystal, 1987). Either way, it does not indicate how well the applicant has mastered the English language itself. Accent was primarily reflected on by those from the Indian subcontinent and South Asia. These participants either had English as one of the official languages, or grew up in an environment that is considerably influenced by British colonial history.

Javana, a Malaysian, perceives that accent is an important factor on which Malaysians are potentially discriminated against in the professional employment market. Similar perceptions are also held by Aadi, Sophia, and Aamir. Aadi, an Indian, also feels it is important for Indians to improve their accent:

If something has to be improved, they could do [that by] ... thinning their accent.

Aamir, Sri Lankan, sighs when mentioning his incompetency with a New Zealand accent:

I cannot polish my accent overnight.

Thinking about accent is sometimes intermingled with thoughts about New Zealand slang, which weakens a migrant accountant's communication ability. As Hasan (Indian) perceives: 
It might be lack of communication because their mother tongue is English and my mother tongue is another thing, and I cannot use slang as they do.

\subsubsection{Surname}

Surname, like accent, signifies an aspirant accountant's country of origin or ethnic background. Aryan, a local Indian, emphatically points out that there is "racial filing" going on in the New Zealand job market.

I think that racial filing definitely still happens... When an employer looks at your $\mathrm{CV}$, he does see the name and chucks it sometimes into the wrong file and disregards, and considers [he has been] thinking and reading it through. You see what I mean? Someone has got a long name, they just chuck it in a disregard pile.

Hua (Chinese), when relating her experience, clearly identified the impact of a surname for Asian accountants.

I came across a case that there is a role in a company, and we got a standard reply as declined, a kind of reply from the financial controller to a group of people, saying like, "Your application has been declined because blah blah blah..." and we noticed that all of the recipients are with either a Chinese name or an Asian name. One of the candidates had actually replied to her and copied it to all of us, saying 'Thank you for replying to us, as a group; and we see it as not professional, on behalf of all the Asian candidates, because all of the ethnicities are, at least look like Asians.' First, she does not really respect Asian candidates. If she wants to decline a candidate, she should have done that individually, rather than to a group. And she put all of the recipients' names, so we can see each other, and we all recognized the others are all Asians. It is another disrespectful matter. 
Shada, Iraqi, identifies the hardship that is associated with Muslim surnames:

I can totally imagine how hard it would be if someone used a Muslim surname such as Mahmud and Husain when seeking an accountant job.

\subsubsection{Cultural stereotype}

Cultural stereotype refers to perceived or presumed typical characteristics, in particular, the work ethic, as being possessed by the members of an ethnic group. Shada, an Iraqi, contributes her view that accountants from different ethnic groups are different.

Western accountants, Asian accountants, Middle-East accountants, they are all different. All those types of accountants are all different; they all have different values and different backgrounds. Asian and Middle-East backgrounds are probably known as more productive, efficient and hardworking, which is a generalization, of course. [These are] the sort of assumptions that I've seen.

Javana (Malaysian Chinese) reflects the impact of her own ethnicity.

I know there are a few employers in Wellington. They have good opinions about Malaysian accountants. Because maybe [when] we speak they can understand, and also work ethic. We are very hard-working, we are very honest, and we always deliver the work well.

Jiayi (Chinese) provides a distinction between Chinese and New Zealanders.

From my years of experiences in both China and New Zealand, I think, in China, accountants are usually better trained, with better technical skills, and usually work harder, and produce a better quality of accounting job, for example, measures and the report. New Zealanders, say, they are more enjoying the working style, also they are more likely to [put] emphasis on their work life balance. 
Ansh (Indian) further echoes this.

Asians have a reputation of being hardworking, of being loyal, of being somebody who doesn't talk back and who are taking orders... They do not challenge their managers. They will take the orders and don't complain. They obey, just go there and do what they are told as opposed to challenging their bosses. That perception certainly translates into their ability to get jobs.

Ansh, Indian, provides a view which is different from all the above.

There are stereotypes. There is a perception that Asians overall, don't have the same level of ethics, as Europeans.

Thus the extent to which stereotypes are a factor in the exclusion processes remains subjectively perceived, and may even be consciously counteracted in both interviews and work behaviours, among this cohort of interviewees.

\subsubsection{Social capital}

As already described, social capital comprises of social networks or social connections; and these may be used by an individual to advantage himself or herself ahead of others. In this project, the only well-observed form of social capital was the social networks.

\subsubsection{Local social networks}

Local social networks encompass an accountant's social connections, including connections to local New Zealander employers. Aryan, an Indian who grew up in New Zealand, describes how a New Zealand company sought to employ an accountant, harnessing social networks.

I think in Wellington, the key thing is you know someone. I think even in New Zealand, maybe. It is such a small country. A lot of jobs don't get advertised. The job I am going to move into will be the same kind of situation that I did at the company where I am now. For that job, I have known it was offered to three 
people first before [being] advertised on the $\mathrm{SEEK}^{4}$, because they thought SEEK will cost them a lot of money. It is a huge firm, an international firm.

Ishan, with the same ethnic background as Aryan, claims that he is disadvantaged because he lacked social networks.

I don't have many connections with people who work in firms. None of my family works in accounting. Some of my friends, they have family members or relatives working in firms, that would at least help them some way as a recommendation.

Realizing the lack of social networks, Ishan had to knock on the doors of potential employers, introduce himself and ask for a job. In comparison, Aryan partly attributes his success to having the social network.

Back to my background, I actually helped to build a house in Kilbirnie for my grandpa, and because his manager [the employer] was building something of his as well, we shared some of the supplies... So he could see me... as a more technical chap. After a little while, he needed someone in his office to replace someone else, and he said to my brother 'What about your brother there?' So I went for an interview there. It lasted about 4 minutes and they offered me the job straight away.

Tomoko (Japanese) feels that accountant employers prefer to use their own family members and relatives rather than others, and this is particularly true in small towns.

In Hastings ${ }^{5}$ especially, accounting students who have already got accounting jobs, they have connections like daddies and aunties who work in the firms. I don't have such connections. Although I have better qualifications than them, I mean, higher, they got the jobs because they have connections to relatives, especially here in such a little town.

\footnotetext{
${ }^{4}$ SEEK is one of the most popular job websites in New Zealand and Australia.

${ }^{5}$ An alibi was used for the actual town name to denote rural/size attributes
} 
Ming, a Chinese, echoes Tomoko by telling a story how a Chinese girl found a trainee accountant position at an accounting firm: the girl was helped by her mother-in-law who knew the partners in a Wellington firm. As Ming sees it, in New Zealand, many accounting firms are a family business and therefore give preference to the partners' family members and relatives.

With Kiwis, especially accountants, a lot of accounting firms are a family thing. Parents are accountants and later their children are more likely to be accountants, and then their grandchildren. So they would have a big network. I know a lot of people get the job because of their networks.

Comparing Chinese migrants with locals, he observed the following.

There are a lot of jobs which are not advertised, more by word of mouth, or more of networks or connections. That is where I think a lot of Chinese students are on a disadvantageous side because as a student, we even do not have any connections, all of your parents are back in China, so that potentially you have already lost a lot of opportunities.

Jiayi (Chinese) echoes this.

In terms of social network, I've found new migrants are often disadvantaged, because they come from different backgrounds. That is something which is quite real. You don't have many associations or relationships to utilize.

Similar to the Japanese and Chinese, Uche from Nigeria and Biscero from Tonga also feel they lack the local social networks. To prove what he claims, Jiayi further reveals an interesting phenomenon in the New Zealand public sector.

I know, from my years of experience in the public sector, some Kiwi accountants are always working as a contractor because that way, they can make more money. They do not like a permanent position. When they finish a project 
for this department, they jump to another, and some years later, they jump back. The reason for them to do it this way is that they are so familiar with employers of the different departments.

Ming (Chinese) provides a more cynical view on HR procedures of the public sector.

Because a lot of times, when they do the interview, it is not really for the purpose of doing, you know, selecting people as a formal procedure. Before they take the interview, they already knew who they are going to hire. So they do it just for the sake of doing it, not really looking and selecting the best candidates from all the applicants.

It is worth noting that the importance of local social networks may not be recognised by all the interviewees, especially those who were once accountant employers. When talking about his own selection criteria, Jonah (Kenyan), the former CFO of a big company, says:

When I employed them, I looked at who'd fit best to the organisation's culture. I didn't care whether it was a migrant, whether it was a woman or whether it was a friend.

Jacob (Dutch), a former partner in one of the Big $4^{6}$, explains his stance.

A good accountant, is like, you know these criteria from the Big 4 professional firms. They have seven criteria, seven competencies they look for, which include things like ability to engage with clients and with others, ability to manage projects, an ability to complete tasks, ability to persevere against challenging conditions, to work under stressful and time pressure conditions, ability to analyse and critique, and conclude on difficult and technical issues, and so on and so forth. I think they have, over 150 years, they've been consistent, and built up a very good sort of framework which is what I looked for.

${ }^{6}$ Ernst and Young, Deloittes, KPMG, PWC 
It may appear, at first glance, that there is little common ground between the views of those who sought to be employed, and those who had experience of employing, in their appreciation of the functioning and role of social networks. However, the selection of the sample was not structured to enable the study to encompass, and reconcile, the views of both employers and employees.

\subsection{Summary}

This chapter describes how different ethnic groups are separated from each other when entering the accounting profession via the accountant job market. Ethnic minorities may find themselves the most disadvantaged. To explain why they are in such positions, their forms of capital have been examined. It is found that they perceive they lack capital across all Bourdieu's three fundamental categories: economic capital, cultural capital and social capital.

The specific forms of capital that are found to potentially disadvantage ethnic minority aspirant accountants are: language, local cultural understanding, local accounting work experience, personality traits, local accounting degree, country of origin, accent, surname, cultural stereotype, and local social networks.

Chapter Six presents the strategies that are often used by ethnic minority aspirant accountants to overcome that lack of capital and to gain employment in the New Zealand accountant job market. 
Chapter Six: Choosing and Using Strategies 


\subsection{Introduction}

This chapter presents the findings that will answer the second research question: What strategies may be adopted by ethnic minority aspirant accountants to overcome any potential discrimination?

Bourdieu $(1972,1980,1984)$, in his theory of practice, divided such strategies into two kinds: subversive and conservative. The former aims to circumvent or undermine collective habitus in the field, and the latter to conform to or reinforce it. Both subversive and conservative strategies are found to have often been used by ethnic minority aspirant accountants in this study to subvert or overcome potential discrimination. They are presented as follows.

\subsection{Subversive strategies}

Subversive strategies are used to overcome the potential barriers erected by hidden or tacit ideologies (ref. Section 3.3.3). Such strategies used by aspirant accountants in the New Zealand employment market could include:

- $\quad$ Adopting an English surname;

- Meeting the employer face-to-face, and

- $\quad$ Cutting down the CV.

\subsubsection{Adopting an English surname}

A surname and its associated country of origin, as presented in Chapter Five, are two forms of capital that may distinguish aspirant accountants from each other when aiming to enter the accounting profession. With a surname which suggests they belong to an ethnic minority, aspirant accountants are likely to be discriminated against by "racial filing". To combat racial filing, some aspirants change their surnames. This strategy makes it more likely that they will be asked to attend a job interview. Nishat (Bangladeshi) articulates the experience of her Indian friend. 
One of my friends is an Indian and he has an Indian surname. When he was applying for jobs with that name, he did not get any interviews or a call whatsoever. The moment he had changed his name, it was much easier and he got several interviews.

Shada, Iraqi, attributes the success of her father, an Iraqi accountant who found an accountant job in New Zealand, to his Celtic surname:

My dad has an easier time, because he has got an Anglo-Saxon name, which is quite a Celtic name.

Jiayi, switched his Chinese surname Deng and English surname Dane back and forth, depending on where he was looking for an accountant job, China or New Zealand. Deng and Dane are similar in pronunciation. Similarly, Hua has changed her surname from Sha to Sands. Sha and Sands have the same meaning. Even a candidate who grew up in New Zealand has to do something with his name. Ishan, a local Indian, reports:

For my job I have changed my name. When I apply for jobs, I will use that name.

Ling, a local Malaysian Chinese has kept her Chinese surname. She phoned an employer when her application was pending, to clarify her local New Zealand identity.

I think my first thing was that when I was applying for jobs, I went by my little name, which is the Chinese name. When people saw my name, my Chinese name, they thought I might be a foreign or international student. So I think, when a lot of people saw that, they might put me at the bottom of the pile, rather than, 'Oh, she is just another applicant'. When I was applying for the job that I have now, I actually called them, I told them that I was actually a Kiwi but that I go by my Chinese name.

Changing to an English surname might work for some candidates but it is not everyone's choice. Aamir, a Sri Lankan, described this choice. 
My surname; definitely they know I am not a Kiwi. To them it is a strange name. That could be a reason why I did not receive an invitation for interview. But I cannot change my surname. That is, I lose my identity. That is a crazy option.

Issur (Israeli) echoes this view, but with his first name.

Some people told me, 'My first name is very Jewish. Why don't you change it to an English one?' I said, 'Why should I change who I am? That is my identity.

Thanhha (Vietnamese) sees it more pragmatically. She realises her ethnic and national identity will be discovered when she comes to the job interview stage.

Because my surname is Vietnamese, they will know that I am not a Kiwi. In my $\mathrm{CV}$, I do put my nationality, because I think anyway they will know it if I get an interview.

\subsubsection{Meeting the employer face-to-face}

To circumvent "racial filing", some candidates attempt to meet the employer face-toface in a bid to distinguish themselves from others, thus demonstrating their English proficiency, local cultural understanding and key personality traits. Druv, an Indian, tells the story of how he obtained a job in accounting.

Maybe there was a name effect ... I can't say; but I heard from someone later ... (when I started annoying a few more people) that your CVs are assessed based on your name, ethnicity or stuff like that. But I went for the open day interview, and there I was talking to a consultant. She quite liked me, [and] the way I communicated with her, and straight away she called three or four other consultants over and they recommended me straight away to go for a next stage interview.

The open day was offered to allow any candidates who were interested to come in and meet their consultants. Without that, my chances would still be slim. Before that, I had applied to that organisation for a similar role and different roles about five times and my applications were always declined. No reasons 
were given. When I was interviewed for my role, I mentioned those applications as well; the interview manager said that it was quite surprising that they didn't shortlist me for an interview...I arrived there with my CV, and that was the same CV I had used over and over again.

Ishan, an Indian who grew up locally, took a similar approach. He knocked on the door and "forced" the employer to see him face-to-face.

When you go in I think that will make a lot of difference...the name from the online application would give employers a wrong impression that I am a foreigner. That was how I got the job [I am in] at this moment, because I actually went into the organisation and spoke to the manager.

Meeting the employer face-to-face has worked for Druv and Ishan, and some others indicated they would use it in future. For example, Uche, a Nigerian, planned to meet the employer in person. As he reckons:

If they can see me, they will see me as a real person.

However, Uche's plan may not be attempted by others. Aadi (Indian), for example, does not think it a good idea.

Knocking at the door for an accounting job, how can you do that? Every company uses accountants here. You cannot go there [and] simply knock on the door, because if they have got an accounting job they will advertise it on the Internet.

\subsubsection{Cutting down the CV}

Not having a local accounting degree and local accounting work experience are two factors that potentially disadvantage migrant accountants. As presented in Chapter Five, those whose accounting degrees and work experience were obtained in India, Philippines and Nigeria (and maybe other countries) are seen to be "over-qualified" for entry-level accountant positions. To avoid being seen as "over-qualified", some have 
chosen to remove their overseas accounting degrees and work experience from their CV when applying for an entry-level accountant job.

Kasim, a former CFO in Iraq, reveals what he did to get an accountant job in New Zealand.

Because when I wrote my CV for the first time here, it was very senior so it wasn't that easy to find a job to the same level I was. So every time I applied for a job, I was rejected because I was a senior. I couldn't find a job like that. So I talked to my cousin who said, 'Cut your CV to one page and see what happens.' When I cut my CV to one page, it started getting results. The result for me was I started finding a job.

Remove all of those [so that] it is a very generic CV: I am able to do this, I have this and this, without talking about my experiences, about my CFO experience, about finance manager experience; otherwise you will never find a job.

Aadi, a former cost accountant in India, took a similar approach.

Initially I used to give a five or six page $\mathrm{CV}$, giving all the qualifications. But later on, for [the] entry-level jobs I started applying [for], I cut down the CV to two pages. That was how I presented my CV.

Uche, a fully qualified accountant in Nigeria, did the same thing.

So when you look at my CV now, you won't see anything about Nigeria. You will see I have studied in New Zealand and I've met the requirements of a provisional member.

Kasim, Aadi and Uche's approach was also adopted by other participants including Druv, Jiayi, and Ansh. In Druv's case, he gained a Master of Commerce majoring in accounting from India, but when he applied for an accounting job in New Zealand, he deleted it. 
In my CV, I only showed I am a second-year student, I have no master's degree or anything like that, because anywhere I put that in my CV, they will not give me a job because I am overqualified, so I had to show I am a second-year student. Yes, on that basis, I got the job.

Thus, cutting down the overseas qualifications and work experience in a $\mathrm{CV}$ may be accompanied by building up the $\mathrm{CV}$ with New Zealand-related experience. Issur (Israeli) for example, started his MPA study in New Zealand so that he could show he is a local accountant:

The reason why I start doing this MPA course is to get recognised as a New Zealand accountant.

Similar to what Issur is doing, Kasim (Iraqi) volunteered his accounting services for two years so that he was able to show he had New Zealand accountant experience.

\subsection{Conservative strategies}

Conservative strategies are used to conform to or reinforce the potential criteria erected by hidden or tacit ideologies (ref. Section 3.3.3). Such strategies used by aspirant accountants in the New Zealand employment market include:

- $\quad$ Accepting an undesirable offer;

- $\quad$ Seeking a niche;

- "Knitting the web", and

- $\quad$ Transforming the self.

\subsubsection{Accepting an undesirable offer}

In Bourdieu's view (2005), everything may be weighed on an economic scale. This principle sounds harsh and brutal but it brings to light the importance of economic capital to those who are deficient in English proficiency and local cultural understanding. They use their cultural stereotypes, such as being hardworking, compliant and less demanding, to find a job opening in a market that is less favourable 
for them. And at times they accept what would otherwise be viewed as an undesirable offer.

Anna, a Russian, reports what she took to get her first job.

It was a part-time from 9am to $3 \mathrm{pm} . .$. She [the employer] just wanted somebody to do GST returns...It is like a small job but so many of them. It was a dirty job. She wanted someone just to be shown a little and then left to do it, do it, do it, no asking questions, just do it fast like a machine. When everybody left the office, I was still working.

For that job, Anna needed to face driving over a very high and winding hill route twice a day.

I drive over the hill every day because, for me, I was able to take anything. It was not easy, but I haven't had any accident. It is dangerous in winter time; sometimes the road was closed.

Wei, a Chinese, took a similar offer, requiring a Wellington/Upper Hutt commute:

She [the employer] asked me, 'Do you mind just travelling for a long time?' [meaning a long commute]. I said. 'I don't mind. '... 'Are you willing to do this kind of job?' she asked. 'As a routine job, probably it is boring.' And she asked me whether I could stay here just [on the basis of a] half day?

She further reveals the work environment of that job.

What we did was very old fashioned. We did all the journals using paper including journals, general ledger and trial balance, and then posted it to the balance sheet. Nowadays, accounting software does all of these, but we did it manually for everything, even depreciation, we did it manually. 
Differently from Anna and Wei, who had to accept somewhat dreary work conditions, other candidates proactively invited employers to exploit them in order to obtain an accounting job.

Liang (Chinese) tells that when she was interviewed, she purposely sent a signal that she would accept lower pay and longer working hours.

When they asked me what I can contribute to the company, I said, 'I can do any job you ask me to do. I am flexible on salary and I can work for long hours.' I thought that was to my advantage, otherwise why should they employ someone whose English is not very good?

Compared with Liang, Lai (Chinese) made her intention even more obvious.

When I got an interview, he asked me what did I think about my salary? He was offering me a salary of $\$ 27,000$ a year, but I said, 'If you can offer me this job, I can accept $\$ 26,000$.'

Wei and Liang's attempts are justified by Hua, another Chinese.

That will make them [non-Kiwi applicants] welcome, make them competitive. They work for longer hours and at the same wages as others who work for shorter hours, offsetting their communication shortfalls, because they know their communication skills are below average.

\subsubsection{Seeking a niche}

If accepting a sub-optimal offer is a negative strategy, seeking a niche in the accounting job market appears to be a positive one. In this strategy, some migrant candidates, based on what they have and what they don't have, seek their niche in the market. They choose a place which is either less sensitive to cultural and linguistic differences, or less attractive to local accountants. Jiayi (Chinese) has an opinion which might be useful for future Chinese applicants when considering what kind of an accounting job they should be looking for. 
Local employees are successful because they are very good at talking, but people from Asia are usually not as good as locals when they are trying to talk a lot. For Asian candidates, they should focus on the jobs that require utilizing their technical skills.

Liang (Chinese) tells of her experience, which supports Jiayi's opinion.

I think employers, when they employ a Chinese, they pay much attention to whether she has worked in this industry and whether she is familiar with the accounting software. They don't expect you to have good English. That was why, when I prepared for the interview, I spent a lot of time studying the software.

Jiayi and Liang are supported by Diya (Indian) in her strategy for accessing the accountant job market. She sees a niche which blends accounting with IT. She thinks this niche is not as sensitive to cultural or linguistic differences and therefore is suitable for migrant accountants.

Apart from the category of accounting employment, the location of the job also needs some consideration. Some migrant accountants think focusing on job vacancies in smaller or rural towns, rather than big cities such as Auckland, Christchurch and Wellington, will result in better chances. Jiayi (Chinese) took a job in a small town which is a one-hour drive from Hamilton. As he sees it, not many local candidates wanted to go there, but for him, as a migrant:

I can go anywhere.

Anna (Russian) is seeking a job in a small town on the outskirts of Wellington. She sees it as a place of hope.

Martinborough is quite different, because there are lots of farms and wineries, and [it is] ongoing in a good shape. It is like a different part [of the market], otherwise it would be quite [hard to get a job]. 
Similarly, Nimra (Malaysian Indian) reports that a Chinese acquaintance, when seeking an accountant position, has recently moved from Wellington to a small town. There he found work.

In finding a suitable niche, Jonah (Kenyan) introduces the concept of "sectors". He sees that migrant accountants are thriving in certain business sectors, especially the public sector. One of these is the education sector.

If you go to any university, you will find a substantial number of migrant lecturers. Academia has always been much diversified anyway, all over the world. Canada is the same, UK is the same, here [New Zealand] is the same, and Australia is the same.

Fan (Chinese) agrees with Jonah and adds another sector, the not-for-profit sector.

I was told by a local student that some employers in industry will have more discrimination than employers in academic area or not-for-profit organisations. So he suggested [I] work for not-for-profit organisations. Those organisations have a very limited budget and their pay is not that much.

Following what was suggested (as quoted), Fan then found an accounting job in a notfor-profit organisation. Jiayi (Chinese) also extends these niche sectors to include the public sector.

You'd better go to the public sector. Probably in the public sector, you will receive much [more] respect because the public sector has an EEO policy; and the private sector doesn't have to comply with that requirement. Probably there is much discrimination [in the private sector] towards ethnic minorities.

Ansh (Indian) identifies a new sector which is involved with doing a lot of trade with Asia. 
There is a free trade agreement with India; there is a free trade agreement with China, so companies [in] import and export-oriented industries, such as Zespri Kiwifruit, Sealord and Fonterra, are export-oriented. They obviously have a lot of interests in Asia, in China, so they will have businesses in China and obviously they would like to employ Asians.

Jacob (Dutch) provides a case to support Ansh.

I know somebody [who] employed a young Chinese accountant. They employed him because they were operating in China so they needed somebody who can speak to the local Chinese staff in China. They hired a fresh graduate to actually do the accounting work, and also because he could speak Chinese and could communicate with the operations in China.

He further reasons:

I think a good Chinese professional in New Zealand, with good language skills in English and Chinese, [can] therefore create a similar bridge, which is very important to try to smooth the path towards the resolution of the conflicts which will arise because of the inter-cultural misunderstandings.

Jacob's view is supported by Biscero (Tongan).

If a New Zealand company is cooperating with [a] Chinese company, hoping they will understand the cultural norms, the legal requirements, the accounting system. I see that as an asset you can provide to the employer. Maybe the language may assist in terms of interpreting the contract and arrangement and so on.

Jacob's and Biscero's views may not be accepted by others. Lubna (Pakistani), for example, says:

Bilingualism is for marketing; it is not for accountancy. 
"Sector" refers not only to categories of industry sectors, but also to the size of an organisation. Uche, Nigerian, sees his sector lies in smaller organisations:

For smaller firms, I think I have a better chance.

Following his own perception, Uche is seeking an accountant position in smaller firms. Uche's strategy is also adopted by Kiki, a Tongan who grew up in New Zealand. As she sees it:

Small businesses, like small companies, not big firms... They just seem to work for me.

Targeting smaller firms has also worked for Chris (Kiwi) who got a B average in his accounting studies. As he explains:

You have to be a bit realistic. If you got a B average, you would probably not end up with the Big 4.

Although Chris is different from Kiki and Uche in ethnicity, he is similar to them in terms of being in a disadvantageous position with reduced bargaining power (economic and cultural capital). They all have had to lower their expectations and targeted smaller business organisations or non-corporate sectors.

\subsection{3 "Knitting the web"}

The lack of local social networks, as mentioned in Chapter Five, is also perceived as a reason why ethnic minority and migrant accountants have fewer chances to access the accountant job market. To overcome this lack, some of them have chosen to build up their social networks in New Zealand.

Uche, Nigerian, facing a devaluation of his overseas accounting qualification and experience, decided to take a social path to get through. 
I want to build up my social network because I believe that jobs, even with Kiwis, are more about networking. Because in this immigrant society, I put myself in a position of my employer; I don't know you from anywhere. All I see is your CV. I will be more comfortable [if] a friend recommends you to me, even if I don't know you, I know my friend. So I trust that, because my friend is a good guy, you are likely to be a good guy. You know, things like that.

When social networks with local New Zealanders are not available, some migrants have to use the networks within their own ethnic groups. Liang (Chinese) recalls her attempt to find a job when she was about to graduate.

[During] the third year of my university, I started looking for a job. I heard someone saying that many employers first go with their friends or friends' kids, and secondly with someone who is recommended by a person they know. There is hardly any chance for someone who is not in the circle. I thought the best way for me to do [it] at that time was to know as many people as possible. Because I was a new migrant and my English was not good, I didn't have any Kiwi friends, I could only try some Chinese people, especially those who already had accounting jobs. I attended many parties, birthday parties, Chinese festival parties, new house-warming parties, and at the parties, I just asked around and was telling my need [sic].

Liang's attempt is not an isolated case. Other candidates like Druv, Jiayi, Anna, Sophia and Diya, have all attempted this strategy. Fan (Chinese) has recently found an accounting lecturer position. She believes her success came from her efforts in maintaining a close connection with a New Zealand accounting professor. The professor provided a good reference to support her when seeking this position.

To build a good relationship with local New Zealanders, some ethnic minority accountants choose to offer an exchange of artefacts from their own cultural origins. For instance, Druv brought some Indian scarves back to his Kiwi supervisor when he returned from India; Hua invited her Kiwi colleague to a Chinese restaurant specializing 
in dumplings; and Ji-eun prepared Korean Kimchi for her Kiwi manager's birthday party.

Kasim, an Iraqi, had been attending a local church for 16 years.

We found the Catholic Church in XXX and it was very helpful for us. They opened the door for us. . The church experience helped me a lot with introducing me to people. It is a social network and also a work network. You have to build social networks to find something, for people around you to know who you are, what you are capable of, what are your knowledge and your skills, and then they will start helping you to find something. This is what we have achieved through the church.

Now, I know many people and I am in the network of our people. This has not happened like that [clicking fingers], this is a result of hard work, of building the network, building the relationship with people. It was hard work, 16 years of hard work.

\subsubsection{Transforming the self}

Personality traits, in particular appearance and manners, which are viewed by potential employers as typical of ethnic minority aspirant accountants, may be thought of as not pleasing to clients. These will therefore affect employment opportunities for such aspirants. As explained in Chapter Five (ref Section 5.3.1.4), these traits are nearly always associated with a limited language proficiency and a lack of local cultural understanding. The traits are also associated with diverse cultural habitus. These applicants have to change their language, appearance, manners and cultural habitus to demonstrate the extent to which they have adapted to New Zealand norms.

Liang (Chinese) started her transformation with deciding on a new dress/appearance. She bought a few black suits. 
Don't you notice that a lot of women here dress in black? It is not that common in China. But to work in the professional arena, you have to have one or two suits in black.

Diya (Indian) recalls a rule of a company where she worked, that on Friday, one can dress casual but in a smart way. As she was unsure what the smart way was, she choose not to dress in her Indian sari, which she quite liked, but kept wearing her shirts and jeans.

I think New Zealanders take a lot of American stuff. Shirt and jeans is an American way, so nobody can find fault.

Apart from modifying dress/appearance, some focus on their own language and cultural behaviours. Biscero (Tongan) chooses to stay outside his ethnic group so that he can adapt to local cultural norms.

I go to church and sport activities. I've chosen not to go to my Pacific Island community because I know if I went there, I would feel comfortable with my people and my culture, but I won't be learning because I am not out there and changing myself.

I am trying very hard to change my cultural upbringings. For example, I try hard to keep eye contact. I try to associate a lot with New Zealanders, mix in and try to learn their slang and their types of protocol.

Ming (Chinese) takes a similar approach.

That is what I did. When I was studying at Victoria [University], when I looked for flatmates, I didn't go to the Chinese newspaper to find some Chinese flatmates. Actually I went to the Dominion Post [the local mainstream newspaper]...So I purposely looked for some Kiwi students, you know, to flat with. That was what I did, and I have made a lot of interesting Kiwi friends; even now, we are friends. We keep in contact and [have] become lifelong friends. 
When you live with some Kiwis and there is no Chinese, you will force yourself naturally to talk with them, to understand them and also you learn daily English as well, not just formal academic English, but more community English, where you start to have jokes with them, and you learn some idioms and Kiwi English.

Nishat, as a Bangladeshi Muslim woman, found dealing with attitudes to alcohol and drinking problematic.

As a Muslim woman, I don't drink alcohol, but there is a heavy drinking culture in New Zealand. I have been able to integrate with the Kiwi culture over the years [but] there are certain things I do not want to give up: that is, my Bangladesh identity. I am a Muslim. I do not want to drink alcohol, but sometimes I found it really difficult within the organisation, for those social programmes. I had a colleague who was a Kiwi girl and she was pretty much used to that drinking culture; ... I found I am not that, I am really not that. I was feeling really awkward and a bit left out as well. Sometimes I feel like I have to break that shield, and I have to change myself to that, and I feel the pressure. Sometimes I just feel that I don't want to be that person. I've found that process of becoming [Kiwi] difficult.

Javana (Malaysian Chinese) tries to reduce any possible impact arising from such enforced cross-cultural socialisation with a sense of humour.

[The] social aspect of it is a vast difference. I am not interested in rugby and cricket, you know, I am a typical Asian person. I can laugh at my own jokes, I am not that sensitive, sometimes a good laugh will break the ice, and a lot of times you should not take it personally. 
Nimra (Malaysian Indian) takes a similar stance.

I don't drink alcohol, and that is culturally something I was brought up to. But that has never stopped me from going out to the pub or somewhere to socialize, because I can still have a juice, lemonade.

Mannerism is about entertaining clients as well as fitting into the norms of the local place of employment. For this purpose, some migrant accountants go even deeper. They adjust their cultural interests and tastes to suit locals and to avoid being seen as "boring" when socialising. Qing (Chinese) keeps reading local newspapers and listening to the radio every day.

You have to be interested in other people's culture, because if you show your interest, people like to talk to you. It is not only your language, but also your knowledge about locals. When people are talking about the country, if you don't know anything, this is not really good. Just try to be open-minded and try a bit hard, read newspapers, and know the stuff around you, what is happening around the country, not only, 'How are you? How are things?'

Uche (Nigerian) does the same as what Qing does.

I think it is an attitude thing. You have to consciously tell yourself that you have to relate to all that... You can't have a job, you can't enjoy a job really if you don't try to enjoy the society.

Ming (Chinese) often goes to cinemas and shops that are run by Kiwis. He provides a pragmatic explanation.

I guess one thing we can improve on as immigrants is to get the common topic which most people are talking about. For example, for guys it might be rugby; for girls, it may be shopping or something. If you really want to join the culture, go to the street and find out some fashions or shops, just for later on when you 
are talking with people and you say, 'Oh, that is the shop I like, and that is the one I don't like'. You know, people start talking and get to know you.

It is not like the culture, you know, Asian culture, or Kiwi culture, or different beliefs and religions... that is not the real barrier. The real barrier is whether you watch the same TV as they do, or you go to the same shops as they do, or you watch the same sports programme as they do. Then you have some common topics, the culture will become a less and less barrier...because the best way they will know you is through some basic and daily kind of things.

\subsection{Summary}

This chapter has presented the strategies that are often used by ethnic minority aspirant accountants to overcome any potential discrimination. Consistent with Bourdieu's views, these are of two kinds: subversive and conservative. The subversive strategies include adopting an English surname, meeting the employer face-to-face and reducing the $\mathrm{CV}$. Conservative strategies include accepting an undesirable or sub-optimal offer, seeking a niche, 'knitting the web' and transforming the self.

Chapter Seven will present the discussion based on the findings in Chapters Five and Six. Its purpose is to better inform accounting academics, aspirant accountants and others who have an abiding interest in fairness, equity and open-mindedness in the accounting profession and among accounting employers. 
Chapter Seven: Discussion 


\subsection{Introduction}

This chapter provides further discussion related to the findings already presented and analysed in Chapters Five and Six. This discussion will focus on the manner in which Bourdieu's invocation of the field helps in further understanding the discrimination of ethnic minorities; and hence will provide an increased understanding of these issues by accounting academics, aspirant accountants and others who have an abiding interest in fairness, and equity, both within the accounting profession, and also amongst accounting employers. To achieve this the chapter describes how Bourdieu's theory of the field applies in this study, in addition to providing insights from other accounting scholars. It then describes five core topic areas, and integrates these into the theoretical analysis.

\subsection{Bourdieu's field, and insights of accounting scholars}

Bourdieu's concept of field is central to understanding how and why ethnic minority accountants are discriminated against. Field, along with capital and habitus, forms a triad at the core of Bourdieu's Theory of Practice. It cannot be considered without reference to the other two (ref: Appendix IV). In the following review, capital and habitus are invoked whenever needed in the description of field.

Bourdieu presents a field as an arena where people with different forms of capital and habitus struggle against each other. They struggle under the rules of the collective habitus, i.e., the "taken for granted" ideologies in the field. The ideologies validate the forms of capital, and determine the outcomes of their competition in the field. Examining these ideologies provides a further focus for the results of this study, and can be seen as manifested in the five topics listed below.

Bourdieu is of the view that those people whose forms of capital and habitus best fit within the field ideologies are most likely to be 'the winners'; and those without, 'the losers'. In terms of clarifying who the winners and losers are, Chapter Five (Figure 5.1 
in particular) tells part of the story, and highlights three ethnic groups who were potentially discriminated against. However, it does not clearly identify whether it is only one or two of the ethnic minority groups (Chinese and Indian) who suffer discrimination, or whether discrimination is also experienced by other ethnicities. In other words, the earlier analysis in Chapter Five did not directly address the gap, left by both James and Otsuka (2009) and Annisette and Trivedi (2013); that is, what ethnicities are explicitly discriminated against.

Within a field, capital takes three fundamental forms: economic capital, cultural capital and social capital; for these forms to be effective, they must be recognised by those people in the field, and take on a symbolic form (in their minds and mentalities). In this sense, all capital is symbolic in nature (ref: Section 3.4). The symbolic form is where the fundamental forms unite and integrate with each other, and thereby produces the mechanism to mobilise those in the field to compete effectively. The process by which the fundamental forms of capital, in particular, skills and attributes (typically, economic capital), and social and cultural backgrounds (typically socially-constructed capital), are integrated with each other in the field of an employment market, is key to a complete understanding of the challenges for new entrants to that market.

Bourdieu perceives that a profession (and its employment market) is a field which appears natural, and impartial to different groups; but in fact favours one group over another (ref: Section 3.3). Bourdieu's view is supported by the study of Richardson (1987), who claims accounting (and its associated professional environment) is both a tool and a social context where people are discriminated based on their social and cultural backgrounds. The findings of this study also supports this view.

Further, if accounting is used as a tool that favours one group over another, then it is likely that aspirant accountants who are less favoured will be unable to have their potential duly recognised by some accountant employers. This is not a new situation, as in the past women did not have their potential recognised in the accountant employment market and were thus excluded from the accounting profession (Ikin et al., 2012). It is likely, as suggested in this and other prior research, that ethnic minority accountants also suffer the same problem. 
Furthermore, Bourdieu perceives that a field consists of different aspects (or sub-fields); and most importantly, the different aspects of the field appreciate different forms of capital (ref: Appendix IV). The relationship between field aspects and capital is a dynamic one, as they co-respond to each other. Such a dynamic relationship has been used by different groups to access the accountant employment market and the accounting profession. For example, women used it to access the Australian accountant employment market during the World War II (Ikin et al, 2012). It was also used by Francophone accountants to enter the accounting profession in Quebec of Canada (Spence \& Brivot, 2011). Chapter Six identified and discussed the strategies that could be or were used to gain employment rather than to reveal the dynamic relationship of capital and field. For example, the "seeking a niche" section (ref: Section 6.3.2) explains what the strategy was and what a niche could be rather than exploring the logic by which "seeking a niche" works. An exploration of this logic would enable ethnic minority accountants to better understand the "seeking a niche" concept, so that they can create their own opportunities to use it in future.

Given the above consideration of the accounting profession field, further analysis of five topics can be undertaken. These topics are:
a) The "taken for granted" ideologies that impact on the accountant employment market;
b) The groups who may suffer discrimination on the basis of ethnicity;
c) How skills and attributes are integrated with social and cultural backgrounds;
d) The function of hegemony in the processes of discrimination; and
e) Making use of dynamics between capital and field to overcome discrimination

\subsection{The "taken for granted" ideologies that impact on the accountant employment market}

Bourdieu believed that the various forms of capital and strategies reflect the habitus in the field (Ref: Section 3.4). Forms of capital, such as oral proficiency, country of origin and cultural stereotype, that are identified by ethnic minority aspirant accountants, and 
their strategies, such as adopting an English surname, accepting a undesirable offer and 'knitting the web', suggest there are certain "taken for granted" ideologies that exist in accountant recruitment and selection processes. These ideologies are more complex, and even inter-related, than some prior explanations based on classism, racism and sexism might allow (e.g., Jacobs, 2003; Kim, 2004a, 2004b; Fearful \& Kamenou, 2006). The forms of capital identified in Chapter Five suggest that other ideologies are also present, such as economism, mannerism and favouritism.

Economism favours those aspirant accountants who can do the job, but cost less (Gammie, 1996); mannerism excludes those whose appearance and manners are thought unlikely to please clients (Anderson-Gough et al, 1998) and favouritism prefers those aspirant accountants who have close social connections with employers (Baskerville, 2006b). Those ideologies which are apparent in the Chapter Five and Six analysis may be equally important as classism, racism and sexism that are argued in the prior research, but appear to have been overlooked by accounting scholars. Alternatively, they may be embedded within the concepts of classism, racism and sexism. If so, such potential embeddedness would benefit from further research.

\subsection{Groups who may suffer discrimination on the basis of ethnicity}

James and Otsuka (2009) reported that the Chinese are racially discriminated against when entering the accounting profession in Australia. Annisette and Trivedi (2013) raised the same issue for Indians (from the sub-continent) in Canada. However, neither sought to determine whether this racial discrimination is suffered by only one or two ethnic groups, or is it suffered by others as well. The findings of this study suggest the latter. Multi-group ethnic discrimination is experienced by those seeking to join the professional accountant community in New Zealand; not only by those from Asia, but also by those from the Middle-East and Africa. More importantly, it is experienced not only by migrants but also by ethnic minorities who grew up in New Zealand. The discrimination issue is therefore a common one (across multiple ethnic groups), and needs to be addressed by the accounting profession and others openly and frankly to enable a change to occur within New Zealand society. 


\subsection{How skills and attributes may be integrated into social and cultural backgrounds}

There are generally two perspectives in the research into what determines entry into the accounting profession: the functionalist perspective and the socially-constructed perspective. The former pays more attention to accounting knowledge, skills and personality traits; and the latter, the social and cultural backgrounds. Little is known about how the two perspectives integrate with each other to exclude people from entering the accounting profession. Only Jacobs (2003) has considered this issue and he argues that "transferable skills", such as charisma, interpersonal and leadership skills, associated with an aspirant accountant's class background along with other personality traits and skills, may exclude people. However, that study lacked empirical evidence to support these propositions.

The findings of this study enhance Jacobs' argument by providing ample empirical evidence (in Chapters Five and Six) to support the potential integration of the two perspectives. Although addressing the issue from an ethnicity perspective, this study also demonstrates that those seemingly meritocratic skills, such as preferred personality traits, communication and socialisation skills, are interlinked with local cultural understandings and oral proficiency that are very dependent on an aspirant accountant's ethnic background. The need to display accounting skills, knowledge and personality traits, by aspirant accountant, has to be undertaken whilst acknowledging the advantages of their own unique social and cultural background. Further, the accounting knowledge and skills required by employers, such as having an accounting degree and accounting work experience, are prefixed with the notion of "local". Therefore there is no easy route for migrant accountants to gain the "local" if they grew up in a country outside New Zealand. 


\subsection{The function of hegemony in the processes of discrimination}

In order to further understand hegemony in the processes of discrimination, it is necessary to consider the views of Richardson (1987), in his 'Accounting as a Legitimizing Institution'. He suggested accounting is not just a technique for fulfilling certain special tasks in the functioning of society; it is also a tool used by ruling classes or elite people to exclude others from joining them and to reinforce their economic and social status. Richardson further directed that the accounting profession, in particular its recruitment process, was such an area where accounting contributes to the stratification or segregation in society.

Richardson's view is supported by this study, in that ethnic minorities find it hard to enter a profession, which historically is dominated by those of Western/Anglo-Saxon origins - the ethnic majority - in various jurisdictions. The findings also enrichen this view by suggesting that ethnic minorities have to transform themselves to conform to the norms set by, and favouring, the ethnic majority.

\subsection{Making use of dynamics between capital and field}

In Bourdieu's Theory of Practice $(1972 ; 1980 ; 1984)$, the dominant group takes conservative strategies and those who are dominated, subversive strategies. His reasoning was that the dominant group possesses the required forms of capital whilst the dominated group does not. The fact that ethnic minority accountants take both subversive and conservative strategies (Ref: Chapter Six) further confirms above suggestions that they possess some forms of capital that are required by accountant employers.

Bourdieu further pointed out that whether or not a form of capital is required depends on whether it fits with the collective habitus in the field. Because ethnic minority accountants possess some of the required forms of capital, there must be some "takenfor-granted" ideologies which favour or accommodate these forms of capital within the 
accounting profession field. As demonstrated in Chapter Six, ethnic minority accountants can and do identify their most useful forms of capital, and utilise them to distinguish themselves from others.

The usefulness of their forms of capital rests on what is required from the accountant employment market. This ever-changing market creates new opportunities for ethnic minority and migrant accountants. For example, globalisation and immigration have brought many new Chinese businesses to Auckland and other northern cities such as Hamilton and Tauranga. A Chinese migrant accountant may consider moving to these cities to seek work as accounting firms will be required to serve Chinese clients in these cities. Serving Chinese clients may be enhanced with Chinese language skills and an understanding of Chinese personality traits, and these are types of capital possessed by Chinese aspirant accountants.

In another example, the advances of information technology have changed the nature of accounting (Velayutham \& Perera, 1996): suggesting that those with double major degrees in IT and accounting may find it easier to find employment. Thus migrant accountants who had obtained their accounting degrees in their home countries could consider also studying for an IT degree in New Zealand. With such a degree, their overseas accounting degree could provide an advantage for seeking a business analyst/intelligence/systems related accountant position.

\subsection{Summary}

This chapter has outlined Bourdieu's concept of the field, and linked the results of the study to this concept and prior insights of accounting scholars, by relating them to five topics. The discussion provided will be of interest to those with an abiding interest in fairness and equity, both within the accounting profession, and also amongst accounting employers. The last chapter is Chapter Eight, which presents the conclusions of the thesis, as well as offering some recommendations to the profession. 
Chapter Eight: Conclusion 


\subsection{Introduction}

This chapter presents the conclusion for this study. It is presented in the following sections: (8.2) a general review of the study; (8.3) the answers to research questions; (8.4) contribution; (8.5) limitations; (8.6) implications for the accounting profession; (8.7) directions for further research; and (8.8) concluding statement.

\subsection{Review of the study}

This study addresses two research questions: (1) What forms of capital do ethnic minority aspirant accountants perceive they lack for successful entry into the accounting profession? and (2) What strategies have these aspirant accountants used to overcome any potential discrimination? The answer to the first question will help reveal the social and cultural factors that are in the play to discriminate people one from another when entering the accounting profession. The answer to the second question will confirm the answer found for the first question in that, if a particular factor does exist, it will mobilise people in their specific real-life strategies. Both answers will be used to fill the gap in the accounting literature relating to how people are discriminated against when entering the accounting profession based on their social and cultural backgrounds. Their ability or insight to clearly identify what they need to do is a key competency enabling them to succeed profitably in the $21^{\text {st }}$ Century world of business. Being prepared to adopt such strategies at a cost to their own identity is no small sacrifice.

In order to provide the answers, Bourdieu's Theory of Practice has been used as the theoretical framework. This is because it is seen as a suitable framework to reflect the hidden and subtle nature of discrimination and has been adopted by other researchers who study discrimination issues in accounting.

In carrying out the research, 45 aspirant accountants of 20 ethnic backgrounds or countries were used. They comprise a sample which is ethnically more diverse and inclusive than samples used in previous studies. Interviews with semi-structured 
questions are used to collect the data, which enabled the researcher to obtain more varied and in-depth data for this study than had been obtained in previous studies.

Bourdieu's epistemological approach to data analysis, that is, to map out the field first and then explain people's different positions in their capital and strategies, is followed. This approach enabled the researcher to identify the spaces occupied by different ethnic groups as they relate to each other, and to demonstrate that ethnic minority aspirant accountants are in disadvantaged positions. The researcher then examined their forms of capital, and this examination explained why they are situated where they are. According to Bourdieu, people take disadvantageous positions because they lack the forms of capital required to successfully compete in the field. The examination found eight specific characterizations of such capital. Bourdieu further notes that people will use strategies corresponding to their positions in the field and their available forms of capital to counteract an absence of other required forms of capital. Ethnic minority aspirant accountants, because they are in a disadvantageous position and lack some essential forms of capital, will use strategies to avoid potential discrimination. Following Bourdieu, the researcher examined the strategies that have been used by ethnic minority aspirant accountants to overcome intended or actual discrimination against them.

\subsection{Answers to research questions}

Mapping the field has yielded this situation: Pakeha, the ethnic majority, take the most advantageous positions; migrants from China and East Asia can be observed in the most disadvantageous positions; between them are ethnic minorities who grew up in New Zealand and those who migrated from the Indian subcontinent and South Asia.

\subsubsection{Research question one: the forms of capital}

Ethnic minority aspirant accountants are in disadvantageous positions because they lack some required forms of capital. These forms of capital are seen in the three fundamental categories defined by Bourdieu: economic capital, cultural capital and social capital. 
Economic capital includes sufficient language proficiency, local cultural understanding, local accounting work experience and the desired personality traits. Cultural capital includes having a local accounting degree, country of origin (and its associated accent and surname) and other resources derived from their cultural stereotype. Social capital consists of access to local social networks.

English proficiency (in particular oral proficiency), understanding of local New Zealand culture, accounting work experience in New Zealand and personality traits (in particular appearance and manners) are all important so as practicing accountants they may communicate and socialise well with clients and thus generate future revenue for their employers. A local (New Zealand) accounting degree combined with their country of origin identify/signify an accountant's social and cultural background. That background is perceived as an important factor affecting the opportunities for one from an ethnic minority, or migrants, to successfully enter the accounting profession. Being part of a social network with local Kiwis is perceived as an advantage as it places local aspirant accountants in advantageous positions; thus recognition of the lack of this resource by an ethnic minority aspirant accountant may lead to steps being taken to enter a local social network, which leads to the next section: strategies observed in practice.

\subsubsection{Research question two: the strategies}

To overcome potential discrimination due to the lack of the required forms of capital, ethnic minority aspirant accountants have used two kinds of strategies: subversive strategies and conservative strategies. As presented in Chapter Six, subversive strategies include adopting an English surname, meeting the employer face-to-face, and cutting down the CV. Conservative strategies include accepting an undesirable offer, seeking a niche, 'knitting the web', and transforming the self.

By using an English surname, an aspirant accountant may circumvent the 'racial filing' that potentially exists in the accountant employment market. Meeting the employer face-to-face enables an aspirant accountant to avoid potential misjudgements about his or her English proficiency, local cultural understanding and personality traits. Both strategies undermine or circumvent the racial exclusion hurdles that may be held by 
accountant employers. Cutting down the $\mathrm{CV}$ relates to removing accounting qualifications and experiences obtained overseas so that a migrant accountant will appear more junior and suitable for an entry-level accountant position.

Accepting an undesirable offer means taking an accounting job which has lower remuneration and at times is less interesting, and therefore appears as undesirable to New Zealanders. 'Seeking a niche' is to find a position which is less sensitive to linguistic and cultural differences. The niche can be a particular type of accounting role, a different locality, a different sector (such as not-for-profit), or a smaller business. 'Knitting the web' is about building up social networks with New Zealanders, important both at entry and for generating more desirable accountant employment opportunities in the future once employed. 'Transforming the self' is to make seemingly endless efforts to change one's own cultural habitus and to adapt to New Zealand culture. Accepting an undesirable offer, seeking a niche and transforming the self are similar to each other in that they are all used to accommodate or adapt to the cultural differences that potentially exclude ethnic minority accountants from achieving a professional employment position or a better position in the accountant employment market.

\subsubsection{Additional Insights}

Enlightened by Bourdieu's Theory of Practice and the prior research of accounting scholars, the researcher was able to provide five additional insights.

1) There are some "taken for granted" ideologies, such as economism, mannerism and favouritism, which might be involved in excluding aspirant accountants from the accounting profession.

2) Discrimination is suffered not only by a few ethnicities already under the spotlight of accounting researchers, such as by Chinese and Indians. Many other ethnicities are also discriminated against.

3) The accounting knowledge, skills and individual personality traits that are used to identify a most suitable accountant employee are interlinked with his or her social and cultural background and upbringing. 
4) As already determined in other accounting research, this study confirms that accounting is a tool which is used for producing and reproducing economic and cultural domination.

5) Ethnic minority aspirant accountants possess useful forms of capital and the usefulness of their capital rests on the dynamic between the capital they possess and the capital deemed desirable in the continually changing accountant job market.

\subsection{Contribution}

\subsubsection{Contribution to the accounting literature}

This study has contributed to the debate on what determines entry into the accounting profession; whether it is based on certain functional attributes or on certain social and cultural backgrounds. This study presents evidence that demonstrates that functional attributes are interlinked with the aspirant accountants' social and cultural backgrounds.

The study has also added to the ongoing debate as to whether or not accounting operates as a tool which is used by ruling classes or the elite to exclude others from joining them, and to reinforce their economic and cultural domination. The results suggest potentially that accounting is such a tool and this appears manifest in the recruitment and selection processes for those wishing to enter and later represent the accounting profession. Ethnic minorities in New Zealand still find it difficult to be accepted into a profession which historically is dominated by 'whites' of Anglo Saxon origin, the ethnic majority, and those of an ethnic minority have had to transform themselves to conform to the norms set by and favouring the ethnic majority.

The study has further shown the mechanisms by which ethnic minority aspirant accountants are potentially discriminated against and identified the strategies they have used to overcome that potential discrimination. This discrimination is based on the perceived lack of certain knowledge, as well as personality traits that are often 
determined by national or ethnic backgrounds. These ethnic minority aspirant accountants have used both subversive and conservative strategies to overcome the discrimination.

Lastly, the study has provided information which is useful for accountant employers, aspirant accountants and those who have an interest in the accounting profession as further discussed in Section 8.6.

\subsubsection{The benefits of Bourdieu}

This study will also help inform those who decide to use Bourdieu's Theory of Practice in accounting research. Bourdieu's theory is centred on habitus, the "taken for granted" ideologies. Habitus is what a profession is about, and what should be focused on by researchers. It is, however, difficult to modify even for the people who hold it, and thus is difficult for others to adopt. Some aspects of the means to resolve such a dilemma are indicated in this study: although habitus cannot be clearly identified and responded to, the forms of capital and strategies adopted - the two elements that are logically interrelated with habitus - may be perceived and responded to. This is because the forms of capital and the strategies are respectively the causes and results of habitus and therefore reflect habitus.

Bourdieu's Theory of Practice is also used in analysing the data. In this study, Bourdieu's two- step approach is followed: map out the field and then explain people's different positions in respect to their capital and the strategies adopted. This approach enabled the researcher to make explicit the different positions occupied by different groups, and further reveal the subtle factors and hidden processes that underpin their specific positions. Bourdieu's approach makes the analysis more logical and easier for the intended audience to follow. The outcome in this study from applying Bourdieu's two-step approach may further assist other researchers when using Bourdieu's Theory of Practice for their research. It has many different potential and beneficial applications in research on professions, and research on accounting behaviours. 


\subsubsection{The contribution of the validation exercise}

As mentioned in Chapter Four, at the last stage of this research, the supervisors sent the findings to the participants seeking their validation. The participants not only confirmed what had been found and what were presented in the thesis, but also provided new insights which reflect New Zealand society and the accounting profession at a deeper level. For example, a participant presented that Kiwi employers are less open-minded when hiring migrant professionals than the U. S. and Canadian employers; he attributed it to New Zealand society lacking multiculturalism. Another participant presented that NZICA, the New Zealand accounting professional body, lacks consistency when appraising overseas qualifications, with those from certain countries favoured and others less favoured; this has forced some candidates to go for CPA, an accounting professional body in Australia. More than one participant also commented that reading these findings would alter their behaviours in future, hopefully to their personal benefit.

\subsection{Limitations}

\subsubsection{Limitations in general}

As with any thesis, the limitations are many, but four in particular are described as follows.

First, this study is based on a theory. The perspectives used and the findings produced are circumscribed by Bourdieu's Theory of Practice. Were his theory not used, different perspectives and different findings might have been achieved. But this limitation is also a strength of this study, as the theory provides a coherent and unified approach.

Second, this study has used a cohort of accounting graduates from Wellington (mainly Victoria University of Wellington) in New Zealand as the participants. This means it may suffer limitations in terms of generalisability. Some part of the findings may not be replicated either in a specific accountant job market in another major city, or for a population of graduates from a different university, or those seeking to enter other professions. This limitation is not unique, and does not detract from the analysis and findings. 
Third, this study did not seek the perspectives from current accountant employers, although some participants did offer the viewpoints as they had, surprisingly, been in such roles as well as being graduates. The views of current accountant employers may be sought in future as an extension to this project.

Fourth, the study could have been expanded to consider population statistical data obtained either from the government or from the accounting professional body which might offer ethnicity-based or gender-based data on employment patterns. However, the essence of qualitative research is to provide field-based rather than statistic-based analysis.

\subsubsection{Limitations specific to the researcher}

My own personal status as a Chinese who has been in New Zealand for 15 years may well have resulted in limitations during the analysis and reflection on outcomes from the interviews. The interviews were not completely transcribed and the selection of sections for transcription would also introduce a bias.

I would like here to also share a personal reflection. The accounting profession and its associated professionalism are very salient concepts in New Zealand and other Western societies. People are sensitive about who is suitable to become an accountant and what being an accountant means in terms of their impact on the economy and on the preferred image of a professional in society. Unfortunately, the preferred image is built on certain "taken for granted" ideologies which may not help in selecting the best persons to represent the accounting profession. But how can people realise their ideologies if they are "taken for granted"? This is hard to answer. They stick to what they have and seldom mount a challenge. They do not realise that they may be victimising themselves, as much as they blame others, as they squander talents and human capital irresponsibly.

Habitus is habitus. It is an historical impetus that one cannot change overnight. While pitying what other people have lost and may be still losing, I cannot change them. I can only "shout aloud" in the hope of stirring up some new consciousness. 


\subsection{Implications}

\subsubsection{Implications for the accounting profession}

One of the findings in this study is that discrimination based on ethnicity remains an employment issue, not only for Chinese and Indians but also for other ethnicities in the accounting profession. It is an issue not only in Australia (James \& Otsuka, 2009) and Canada (Anisette \& Trivedi, 2013), but also in New Zealand. It may well be an issue that affects the accounting profession worldwide. There are no benefits for the accounting professional bodies in permitting such discrimination to continue.

Discrimination issues can be addressed by the accounting profession in such a way to target the particular factors that have been identified in this study, hopefully to thereby reduce its ongoing perpetuation. For instance, accounting professional bodies could sponsor programmes, similar to Executive Insight ${ }^{7}$, but focusing on improving migrant accountants' language proficiency and communication skills in the accounting workplace. The professional bodies could also launch an awareness campaign for accounting firms and other accountant employers to better understand ethnic minority accountants and their associated personalities. Furthermore, they can emphasize their EEO stance when accrediting training organisations, and find ways to raise awareness in these organisations about 'racial filing' or other procedures which might discriminate against ethnic minority accountants.

In addition, the accounting professional bodies could set up a division or a function focusing on handling and resolving migrant and ethnic minority issues as they arise on an ongoing basis as part of membership services. However, such issues may be infrequent because potential employees may not wish to draw attention to their plight, or being seen as a trouble-maker.

\subsubsection{Implications for aspirant accountants}

In addition to the above implications for the profession, there are implications for each graduate in New Zealand, as they seek the employment they hoped to gain when first

\footnotetext{
${ }^{7}$ Executive Insight, arranged by Chartered Accountants of Australia and New Zealand, allows undergraduate students to 'shadow' a CEO or CFO for a few days.
} 
setting out on the degree qualification. In understanding the findings of this study, they may identify their issues more clearly and may also figure out in which ways they could improve themselves in order to enhance their own employability. They can also consider how to utilise the forms of capital they can already access, to convert them, to monitor the dynamics between their forms of capital and the changing field, i.e. convert their disadvantages into advantages. There is much hope here.

\subsection{Directions for further research}

The gap in the accounting literature, as found from the literature review, rests on the explanations of how people with certain social and cultural backgrounds have been excluded from the profession. It was important to offer a study showing how knowing the exclusion strategies by employers (such as racial profiling) means these minorities may then mobilise and make manifest in their own employment strategies. Such illustrations and explanations are provided by this study, with a focus on ethnicity. An alternative focus, such as class, gender and age, could be used in new studies. These studies, again, may choose also to use Bourdieu's Theory of Practice as the foundational theory for inquiry.

As previously acknowledged, this study has not included an evaluation of perspectives from current accountant employers, large or small. A study of their employer perceptions and experiences could triangulate with what is discovered in this research - or not, as the case may be. Either way, this would be extremely useful.

The study has focused on the factors that are shared by a number of ethnicities rather than by one or two, as is undertaken in much of the accounting research reviewed in Chapter Two. These ethnic factors thus provide an unusually broad view of ethnic issues, rather than a specific view of a particular ethnicity. A narrower focus on one specific ethnicity might reveal new factors as follows: country of origin is a factor found in this study, but within the same country, China for instance, there can be wide linguistic and cultural differences between its southern and northern regions. A comparison between the two regions may reveal the issues that are more specific to people from particular regions. 


\subsection{The last word}

A review of the limitations and directions for future research reflects the open-

endedness of all research, but every project must have its last full-stop. Much more will be written about the problems a profession has in accommodating the profile of the workforce in each generation, changing and fluctuating as global movements of people and cultures occur. Much more will also be written of how people live their lives, the strategies they adopt and the rewards and challenges of a professional career for women and men of all beliefs and values. This thesis is but one contribution to this rich field of research. 


\section{References}

Anderson, M., Edwards, J., R., \& Chandler, R. A. (2005). Constructing the 'well qualified' chartered accountant in England and Wales. Accounting Historian Journal, 32(2), 5-54.

Anderson-Gough, F., Grey, C. \& Robson, K. (1998). Making up accountants: the organizational and professional socialization of trainee chartered accountants. England: Ashgate Publishing Ltd.

Annisette, M. \& Trivedi, U. V. (2013). Globalization, paradox and the (un)making of identities: immigrant chartered accountants of India in Canada. Accounting, Organizations and Society, 38(2013), 1-29.

Annisette, M. (2000). Imperialism and the professions: the education and certification of accountants in Trinidad and Tobago. Accounting, Organizations and Society, 25(7), 631-659.

Annisette, M. (2003). The colour of accountancy: examining the salience of race in a professionalisation project. Accounting, Organizations and Society, 28(7/8), 639-974.

Anon. (2012). Overcoming ageism in the accountancy world. Insight, May 2012.Retrieved April 10, 2014 from http://www.cimaglobal.com/Thoughtleadership/Newsletters/Insight-e-magazine/Insight-2012/Insight-May2012/Overcoming-ageism-in-the-accountancy-world/

Baskerville, R. (2006a). Professional closure by proxy: the impact of changing educational requirements on class mobility for a cohort of Big 8 partners. Accounting History, 11(3), 289-318.

Baskerville, R. (2006b). A very private matter: anti-nepotism rules in accounting partnerships. Oral History in New Zealand, 18 (2006), 13-17.

Baskerville, R., Wynn-Williams, K., Evans, E., \& Gillett, S. (2014). Researching ethnicity in the Pacific region. Pacific Accounting Review, 26, 302 - 323.

Biggart, N. (2002). Readings in economic sociology. Blackwell Publishers Ltd. Oxford: UK.

Birrell, B. (2007). Lack of English locks out migrant accountants. In the Black, 77(1), 14-15.

Birrell, B., \& Healy, E. (2008). Migrant accountants - high numbers, poor outcomes. People and Place, 16(4), 9-22. 
Bourdieu, P. (1972). Outline of a Theory of Practice. UK: Cambridge University Press.

Bourdieu, P. (1980). The Logic of Practice. California: Stanford University Press.

Bourdieu, P. (1984). Distinction: A Social Critique of the Judgment of Taste. Oxon, Abingdon: Routledge.

Bourdieu, P. (1990). In Other Words: Essays towards a Reflexive Sociology. California: Stanford University Press.

Bourdieu, P. (1991). Language and Symbolic Power. UK: Polity Press.

Bourdieu, P. (1993). Sociology in Question. London: Sage Publications.

Bourdieu, P. (1996). The State Nobility. UK: Polity Press.

Bourdieu, P. (1998). Practical Reason. California: Stanford University Press.

Bourdieu, P. (2001). Masculine Domination. UK: Polity Press.

Bourdieu, P. (2002). The Forms of Capital. In N. W. Biggart (ed.) Readings in Economic Sociology (pp. 280-291). UK: Blackwell Publishers Ltd.

Bourdieu, P. (2005). The Social Structures of the Economy. UK: Polity Press.

Bourdieu, P., Chamboredon, J. \& Passeron, J. (1991). The Craft of Sociology: Epistemological Preliminaries. Berlin/New York: Walter de Gruyter \& Co.

Cheng, M., Kang, H., Roebuck, P. \& Simnett, R. (2009). The employment landscape for accounting graduates and work experience relevance. Australian Accounting Review, 51(19), 342-351.

Chia, R, \& Holt, R. (2006). Strategy as practical coping: A Heideggerian perspective. Organization Studies, 27(5), 635-655.

Chia, R., \& Mackey, B. (2007). Post-processual challenges for the emerging strategyas-practice perspective: Discovering strategy in the logic of practice. Human Relations. Sage Publications, 60(1), 217-242.

Chillas, S. (2010). Degree of fit? Matching in the graduate labour market. Employee Relations, 32(2), 156-170.

Chua, W. F. \& Poullaos, C. (1998). The dynamics of "closure" amidst the construction of market profession, empire and nationhood: an historical analysis of an Australian accounting association, 1886-1903.Accounting, Organizations and Society, 23(2), 155-187. 
Ciancanelli, P., Gallhofer, S, Humphrey, C. \& Kirkham, L. (1990). Gender and accountancy: some evidence from the UK. Critical Perspective on Accounting, $1(2), 117-144$.

Collins English Dictionary - Complete \& Unabridged 10th Edition. (2009). William Collins Sons \& Co. Ltd. 1979, 1986 @ HarperCollins Publishers. Retrieved June 20, 2014 from http://dictionary.reference.com/browse/equator.

Courtis, K. J., \& Zaid, A. O. (2002). Early employment problems of Australian accounting graduates: an exploratory study. Accounting Forum, 26(3), 320339.

Creswell, J., \& Miller, D. (2000). Determining validity in qualitative inquiry. Theory into Practice, 39(3), 124-130.

Crystal, D. (1987) Cambridge Encyclopedia of Language (1987, 1997, 2010)

Dezalay, Y. (1995). "Turf battles" or "class struggles": the internationalization of the market for expertise in the "professional society". Accounting, Organizations and Society, 20(5), 331-344.

Everett, J. (2002). Organizational research and the praxeology of Pierre Bourdieu. Organizational Research Methods, 5(1), 56-80.

Evetts, J. (2003). The sociological analysis of professionalism: occupational change in the modern world. International Sociology, 18(2), 395-41.

Fearfull, A., \& Kamenou, N. (2006). How do you account for it? A critical exploration of career opportunities for and experiences of ethnic minority women. Critical Perspectives on Accounting, 17(7), 883-901.

Field, J. (2008). Social capital. (2 $2^{\text {nd }}$ Ed). New York: Routledge.

Firth, M. (1981). Racial discrimination in the British labour market. Industrial and Labor Relations Review, 34(2), 265-272.

Fowler, B. (1997). Pierre Bourdieu and cultural theory: critical investigations. UK: Cambridge University Press.

Gammie, E. (1996). Accountancy graduate selection procedures - a critical analysis. The International Journal of Career Management, 1(2), 31-38.

Gray, F. E. (2009). Making yourself heard: oral communication in the global accountancy workplace. In ANZCA09 Communication, creativity and global citizenship: Referred proceedings. Retrieved on Oct 20, 2011, from http://anzca09.org.

Gray, F. E., \& Murray, N. (2011). A distinguishing factor: oral communication skills in new accountancy graduates. Accounting Education, 20(3), 275-294. 
Grey, C. (1998). On being a professional in a Big 6 firm. Accounting, Organizations and Society, 23(5/6), 569-587.

Griller, R. (1996). The return of the subject? The methodology of Pierre Bourdieu. Critical Sociology, 22(1), 3-28.

Gringart, E. \& Helmes, E. (2001). Age discrimination in hiring practices against older adults in Western Australia: the case of accounting assistants. Australian Journal on Ageing, 20(1), 23-28.

Hall, W. \& Callery, P. (2001). Enhancing the rigor of grounded theory: incorporating reflexivity and relationality. Qualitative Health Research, 11(2), 257-272.

Hammond, T. (1997a). From complete exclusion to minimal inclusion: African Americans and the public accounting industry, 1965-1988.Accounting, Organizations \& Society, 22(1), 29-53.

Hammond, T. (1997b). Culture and gender in accounting research: going beyond Mynatt et al. Critical Perspectives on Accounting, 8(6), 685-692.

Hammond, T. (2002). A white-collar profession: African American certified public accountants since 1921.USA: The University of North Carolina Press.

Hammond, T., \& Oakes, S. L. (1992). Some feminisms and their implications for accounting practice. Accounting, Auditing \& Accountability Journal, 5(3), 5270 .

Haynes, K. (2008). (Re)figuring accounting and maternal bodies: The gendered embodiment of accounting professionals. Accounting, Organizations and Society, 33(4/5), 328-348.

Holmes, J. and Riddiford, Nicky (2009) Talk at work: interactional challenges for immigrants. In: Bhatia, Vijay K. and Cheng, Winnie and Du-Babcock, Bertha and Lung, Jane, (eds.) "Language for Professional Communication: Research, Practice and Training”. Hong Kong, China: City University of Hong Kong; et ors, pp. 217-234.

Holmes, J., \& Riddiford, N. (2010). Professional and personal identity at work: achieving a synthesis through intercultural workplace talk. Journal of Intercultural Communication, 22.

Husserl, E. (1970). The crisis of European sciences and transcendental phenomenology. Evanston: Northwestern University Press.

Ikin, C., Johns, L. \& Hayes, C. (2012). Field, capital and habitus: an oral history of women in accounting in Australia during World War II. Accounting History, 17(2), 175-192. 
Inglis, D., \& Hughson, J. (2003). Confronting culture: sociological vistas. UK: Polity Press.

Jacobs, K. (2003). Class reproduction in professional recruitment: examining the accounting profession. Critical Perspectives on Accounting, 14(5), 569-596.

James, K., \& Otsuka, S. (2009). Racial biases in recruitment by accounting firms: the case of international Chinese applicants in Australia. Critical Perspectives on Accounting, 20(4), 469-491.

Jenkins, R. (2002). Pierre Bourdieu. London: Routledge.

Kavanagh, M., \& Drennan, L. (2008). What skills and attributes does an accounting graduate need? Evidence from student perceptions and employer expectations. Accounting and Finance, 48, 279-300.

Keneley, M. \& Jackling, B. (2011). The acquisition of generic skills of culturallydiverse student cohorts. Accounting Education: An International Journal, 20(6), 605-623.

Kennedy, F., \& Sorensen, J. (2006). Enabling the management accountant to become a business partner: organizational and verbal analysis toolkit. Journal of Accounting Education, 24(2/3), 149-171.

Kim, S. N. (2004a). Imperialism without empire: silence in contemporary accounting research on race/ethnicity. Critical Perspectives on Accounting, 15(3), 95-133.

Kim, S. N. (2004b). Racialized gendering of the accountancy profession: toward an understanding of Chinese women's experiences in accountancy in New Zealand. Critical Perspectives on Accounting, 15(3), 400-427.

Lee, T. (2004). Economic class, social status, and early Scottish chattered accountants. The Accounting Historians Journal, 3(2), 27-51.

Lee, T. (2009). British Public Accountants in America: A Historical Study of Social Mobility and Fluidity with Elite Immigration. Accounting, Auditing and Accountability Journal, 22(2), 247-271.

Lehman, C. (1992). 'Herstory' in Accounting: The First Eighty Years. Accounting, Organizations and Society, 17(3/4), 261-285.

Lehman, C. (2012). We've come a long way! Maybe! Re-imagining gender and accounting. Accounting, Auditing \& Accountability Journal, 25(2), 256-294.

Loft, A. (1992). Accountancy and the gendered division of labour: a review essay. Accounting, Organizations and Society, 17(3/4), 367-378. 
Malsch, B., Gendron, Y. \& Grazzini, F. (2011). Investigating interdisciplinary translation: The influence of Pierre Bourdieu on accounting literature. Accounting, Auditing \& Accountability Journal, 24(2), 194-228.

Maltby, J. (1997). Accounting and the soul of the middle class: Gustav Freytag's soll and haben. Accounting, Organizations and Society, 22(1), 69-87.

Marshall, M. (1996). Sampling for qualitative research. Oxford University Press, 13(6), 522-525.

McLellan, E., MacQueen, M., \& Neidig, L. (2003). Beyond the qualitative interview: Data preparation and transcription. Field Methods, 15(1), 63-84.

Miranti, P. (1998). Professionalism and nativism: the competition in securing public accountancy legislation in New York during the 1890s. Special Science Quarterly, 69(2), 361-380.

Oliver, T., \& Que, A. (1996). Employer preferences for the background entry-level accountants: degree, certification, verification, internship, and experience. Journal of Education for Business, 72(2), 82-87.

Patton, M. (2002). Qualitative evaluation and research methods (3rd ed). London: Sage Publications.

Richardson, A, J. (1989). Canada's accounting elite: 1880-1930. Accounting Historians Journal, 16(1), 1-21.

Richardson, A. (1987). Accounting as a legitimating institution. Accounting, Organizations and Society, 12(4), 341-355.

Schultz, T. (1961). Human capital. The American Economic Reviews, 51(1), 1-17.

Sian, S. (2006). Reversing exclusion: the Africanisation of accountancy in Kenya, 1963-1970. Critical Perspectives on Accounting, 18(7), 831-872.

Sian, S. (2007). Patterns of prejudice: social exclusion and racial demarcation in professional accountancy in Kenya. Accounting Historians Journal, 34(2), 142.

Sidhu, J. \& West, B. (2014). The emergent Institute of Chartered Accountants of India: An upper-caste profession. Accounting History, 19(1/2), 115-132.

Spencer, C. \& Brivot, M. (2011). 'No French, no more': language-based exclusion in North America's first professional accounting association, 18791927.Accounting History Review, 21(2), 163-184.

Steinmetz, G. (2006). Bourdieu's disavowal of Lacan: psychoanalytic theory and the concepts of "habitus" and "symbolic capital". Constellations. 13(4), 445-464. 
Stiles, W. (1999). Evaluating qualitative research. Evidence Based Mental Health, 2(4), 99-101.

Stones, R. (2006). Key contemporary thinkers. London/New York: McMillan.

Sugianto, S. \& Johns, D. (2011). Breaking down the barriers for internationally educated professionals, communication is just as important as management accounting. CMA Magazine, November, 25-27.

Swartz, D. (1997). Culture \& power: the sociology of Pierre Bourdieu. London: The University of Chicago Press.

Swartz, D. (2002). The sociology of habit: the perspective of Pierre Bourdieu. The Occupational Therapy Journal of Research, 22(1), 615-695.

Tempone, I., Kavanagh, M., Segal, N., Hancock, P., Howieson, B., \& Kent, J. (2012). Accounting Research Journal, 25(1), 41-55.

The New Zealand Oxford Dictionary. (2005). Edited by Tony Deverson \& Graeme Kennedy at the New Zealand Dictionary Centre. Oxford: Oxford University.

Thomas, G. \& James, D. (2006). Reinventing grounded theory: some questions about theory, ground and discovery. British Educational Research Journal, 32(6), 767-795.

Throop, C. J., \& Murphy, M. K. (2002). Bourdieu and phenomenology: A critical assessment. Anthropological Theory, 2(2), 185-207.

Velayutham, S. \& Perera, H. (2008). The role of professional accounting programmes: towards a reflective practicum. International Journal of Management Education, 7(1), 29-40.

Velayutham, S., \& Perera, H. (1996). Recent developments in the accounting profession in New Zealand: A case of deprofessionalization? The International Journal of Accounting, 31(4), 445-462.

Wacquant, J. D. (1989). Towards a reflexive sociology: a workshop with Pierre Bourdieu. Sociological Theory, 7(1), 26-63.

Wacquant, J. D. (2006). Pierre Bourdieu. In R. Stones (ed). Key contemporary thinkers, (pp. 261-277). London and New York: MacMillan.

Weber, M. (1987 [1947]). Economy and society. Berkeley: University of California Press.

Wells, P., Gerbic, P., Kranenburg, I. \& Bygrave, J. (2009). Professional skills and capabilities of accounting graduates: The New Zealand expectation gap? Accounting Education, 18(4), 403-420. 
West, B. (1996). The professionalisation of accounting. Accounting History, 2(1), 79102.

Willmott, H. (1986). Organising the profession: a theoretical and historical examination of the development of the major accountancy bodies in the UK. Accounting, Organizations and Society, 11(6), 555-580. 


\section{Appendix I: A list of interview questions}

Q1: For this 'accountant job-seeking' research, in brief, how would you introduce yourself in terms of your ethnic background, education, employment history, and your current situation?

Q2: Why do you identify your ethnicity that way?

Q3: How do you assess your past experience in seeking an accountant job in New Zealand? (Or was it difficult?)

Q4: What were your advantages and disadvantages in seeking an accountant job?

Q5: What were the reasons for that you were employed or not employed?

Q6: How would you assess the impact of your ethnic or cultural background on the success of your seeking an accountant job?

Q7: How would you assess the impact of your language?

Q8: How would you assess the impact of your race and gender?

Q9: How would you assess the impact of your social networks?

Q10: What was it that made it difficult for you to get an accountant job?

Q11: What have you attempted to distinguish yourself from others in order to obtain an accountant job?

Q12: Why have you attempted these ways?

Q13: For this study, how do you evaluate the questions I have asked? (Or are they appropriate?)

Q14: Apart from the questions we have covered, what else do you think I should consider? 


\title{
Appendix II: A sample interview report
}

\author{
Interview report with $\mathbf{P 2 2}$
}

\author{
Interviewee's categories and detailed transcriptions
}

\author{
Advantages and disadvantages
}

\section{Work ethic (hardworking and commitment) - cultural propensity and personality traits}

"I started from an accounts' assistant, and then assistant accountant, and then management accountant, and later on did some costing analysis as well. So, it was a bit rapid progress. One thing, I guess is I worked pretty hard, and I committed to the work.

"I guess the top one is the commitment. You have to make sure your manager gives [work] to you; you are a hundred per cent committed and get the work done. That is very important: it doesn't matter what [else]. If you don't look handsome or beautiful, it doesn't matter. You have to get the work done."

Being asked how employers will know about your commitment in an interview:" I guess people can feel it. It is not something you tell other people, 'I am very committed and blah blah blah,' but how do they know? Actually, they will look at how you say things, and what is your past experience; I mean, something you did in the past. For example, for me, when I go to the uni, I don't want to fail any paper; I want to successfully complete it; I want to finish it earlier compared to other people. That is what I set my goal when I studied at uni., and I did it. So from those kinds of experience, when the employer asked you those kinds of questions, they are not asking you whether you are good or bad, they are more asking you if you set a goal, whether you are committed to it and whether you achieved it or not. So from those simple examples, they can tell whether you are committed or not."

\section{Personality traits}

"Sometimes I asked the people after I got the job, why you wanted me, and are you worried about my language or something like that because of cultural difference? They say once they have interviewed you, then they started to know you and then started to like you. Because getting somebody into the organisation is not just about, oh, you come here to do the job, but also about sharing your life with your colleagues. You know, you spend 8 hours in the office, so some people prefer your personality rather than your professional skills. Although professional skills are essential, a lot of times you get the job because you are being yourself and you have some outstanding personality.

"I think I was too shy and too scared about my English. You know, Chinese people are like that. I should tell the people who are looking for jobs, don't be scared. I know in 
the past I used to do like that. Just be yourself. A lot of time you don't get the job not because you don't have the skills or something; it is because of the manager. Different managers like to interview different people. Managers tend to select people where they have common mentality or common personality traits. A lot of times, when you see a manager, immediately, in the first few seconds, they would know whether they will like you or not. So a lot of times, don't get frustrated when you go to interview and you lost $i t$, you know you did well and you are better than some others, but try another one. Anyway, pass. If you get a job where the manager didn't like you, you wouldn't enjoy the job anyway. ... Even a lot of kiwis, they don't get a job with one or two interviews, they go to a lot. Some of them go to interviews 10 or 20 times. They don't get jobs.

"After 4 years working for Capital \& Coast, I felt like I pretty much got the inside out about all the work to do, I needed more challenge. And afterwards [after becoming a CA] I was head-hunted by a management consulting firm which is the company I am working now. I like to work a lot, because it gives me a big platform to learn new things and utilise my potentials". Even "though his former employer offered a higher salary, he still decided to go.

Being asked what sorts of organisations are likely to employ international students: "Any. Any of them. I can't say all the kiwis, they don't have discrimination. I know some people do. But most of them, they are not. They are very friendly. They take on people not by their colour or by their language, but take them on because of their skills. So if you have the skills, it doesn't matter what kind of organisations, they are happy to have you.

"Also, a lot of people here, they are looking for teamwork. You have to be able to work in a team, not just get the work done, but also be able to work together with other people get the things done, because a lot of work, especially auditing with big engagement, they need people working together, everybody works on little pieces, but you have to work together as a whole team to deliver some big project. That is very essential.

"Also, flexibility and humour; they are important. In the past, I used to be very numb and very inflexible. But now, I tend to have a little joke with other people. Enjoy the work rather than just do the work. People want to see you happy. If you do the work, you are busy and get the work done, and you look very sad, then other people will think, 'Oh, what is wrong with you?' So, you have to relax and enjoy the work and try to be happy and positive, you know, sometimes be humorous. "

\section{Transferable experiences (accounting practical know-hows) - economism and practicum}

"I think [the] sector really is not the issue. That was I experienced? It is the experience you get in the organisation, whether it is transferable to a public or private [organisation]. Because a lot of organisations, especially in New Zealand is a very small market, all the public sector is for basically government departments, and the private sector would be a few big firms like Fonterra, Telecom, Vodafone, those kinds of companies. So if you worked in the public sector, for example, accounting and you do budgeting, for a specific area, then it would be hard to move to the private sector because none of you experiences can add value to the new job you are wanting in the private field. But if you can prove to your new employer, say, 'Okay, I was in the public 
sector, but all my skills I learnt and the knowledge I got from my previous employer, all can be transferred to the new job I am going to take with you.' Then I think there would be no problem for them. So the sector effect is not the sector itself, it is really the employee who can prove he can transfer the knowledge. "

\section{Barriers in the market}

\section{Economic slowing down and tight market - out of the scope of this study}

"After I got the fourth year qualification, I found it hard to get a job, because that was around 2008, while the economy was slowing down and the credit crisis started to impact on all the job market."

\section{Culture and communication barriers - language and local cultural understanding}

"If you look at what a good accountant needs, it is not the language itself, it is the communication. They are different. So, you have good English, it doesn't mean you can communicate. I know, even some kiwi people, English is their native language, but when I talk with them, they don't know what they are talking about. . . the information they want to convey is very obscure; it is very hard to follow their logic. In terms of communication, they are trying to communicate, right? But you know, they have the English language skills, but they don't have the communication skills.

"I think, with a lot of those very good communicators, they don't use very complicated sentences, they use a very simple sentence structure and they use all the words which you can basically find from the daily life. It is very simple words and they can use those simple sentence and simple words to express themselves and they make people understand. These are the things, I think, being a foreign migrant coming into New Zealand, we should not just focus on the language itself, but focus on the way how to express yourself, like the logic between your sentences, what do you want to tell people, and use some simple words and simple sentences rather than big ones, because English is not your first language. If you use big ones, you are more likely to not just confuse yourself but also confuse the person you are talking to. . That is my take on the language.

"With the culture, I think it is more important, especially once you come to a higher level in terms of an organisation structure. You have to deal with all different kinds of people, and a lot of time you have to finish up a project within a very limited time. That means, you are on the move all the time. For example, there is a meeting going on, suddenly you have to cancel it. You have to let all the attendants know why you are leaving and also you have to make people feel comfortable for the change. That comes to that you have to communicate with people with a strategy. Also, some times, to get the project done, you have to persuade people to do things in your way. So, you have to build a good relationship, not just like a working relationship but also a personal relationship. That is where the culture comes into play.

"When you have a good understanding about kiwi culture, then it is easier for you to build a personal relationship on top of the working relationship, which will make your work a lot easier. 
"When I am talking about the culture, it is not just about how many population we have in New Zealand, or those kinds of basic things. It is more like a shared experience about past, about your value proposition. For example, when somebody said, in my childhood, what I had done, blah blah blah, and those kinds of things. If I come from China, my childhood would be totally different from their childhood. When we talk about something about that, it is very hard to join the conversation, to build a very quick and close relationship with them. ... I guess, one thing we can improve, as immigrants, they tend to get the common topic which mostly people are talking about.

For example, for guys, it might be rugby, for girls, it maybe shopping or something. if you really want to join their culture, go to the street and find out some fashions or shops, just for later on when you talking with people, and you say, 'Oh, that is the shop I like, and that is one I don't like.' You know, then people start talking and start to know you. Because the best way they will know you is through some basic and daily kinds of things",

"It is not like the culture, you know, Asian culture, or kiwi culture, or different beliefs and religions; that is not the real barrier. The main barrier is whether you watch the same TV as they do, or you go to the same shop as they do, or you watch the sports programme as they do. Then you got some common topic, then culture will become less and less a barrier. "It is the same communication reference and behaviour, rather than cultural labels that determine the people's relationship. "I think this is one of the ways where you can get close to the native. If you don't do the things like they do, you will never understand the topic they are talking about, then how can really join the team, or build a relationship?

"I guess it is natural, people are trying to get into the social groups of their own ethnicity. One thing is that they feel more comfortable. When someone comes to a foreign country, come here, they are sort of in a culture shock, a new environment, they feel lonely, they need someone to talk with them. A lot of people, when they come here, their English is very basic. It is very hard for them to communicate with natives. They want to express, they want to find some friends they need to talk to, then naturally, they would go to some people where they can communicate, which is using Chinese to communicate with Chinese people. So, naturally they come together.

"It is not like that they don't want to mingle with kiwis. They do. That is the reason they come here. They wanted to experience the community here. But, practically it is very hard for them. So, I think, sometimes, kiwis take it wrong way. They look at Chinese people: 'Hey, all of you Chinese become a group and come together and talking Bing Bing Bang Bang and you don't understand," so they think they purposely do it. But actually it is not, because if, for example, some kiwis go to China, they would do the same thing. They would say, 'Oh man, we should keep contact, you know, go for dinner together.' I am sure. It is natural, it is human nature, right?

"That is why, being a university, you have to play a role where you have to encourage immigrants and foreign students to step out of their comfort zone. You know, if they don't understand, maybe try it again, and see it differently, and then start to make kiwi friends.

"That is what I did. When I was studying at Victoria, when I looked for flatmates, I didn't go to the Chinese newspaper to find some Chinese flatmates. Actually, I went to 
the Dominion Post. . . if I want to graduate from the uni. successfully, I have to improve my English. Not just writing and reading, but also speaking as well. So I purposely looked for some kiwi students, you know, to flat with. That was what I did, and I have made a lot of interesting kiwi friends, even now, we are friends, we keep contact and become lifelong friends. When you live with some kiwis and there is no Chinese, you will force yourself naturally to talk with them, to understand them and also you learn daily English as well, not just formal academic English, but more community English, where you start to have jokes with them, and you learn some idioms and kiwi English. When you meet people, you don't ask people 'How do you do?', that is not kiwi English, it is too formal. That is what you learn from academic English, while as a kiwi, they say 'What is up?' or 'How are things?', so people feel, 'Oh, you are one of us and you are asking a question we are expecting you will ask,' so they will feel you are closer to them. So, naturally you will break the ice. "

\section{Racial filing - racism and nativism}

Comparing Chinese graduates and local kiwi graduates in terms of difficulty to find a professional job: "Certainly, it is more difficult for Chinese students to get a job compared with kiwis. Because one of the realities is that, a lot of Chinese people from their CVs, you can tell they are Chinese. And I know a lot of employers have sorted out the CVs based on the names. If it is a foreign student, they wouldn't look at their CVs at all, and they would just chuck it away. This is very, very bad, I mean, they have missed out a lot of good potential candidates. "

\section{Recruiting through social network - lack of social networks with local people}

"Another thing is like the HR people, a lot of their recruitment process is not fair, potentially. You know, in terms of selecting people with regard to the skills. There are a lot of jobs which are not advertised, more by word of mouth, or like more of networks or connections. That is where I think a lot of Chinese students are at a disadvantage because as a student, we do not have any connections; all of our parents are back in China, so that potentially you have already lost a lot of opportunities. With kiwis, especially accountants, a lot of accountancy firms are a family thing. Parents are accountants, and later on their children are more likely to be accountants, and then their grandchildren. . .

So, then they would have a big network. I know a lot of people get the job because of their network. So, that is why a lot of times when you go to interview, you say, 'Oh, I did it very good; why did they select me?' Because a lot of times, when they do the interview, it is not really for the purpose of doing, you know, selecting people as a formal procedure. Before they take the interview, they already knew who they are going to hire. There is a formality, especially in the public sector: they have to do it because that is what their HR policy said, you know, 'Before you select anybody, you have to do shortlist and have to interview 3 or 4 people,' and those kinds of things. So they do it just for the sake of doing it, not really looking and selecting the best candidates from all the applicants."

There is a sector effect in terms of a social network within the public sector. "It is a fact and surprisingly enough, that there is a social network within the public sector, it is easy for people from this department to jump to another department, within the 
government sector. "In terms of people from private sector move into the public sector: "I think, to some degree, there will be a barrier. It is more of culture thing, like in private, people are more likely to have the deadlines and every minute account, but with public sector, it is a more relaxed environment. For a lot of people, it is very hard for them to enjoy the new environment. "

\section{Prejudice or stereotyping on migrants' communication capability - economism and nativism}

"I know a lot of accounting people, after their graduation, they would like to go to big accounting firms, do PCE experience, and then they open the door for you. For those accounting firms, what is important for them? Their clients. Actually a couple of days ago, I heard a story about an accounting firm employing a Chinese student. One girl, she was very good, and she was looking for jobs. She hadn't got a job for a long time. She got her mother-in-law, who is a kind of an experienced accountant and she knows a lot of people in the street. The mother-in-law called another friend who is a partner in an accounting firm. She said, 'I have a Chinese girl. She is really good and she is looking for jobs, do you have any position?' The partner of the firm said, 'Frankly, I do have a vacant position, but we are very reluctant to have some foreign students.' The mother-in-law asked, 'Why is that?' He said, 'Because it is not we don't like them, it is our clients. When we take them, they go for an audit, they need to communicate with clients, and clients come back to me complaining they couldn't understand what your staff are talking about.' For the firm, it is huge risk, it is not just like you cannot get the work done, but you scare the client off. So that is way employers don't want to hire that student, because they are worrying their clients might be... Because you get a Chinese student, they don't understand what they are talking. So that is the communication or the language issue."

"With that issue at the time, the firm was very reluctant. But the mother said, 'You have to try her, you interview her, and you will know her English.' So, off they go. The partner said, 'Okay, for you I will make the interview.' So she went for an interview and the partner of the firm really liked her. Now, a few years later, the Chinese girl is the top accountant in the firm. Can you believe that? Every time when the partner talked about her with the mother-in-law, he said, 'Oh, thank you so much for you come to introduce someone. Now I really like her; she is my best employee that I have ever had!' So, people have their perceptions. They think migrants, they might have language issue, but once they have an interview opportunity, man, if you have the skills, if you have the competency they need, then there is no problem. It doesn't matter what firm. "

\section{What has been attempted?}

\section{Aiming out of town - somewhere local accountants may not want to go - accept an undesirable offer}

"Finally I got a job at Capital \& Coast DHBC. The reason I went there was because I wanted to get my training and everything done. At Capital \& Coast, they would be able to provide me the ATO status, and also they were happy to find me a mentor to make sure I can complete what I wanted." 


\section{Ambitious and study hard - personality traits and cultural propensity}

"Actually I did all of the papers in the length of other people, but I did summer school, and also studied more papers per semester compared with other people, so I could finish my degree, like a 4 year programme within 3 years. So, basically I got an extra time, and so I can use that time to lookfor jobs."

\section{Reasons to be employed}

\section{Personality traits (hardworking and committed) - cultural stereotype and personality traits}

"Actually, when I was studying in the university, I knew for people to get a job, it would be very hard. And also, I know NZ Immigration Services have rules about what you can do in terms of working. The work you can do was very limited, maybe 20 hours, and also once you graduate, they will give you some time. Because normally they will you an extra student visa, just in case you couldn't pass your last paper, so you can finish your degree or something. Actually, I did all of the papers in the length [of student visa] of other people, but I did summer school, and also studied more papers per semester compared with other people, so I could finish my degree, like a 4 year programme within 3 years. So, basically I got an extra time, and so I can use that time to look for jobs... My first employer was very supportive, because he really liked my personality.

"I remember one trimester, I was taking five papers while other students normally take three."

\section{Some NZ accounting experience (to be judged in terms of fitting-in than technicality) - local accounting experience and practicum}

"Before I got the full time job, I also was having a part-time job while I was studying at university. I just did some bookkeeping, GST, PAYE and those kinds of things. I had a little extra compared with some of the students when they come out of the uni. They got no experience at all. Then it would very hard for the employers to actually say, 'If I take you, whether you can join the team and be part of the team or not.' You know, for international students, language is one thing; culture in terms of fitting in the team is another. " 


\section{Appendix III: Report of Testimonial Validation}

Testimonial validity is to ensure that the themes elicited by the researcher are agreed by the participants and also to further confirm that the quotations and interpretations of their narratives that are included in the thesis are accurate. As mentioned in Section 4.7, this procedure was carried out by the supervisors independently without involvement of the researcher. They sent out the drafts from Chapter Four to Chapter Eight to all the participants who agreed to participate in the validation. The validation was carried out 15 months after the interviews had been completed, when the drafts of the five chapters were prepared. Each of the 45 participants was sent an invitation to participate in the validation and the invitation was sent to the email addresses they had given to the researcher when they were interviewed. 23 participants responded to the invitation and were then sent the drafts. They were allowed 20 days to provide their validation results. Nine of them commented on the five chapters. They are: Dominika (Russian), John (Pakeha), Tomoko (Japanese), Biscero (Tongan), Nishat (Bangladeshi), Druv (Indian), Jiayi (Chinese), Ansh (Indian), and Judy (British).

Their results were confirmative and positive in general. As mentioned in Section 4.7, there were minor changes and checks requested and these requests were attended to and resolved by the researcher. They did not affect the themes, quotations and interpretations that are contained in the thesis.

As mentioned at the beginning, this validation process was designed to confirm with the participants the themes found by the researcher and the quotations and interpretations used in the thesis. The results of this validation can be classified into three categories: (1) testimonial validity; (2) reflexive validity, and (3) catalytic validity. As defined by Stiles (1999, p. 100), testimonial validity verifies whether the themes, quotations and interpretations that are presented by the researcher are accurate and consented to by the participants; reflexive validity verifies whether the findings of the research enable the participants to have a deeper understanding of the study field and to offer new ideas that evolve from the findings; and catalytic validity verifies whether the findings reorient or reaffirm the participants' actions in their efforts to achieve their 
goals in the future. The testimonials, both positive and negative, in each of the three categories are presented as follows.

\section{A. 3.1.Testimonial validity}

There are generally two kinds of testimonials in this category: (1) those that validate the overall findings; and (2) those that validate specific quotations, themes and other interpretations included in the thesis. Below are the testimonials.

\section{A 3.1.1 Validating the overall findings}

"Can I firstly say that George ${ }^{81}$ s work was a very interesting read? I found it to be a very accurate account of what I have experienced personally and gleaned from other graduates that I have spoken to.... Finally, thank you for giving me the opportunity to make comments and I hope they provide some validity, I certainly think George's work as I read it was well-researched and accurate." (John)

"I have read the chapters and am pleased to find that my comments have been quoted and interpreted correctly. I'm not surprised that many participants interviewed share common experiences and perceptions on situations surrounding migrant accountants in the New Zealand accountant employment market." (Jiayi)

“[I] really enjoyed reading it. It's actually really good. Page 5 [this page number may have changed after the following revision], ref. to $\mathrm{xxx}$ [an original fictitious name, garbled for confidentiality] - not sufficiently anonymous - please change. " (Nishat)

\subsubsection{Validating specific quotations, themes and other interpretations}

\footnotetext{
${ }^{8}$ George is the English first name that used by the researcher to communicate with all the participants.
} 
"I would like to validate the readings and confirm the text provides relevant iteration to what was discussed with Mr. Huang during my interview session." (Druv)

"Anyway, on the paper itself I confirm that the parts on my interview are correct however probably just minor corrections. On Section 4.3, page 3 [this page number may have changed after the following revision] on the paragraph stating the sample size. This should be 19 instead of 18 because Tonga is not listed as a country in the sample [It was not missed in Table 4-1 but missed in a sentence and it is now corrected]. " (Biscero)

"I confirm that the paragraphs where I was mentioned are quite accurate. Also, I have recognised one of my friends in the draft and I think George has done a great job expressing her opinion. Reading those paragraphs (where my friend was mentioned) was like reading what my friend has written herself. It was well done. "(Dominika)

"Now that I am employed, I can agree with some foreign accountants' opinion such as Jing's comment when she picks up the phone. I have no problem communicating with people face-to-face but I realise my limited English vocabulary in the professional environment. I have a request for you and George. In order to protect my privacy, would you mind eliminating $\mathrm{xxx}$ [a small town's name, garbled for privacy; it is changed to 'Hastings' now] on page 38? [This page number may have changed after the following revision] In xxx [the town's name], there are no other Japanese other than myself who study accounting (as I know most Japanese in this town). It is a small community and many people know each other here. " (Tomoko)

"I would support George's findings and want to mention that a number of the strategies others employed I also used to try and find work especially 'accepting economic exploitation' [It is changed to 'accepting an undesirable offer' now] and 'transforming the self'. I would like to say that as an older job seeker I was 
unable to secure any paid accounting work and have been forced to modify my expectations and adopt a niche strategy (self-employment). ” (John)

"His research has helped me to not feel so isolated in what has happened to me in regard to work. After reading through I felt a shared experience and increased insight into why I have struggled to find employment in the accounting field. " (John)

"I am not happy with this pseudo-name. It is too close to my real name [It is changed to another fictitious name now]... I don't recall saying this [a quotation to support cultural stereotype in Section 5.6. [It is found to have said by another participant and now is corrected]. "(Judy)

"The research findings are consistent with my perception, such as that "the language is a very important factor that distinguishes" candidates, as well as cultural familiarity, local experience (including work, study and qualification), and character/personality." (Jiayi)

\section{A.3.2. Reflexive validity}

There are generally two kinds of reflexive testimonials in this category: (1) those that provide deeper understanding about New Zealand society and the accountant employment market; and (2) those that provide additional thoughts about the New Zealand accounting profession. Below are the testimonials.

\section{A.3.2.1 Deeper understanding about New Zealand society and accountant employment market}

"From my work experience in New Zealand and North America, and with employers from New Zealand, Europe, and North America, I found that North American employers tend to be more open in employing accountants from nonAnglo-Saxon background than European and Kiwi employers. I perceive this may 
be co-related with the fact that North American societies (particularly the US and Canada) have [a] longer history and [a] larger extent of exposure to multicultural[ism]. With New Zealand accepting more immigrants and becoming more culturally diversified, Kiwi employers and their clients should be more open to migrant accountants. I am sure George's research will contribute to this evolving." (Jiayi)

"5.2 Language - On pg. 26 [This page number may have changed after the following revision] xxx [an original fictitious name, garbled for privacy; it is now changed to another fictitious name], a Russian immigrant's observation about local dialects is an important one and for me there is another aspect to the use of English in NZ i.e. Colloquial expressions. It plays an important role in both written and oral communication at times to an extent where grammar and convention is compromised or ignored. For persons from countries where English is widely spoken or a common medium of instruction, NZ colloquialism in day-to-day communication is at times a barrier in communication and this may affect ESL people even more.

5.4 Local Accounting Experience - on pg. 30 [This page number may have changed after the following revision] last paragraphs on Abdullah's assertion about stereotyping Asians as less ethical is valid. Kiwi employers insist on local references and experience from Asians but the same requirement at times may tend to be overlooked for applicants from UK or North America (this ties in well to the "big brother" syndrome). Recent events involving dismissals of bosses in large public sector enterprises - two from UK and one from Canada - surprisingly revealed that reference checks were not completed reaffirm this fact. Within the accounting sector, a large employer within public sector is well known for advertising for UK and South African applicants to apply for auditing roles in NZ. This once again raises question marks on the very intent behind reference checks." (Ansh)

'I would also like to suggest that George's work provides a clue as to why the 'mode' hiring preference of many employers cheapens the value of diversity; as it describes 
a systemic modal thinking in respect of language, racism and age which may go some way to explain our economy's consistently poor productivity and inability to innovate." (John)

\section{A.3.2.2 Additional thoughts about the New Zealand accounting profession}

"In the recent past, the job market is tough, and it is even harder for the immigrants even after relevant qualifications and working experience in industry. Further dismay is with un-explained process of recognizing their overseas qualifications especially in policy moving environment where NZICA is shaking hands cross Tasman. Recent development shows that many candidates are disadvantaged, where even after completing all required papers, candidates are forced to complete degrees in local universities before they can attain membership status with NZICA and work towards their professional qualifications. " (Druv)

"5.5 Country of Origin (pp 30-32) [These page numbers may have changed after the following revision] In my opinion this variable may have implications for how overseas qualifications are assessed at NZICA towards recognition for eligibility of membership of the Institute which in turn disadvantages them in the job market. From my time at two NZ polytechnics I have witnessed a lack of consistency when NZICA evaluates overseas qualification. One may perceive this as bias based on national origin especially when two candidates with similar qualifications (vetted as equivalent to NZ qualifications by New Zealand Qualifications Authority) but from different countries may not receive similar assessment. For example an individual with a Master of Commerce from India may be asked to complete 11 papers towards gaining provisional membership of the CA College while another from South Africa may end up having to do just two papers. My own experience tells me that overseas graduates must be prepared to stand up and challenge the assessment. In recent times I have witnessed the ones that are disgruntled choose to take membership of CPA (Australia) which offers less onerous entry requirements." (Ansh) 


\section{A. 3.3.Catalytic validity}

Catalytic validity, as mentioned before, refers to testimonials that possibly reorient or reaffirm the participants' actions in their efforts to achieve their goals in the future. Below are the testimonials related to catalytic validity.

"I love my new job and want to be good at it so I am aware that I have to improve my English for that.” (Tomoko)

"Some parts of the work made me laugh; other parts made me think. I enjoyed reading the comments from other people. I don't think that I am likely to change my behaviour in the future but I might be wrong on this one. " (Dominika)

"In my own endeavours at job hunting I have made a conscious attempt to understand what commonly- used colloquial expressions stand for and on the application front the thumb rule has been - keep it simple!" (Ansh)

"I am beginning to doubt the value of the MPA degree as some of the job rejection feedback state that I am over-qualified for entry level accounting work and at the same time under-qualified for work that requires experience." And: "However, if I had access to the views described in George's paper before taking up the MPA degree I probably would have had second thoughts on accountancy." (Biscero)

"In this context [the chapters for validation], I note and value the section where George describes some of the techniques and strategies his sample group have used to be successful in getting an accounting job. Fingers crossed, it will work for me as I try to change my behaviour to be more employable in the NZ accounting job market. " (Biscero) 
Appendix IV: The epistemology of Pierre Bourdieu 


\section{A.4.1 Introduction}

Pierre Bourdieu, although no longer alive, is increasingly seen as a leading thinker of our time (Malsch et al. 2011; Throop \& Murphy, 2002). His theories, in particular the theory of practice, have influenced social scientists in many countries since he first wrote it in his native France. While the theory of practice is applied widely, understanding it with a focus on informing a social study is a challenge. Towards this understanding there have been many attempts from different philosophical and epistemological perspectives, but these attempts are not sufficiently reconciled with each other. For example, while Throop and Murphy (2002) considered that Bourdieu's epistemological stance is against Husserl's phenomenology, Chia and Holt (2006) have a different view. They suggested that Bourdieu's ethnology is close to Heidegger's "dwelling", which is another version of phenomenology. This situation is less than satisfactory because it may encourage an unfair evaluation of Bourdieu and may lead to an inappropriate or undesirable application of his theory (Griller, 1996; Malsch, Gendron \& Grazzini, 2011). Malsch et al. (2011), as mentioned in Chapter Two, in their examination of accounting literature over the ten year period from 1999 to 2008, found that there are generally two problems with accounting scholars using Bourdieu's Theory of Practice. One is that most of them use it in a piecemeal way; the other is that insufficient attention is paid to habitus, the central concept of the theory. The aim of this chapter is to present an examination of Bourdieu's practical theory, with a focus on his epistemology, in order to inform this study and other professionalisation studies in accounting.

For this examination, 11 books and a book chapter written by Bourdieu, and ten books written by others about Bourdieu, are examined. These are listed in the table below. 


\begin{tabular}{|c|c|c|c|}
\hline Book & Author & Year & Publisher \\
\hline Outline of a Theory of Practice & Bourdieu & 1972 & $\begin{array}{l}\text { Cambridge } \\
\text { University Press }\end{array}$ \\
\hline The Logic of Practice & Bourdieu & 1980 & $\begin{array}{l}\text { Stanford } \\
\text { University Press }\end{array}$ \\
\hline Distinction & Bourdieu & 1984 & $\begin{array}{l}\text { Harvard } \\
\text { University Press }\end{array}$ \\
\hline In Other Words: Towards a Reflexive Sociology & Bourdieu & 1990 & $\begin{array}{l}\text { Stanford } \\
\text { University Press }\end{array}$ \\
\hline The Craft of Sociology & $\begin{array}{l}\text { Bourdieu, } \\
\text { Chamboredon \& } \\
\text { Passeron }\end{array}$ & 1991 & $\begin{array}{l}\text { Walter de } \\
\text { Gruyter \& Co. }\end{array}$ \\
\hline Language \& Symbolic Power & Bourdieu & 1991 & Polity Press \\
\hline Sociology in question & Bourdieu & 1993 & $\begin{array}{l}\text { SAGE } \\
\text { Publications }\end{array}$ \\
\hline The State Nobility & Bourdieu & 1996 & Polity Press \\
\hline Practical Reason & Bourdieu & 1998 & $\begin{array}{l}\text { Stanford } \\
\text { University Press }\end{array}$ \\
\hline Masculine Domination & Bourdieu & 2001 & Polity Press \\
\hline $\begin{array}{l}\text { The Forms of Capital, a chapter of Reading in } \\
\text { Economic Sociology }\end{array}$ & Bourdieu, in Biggart & 2002 & $\begin{array}{l}\text { Blackwell } \\
\text { Publishers }\end{array}$ \\
\hline The Social Structures of the Economy & Bourdieu & 2005 & Polity Press \\
\hline Culture \& Power: the Sociology of Pierre Bourdieu & Swartz & 1997 & $\begin{array}{l}\text { University of } \\
\text { Chicago Press }\end{array}$ \\
\hline $\begin{array}{l}\text { Pierre Bourdieu and Cultural Theory: Critical } \\
\text { Investigation }\end{array}$ & Fowler & 1997 & $\begin{array}{l}\text { SAGE } \\
\text { Publications }\end{array}$ \\
\hline Pierre Bourdieu & Jenkins & 2002 & Routledge \\
\hline $\begin{array}{l}\text { Confronting Culture: Sociological Vistas - in the } \\
\text { French Style: the Sociology of Pierre Bourdieu }\end{array}$ & Inglis and Hughson & 2003 & Polity Press \\
\hline Pierre Bourdieu & Wacquant, in Stones & 2006 & Macmillan \\
\hline Social Capital & Field & 2008 & Routledge \\
\hline
\end{tabular}

Table A4.1 Books examined for analysing Pierre Bourdieu's epistemology

A further 14 articles either review Bourdieu's epistemology or have a substantial part that discusses it, as further reviewed in the following discussion. 
Bourdieu takes many ideas from Weber (Swartz, 1997); therefore for this discussion, Weber's (1987 [1947]) book Economy and Society is also referred to. The discussion is presented as follows: (3.2) an introduction to Pierre Bourdieu; (3.3) Bourdieu's world view for social research; (3.4) how Bourdieu's social world is created; (3.5) the logic of practice; (3.6) operationalizing social research using Bourdieu's Theory of Practice; (3.7) concluding a social research project; (3.8) applications of Bourdieu's practical theory in accounting professionalisation studies; and (3.9) Summary.

\section{A.4.1.2 Bourdieu as a leading figure}

Pierre Bourdieu (1933-2002), was one of the leading thinkers in the world, a thinker who may enjoy the same status as such giants in social science as Durkheim, Marx and Weber (Wacquant, in Stones, 2006). His theories, in particular the theory of practice (or practical theory), have influenced a large number of social scientists from different academic domains.

His publications are numerous and hard to tally exactly (Swartz, 1997). Those who published his works are among the world's most distinguished publishing houses, such as Harvard University Press, Cambridge University Press and Polity Press.

Bourdieu spent his life endeavouring to overcome the contradictions between binary structures such as objectivism versus subjectivism, ontology versus epistemology and ethnography versus phenomenology. He introduced habitus (and associated concepts such as capital, field, doxa and practice) as a hybrid construct of objectivity and subjectivity, both for understanding the social world and for theorising social research about this world. Habitus makes Bourdieu's theory unique and is the key to appreciating his position and status (Swartz, 1997; Jenkins, 2002; Wacquant, in Stones, 2006).

Bourdieu's academic span is a wide one: philosophy, sociology, anthropology, education, language, economy, politics, sport and art, to name a few. Such a span has also received its share of criticism. The main focus of such criticism is towards Bourdieu's structuralism where his practical theory is seen to overemphasize the "ironclad" structures while overlooking the social actors' self-agency (Jenkins, 2002; Throop 
\& Murphy, 2002). In epistemology, he is accused of being too much a positivist, in the sense of treating humans as "things" (Griller, 1996). In his Outline of a Theory of Practice (Bourdieu, 1972) and Social Space and Symbolic Power (Bourdieu, 1990), however, Bourdieu distances himself from Durkheim, Saussure and other positivists by highlighting his subjective and interpretive stance.

Bourdieu was a modest person, saying that he was afraid of his own theory because it often turned out to be a weapon against him, and offering his theory as a temporal construct, not something “monumental” (Jenkins, 2002).

\section{A.4.1.3.Bourdieu's world view for social research}

Bourdieu's epistemology, like those of Durkheim, Marx and Weber, is integrated with his world view. One cannot study his epistemology without studying his world view. Bourdieu believed the social world is objective, but only to the degree that social scientists can imagine it.

The degree to which the social world seems to us to be determined depends on the knowledge we have of it. (Bourdieu, 1993, p. 25)

So, it is in effect a subjective world or a world of subjectivity. This world is constructed by social scientists using their theories or presumptions (Bourdieu, 1990; Bourdieu et al., 1991). As a result,

The social world may be described and constructed in different ways in accordance with different principles of vision and division. (ibid, p. 132)

Because this world is constructed by theories, if there are problems, the problems are in the theories. This is because:

Facts do not speak...Those who choose to restrict their means of interrogating the real (and of interrogating their methods for doing so) to elements that are in fact created by an interrogation that refuses to admit it is an interrogation, and who thereby deny that observation presupposes construction, inevitably end up 
observing a void that they have unwittingly constructed. (Bourdieu et al., 1991, p. 37)

Bourdieu's social world and its associated problems, as mentioned above, are subjective in nature. For studying the relations in this world, one needs to understand two important concepts: the symbolic and the relational.

\section{A.4.1.4.Social classes are symbolic and relational}

In Bourdieu's view, social classes are real; not in the sense of "substances" but in "relations" (Bourdieu, 1998, pp. 1-18). He is not confined by Marx's concept that social classes are real and they are real in physical existence.

As he sees it:

The 'real' class, if it has ever 'really' existed, is nothing but the realized class; that is, the mobilized class, a result of the struggles of classifications, which is a properly symbolic (and the political) struggle to impose a vision of the social world, or, better, a way to construct that world, in perception and in reality, and to construct classes in accordance with which this social world can be divided. (ibid, p. 11)

So, classes are a product of ideation; in other words, it is a matter of point of view. But, “[T]he point of view," he stressed, "creates the object” (Bourdieu et al., 1991, p. 33). Although the classes are subjectively created, once they are created their relations with each other become observably objective. That is why Bourdieu (1990, p. 126) saw that sociology has the sense of objectivity:

Sociology, in its objectivist moment, is....an analysis of relative positions and objective relations between these positions. (ibid, p. 126)

But it is a sense, not an essence. The essence of sociology is still the "sociology of symbolic forms" (Bourdieu, 1991, p. 164), and different symbolic forms will be 
translated into different "social forms" in society:

The objectivity of the meaning or sense of the world is defined by the consent or agreement of the structuring subjectivities (sensus = consensus). (ibid, p. 164)

And the consensus is doxa (ibid, p. 165), the doxic or "legitimate" ideologies. Doxa is a very important concept because it is the source of symbolic power for validating objective dominations and inequalities in society (Bourdieu, 1972, pp. 159-197). Social orders are thus created, settled and stabilized.

\section{A.4.1.5 How Bourdieu's social world is created}

Bourdieu believed that the social world is created by social scientists' theories. Among the theories, the theory of practice is the one which Bourdieu often used to create his social world. This theory is used as a metaphor to inform the epistemology for studying a new social field.

\section{A.4.1.6 The social fact is won, constructed and confirmed by social scientists' theories}

Because the social world is relational and symbolic in nature, it becomes a field of struggles ${ }^{9}$ between different ideologies. In social research, one might say there is a struggle between social scientists' theories or "theoretical taxonomies" (Bourdieu, 1980, p. 93) and social actors' "primitive logics" (Bourdieu, 1993, p. 17) or "practical taxonomies" (Bourdieu, 1980, p. 93). The latter, although "primitive" and "practical", which may favour positivist and empiricist stances, tend to see the world based on appearances and are unlikely to reveal the doxa which, in contrast, is something deep and "tacit" (Jenkins, 2002, p. 92). As Bourdieu argued, doxa is an

\footnotetext{
${ }^{9}$ Field is one of key concepts in Bourdieu's practical theory (Bourdieu, 1972, 1980, 1984, 1991). In this theory, Bourdieu treats a field as an autonomous social space which is full of struggles between social actors with different forms of capital. Their struggles are for symbolisms and recognitions that are ideological.
} 
...invisible power which can be exercised only with the complicity of those who do not want to know that they are subject to it or even they themselves exercise it. (Bourdieu, 1991, p. 164)

Therefore it is unlikely to be reflected by social actors unless it is purposely addressed. Besides, the social actors" "primitive logics" tend to make them see the "truth" partially:

Agents have a subjective experience that is not the full truth of what they do but which is part of the truth of what they do. (Bourdieu, 1993, P. 17)

To reveal doxa, Bourdieu suggested an analysis in two levels or orders (ibid, p. 58). The first order analysis is similar to Husserl's phenomenological analysis of the appearances, reflecting the "spontaneous sociology" (Bourdieu et al., 1991, p. 20) constructed by social actors (Bourdieu, 1972, 1980). The second order analysis prioritizes the use of a social scientist's theory, to "break" social actors" "primitive logics" or "practical taxonomies" and to reconstruct the new analogies and relations underneath the appearances.

The theoretical model is simultaneously a construction and a break, since one needs to have broken free from the phenomenal resemblances in order to construct the deep analogies, and this break with apparent relations presupposes the construction of new relations among the appearances. (Bourdieu et al., 1991, p. 54)

Thus the theoretical model is characterized by its capacity for breaking with appearances and its capacity for generalization, these two qualities being inseparable. (Bourdieu, 1991, pp. 54-56)

Further, the reconstructed analogies and relations need to be confirmed by "applied rationalism" (ibid, p. 57), a procedure of confirmation that they are not only true to the empirical data that social actors have presented, but are also explained in the theory which the social scientist has used for breaking the social actors" "practical taxonomies" and "primitive logics". This is because, 
Experimentation is only as good as the construct that it tests...the facts that validate the theory are only as good as the theory they validate. (ibid, pp. 58-60)

Therefore,

If it is true that in their most complete form, scientific propositions are won against the phenomenal appearances and that they presuppose the theoretical act which has the function, as Kant puts it, of 'spelling out the phenomena so as to be able to read them as experiments', then it follows that they no longer find their proof anywhere except in the full coherence of the whole system of facts created by - and not for - the theoretical hypotheses that are to be validated. (Bourdieu et al., 1991, p. 64)

\section{A.4.2 The theory of practice introduced}

A theoretical platform, as discussed above, is very important for social research. This makes us ask: What is the theory that Bourdieu used to "break" and "construct" the social world? There could be several, but the theory of practice is perceived as the most central one (Griller, 1996; Swartz, 1997). This theory claims its centrality because of habitus, its very "core" concept, which shaped Bourdieu's world view as well as his epistemology in his social research. The reasons for calling it a "core" concept are:

(1) habitus lays the foundation for studying all the other concepts which Bourdieu proposed, such as capital, field, doxa and practice;

(2) in Bourdieu's view, habitus, as "structured and structuring dispositions" (Bourdieu, 1980, p. 53) is the source generating social structures and social actors; and

(3) habitus integrates "the things of logic" and "the logic of things" (ibid, p. 49); both are important for a social study, but neither is enough on its own.

In Outline of a Theory of Practice, Bourdieu (1972) explained why he thought habitus is so important for social research. He was not satisfied with Durkheim's objectivism 
which may lead to "mechanism" (ibid, p. 72), treating social actors as a part of a machine, and equally, he disagreed with Sartre's subjectivism which may lead to "finalism" (ibid, p. 72), treating a social actor as a "rational actor" (1980, p. 46) who journeys to his ideal end. In Bourdieu's view, there are "objective limits of objectivism" (Bourdieu, 1972, p. 2) and on the other hand, there are problems such as "omission" (Bourdieu, 1980, p. 49) and "bad faith" (ibid, p. 50) associated with subjectivism. As he stated:

Both are unaware that practice can have other principles than mechanical causes or conscious ends and can obey an economic logic without obeying narrowly economic interests. (ibid, p. 50)

To Bourdieu, habitus was,

...systems of durable, transposable dispositions, structured structures predisposed to function as structuring structures, that is, as principles which generate and organize practices and representations that can be objectively adapted to their outcomes without presupposing a conscious aiming at ends.... Objectively 'regulated' and 'regular' without being in any way the product of obedience to rules, they can be collectively orchestrated without being the product of the organizing action of a conductor. (ibid, 53)

Bourdieu further pointed out that as time goes by, habitus is taken for granted and people tend not to question it.

It is the habitus, history turned into nature. (Bourdieu, 1972, p. 78)

Therefore, in an objectivist sense, it is habitus that deserves study. But, in studying habitus, one has to return to social actors' practice:

One has to situate oneself within 'real activity' as such, that is, in the practical relation to the world...its things to be done and said, things made to be said. ... To do this, one has to return to practice, the site of the dialectic of the opus 
operatum [efficacy for an action] and the modus operandi [way of an action]. (Bourdieu, 1980, p. 52)

It is this view, the ontological view of habitus and practice for both the social world and social research that set Bourdieu apart from the other leading thinkers, in particular Durkheim, Marx, Weber, Sartre, Husserl, Goffman and Schutz (Griller, 1996; Throop \& Murphy, 2002; Wacquant, in Stones, 2006).

Threaded throughout Bourdieu's and his co-authored books (Bourdieu, 1972, 1980, 1984, 1991, 1993, 1996, 1998, 2001, 2005; Bourdieu et al., 1991), addressing areas from epistemology to sport, from science to art, from economy to politics, are seen his logic of practice and its component concepts such as habitus, capital, field and doxa. The logic and concepts are applied in different arguments and in different analyses.

\section{A.4.3 "Applied in an analogical way"}

The logic of practice is a universal theory which is applicable to all social fields (Bourdieu, 1980). The social world is an expansive field under which there are many sub-fields. Fields are "homological" (Bourdieu, 1972, p. 143) with each other; they all have invariant properties,

Among these invariant properties is the very fact that they are the site of a struggle of interests, between agents or institutions unequally endowed in specific capital (as specific resources or specific weapons for the conquest or domination over the field), or the fact that these struggles presuppose a consensus on what is at stake in the struggle, etc. (Bourdieu, 1990, p. 111)

Each field is different and "autonomous" (Bourdieu, 1993, p. 72) but it has its own "stakes" and specific rules (in particular the hidden rules). Because of specific rules, different classes are allocated with different resources and opportunities, therefore:

[T] here is a dominant pole and a dominated pole, and from that moment there are antagonistic truths. (ibid, p. 59) 
While specificity of a field suggests that the field is always a valuable focus of a study, the homological property enables such a study to be undertaken in an analogical way; that is, by applying the invariant logic from a known field to an unknown field.

What is the invariant logic? It is Bourdieu's logic of practice. This logic, as a "metatheory" (Griller, 1996, p. 16), is applied to a specific field at some lower level, and it helps to establish the theory for that field and at that level:

Bourdieu's research is not about testing this theory, but rather is about deductive testing of 'lower level' theories through hypothesis testing - the 'hypothesis that there is an almost perfect homology between the space of the stances... and the space of the positions held by their authors in the field of production. (ibid, $p$. 16)

To Bourdieu, it was the analogy or the way of analogical application that enables discoveries of a new field:

... analogical models aimed at apprehending the hidden principles of the realities they interpret...analogical reason can fulfil its function as an instrument of discovery. (Bourdieu et al., 1991, p. 53)

\section{A.4.4 The logic of practice}

Bourdieu's logic of practice underpins his practical theory (Bourdieu, 1972, 1980, 1998). This logic has universal dimensions which can be used to explore any field in society and is constituted by four key concepts: capital, habitus, field and practice. Each of these concepts is further discussed as follows.

\section{A. 4.4.1 Capital}

In The Forms of Capital, Bourdieu (in Biggart, 2002, pp. 280-291) acknowledged that he took the concept of capital from Marx's economic theory, one which means useful 
resources that can be used by social actors to distinguish and compete with each other. In the social space, capital does not only include economic capital, cultural capital and social capital, the three fundamental forms, but also symbolic capital which is an ideological form corresponding to the three fundamental forms.

According to my empirical investigations, these fundamental powers are economic capital (in its different forms), cultural capital, social capital and symbolic capital, which is the form that the various species of capital assume when they are perceived and recognized as legitimate. (Bourdieu, 1990, p. 128)

Capital needs a strong practical sense in order to function. It has to be "misrecognised" and taken for granted by social actors:

A capital (or power) becomes symbolic capital, that is, capital endowed with a specifically symbolic efficacy, only when it is misrecognised in its arbitrary truth as capital and recognised as legitimate and, on the other hand, that this act of (false) knowledge and recognition is an act of practical knowledge which in no way implies that the object known and recognized be posited as object. (ibid, p. 112)

Different forms of capital are efficacious in different aspects of field. Economic capital, as in Marx's theory, controls relations in production. It is the resource that distinguishes the bourgeois from the proletariat and the capitalist class from the working class. In the professional field, economic capital is translated into "human capital" (Schultz, 1961), or the power of "intelligentsia" (Weber, 1978, p. 218), which relates to skills and knowledge that can be used by professionals to make money and to claim an expertise privilege.

Economic capital is generally well understood but on the other hand, cultural capital needs explanation. It has three sub-forms: objectified, as in paintings, novels and music; institutionalised, as with educational qualifications and athletic awards; and habitus, the internalised dispositions that are carried by social actors. Unlike economic capital, which controls people's relations with production, cultural capital controls their 
relations with consumption. The efficacy of cultural capital was thus described by Bourdieu.

Those people who drink champagne are opposed to those who drink whisky, but they are also opposed, in a different way, to those who drink red wines; but those who drink champagne are more likely than those who drink whisky, and far more likely than those who drink red wine, to have antique furniture, play golf, ride horses or go to see light comedies at the theatre. (Bourdieu, 1990, p. 132)

Bourdieu's perception links to Weber's (1978 [1947]) claim in Economy and Society, that tastes and lifestyles do distinguish people in the social field.

Social capital has a final say in the social arena. Visible in the cliché "It doesn't matter what you know but who you know" (Field, 2008, p. 3), it downplays the role of economic capital but highlights the importance of social connections. Social connections are used not only for social exclusions but also and most importantly, they pave the way for cultural capital such as qualifications, professional experiences and expertise to be recognised and thus converted to economic capital (Bourdieu, in Biggart, 2002, pp. 286-288).

Whatever the form of capital, it works in the field both as means and ends for social actors (Bourdieu, 1980; Throop \& Murphy, 2002), and eventually capital is reduced to “accumulated labour” (Bourdieu, in Biggart, 2002, p. 280).

\section{A. 4.4.2 Habitus}

Habitus is an actor's schema, which correspond to his position in social space. It is a relatively stable schema, a "historical sediment" (Bourdieu, 1980, p. 58) of social structures in the actor's mind. The schema generates and re-generates the ways or patterns of the social actor's practices (Husserl, 1970). As described by Bourdieu (1972), habitus is:

[T]he strategy-generating principle enabling agents to cope with unforeseen and 
ever-changing situations... a system of lasting, transposable dispositions which, integrating past experiences, functions at every moment as a matrix of perceptions, appreciations, and actions and makes possible the achievement of infinitely diversified tasks, thanks to analogical transfers of schemes permitting the solution of similarly shaped problems, and thanks to the unceasing corrections of the results obtained, dialectically produced by those results. (ibid, pp. 82-83)

Habitus can be both conscious and unconscious to the actor who possesses it. In describing the unconscious part, Bourdieu (1990) said:

The habitus entertains with the social world which has produced it a real ontological complicity, the source of cognition without consciousness, intentionality without intention, a practical mastery of the world's regularities which allows one to anticipate the future without even needing to posit it as such. (ibid, p. 11)

Conscious or not, it is a factor which determines the actor's practical strategy, but is not a factor of his or her intentionality. This is a point where Bourdieu departed from Goffman, Schutz and others who emphasized an actor's intention and self-motivation (Bourdieu, 1990). As he perceived:

The habitus, a system of dispositions acquired by implicit or explicit learning which functions as a system of generative schemes, generate strategies which can be objectively consistent with the objective interests of their authors without having been expressly designed to that end. (Bourdieu, 1993, p. 76)

The concept of habitus applies not only to each individual actor, but also to a group, an organisation or a society ${ }^{10}$. Society can be "in the individual as the habitus" (Everett, 2002, p. 65). It is the site of collective habitus which is shared by its members, because

\footnotetext{
${ }^{10}$ A society in Bourdieu's $(1972,1980)$ perception refers to a collective entity which is composed of both dominant and dominated groups in a field. It is the dominant group's doxa or doxic ideologies that engage both groups in the field.
} 
The field, as a structured space, tends to structure the habitus, while the habitus tends to structure the perceptions of the field. (Bourdieu, in Everett, 2002, p. 65)

Collective habitus was conceived by Bourdieu as doxa (Bourdieu, 1972, p. 159), the "misrecognised" ideologies (Bourdieu, 1980, p. 122), the "defensive discourse of orthodoxy" (Bourdieu, 1993, p. 73), and "the unifying cultural code" (Everett, 2002, p. $65)$; and these are, in fact, the hidden rules that validate "symbolic violence" (Bourdieu, 1991, p. 170) in society. Symbolic violence, unlike the physical means of the police or the army, enforces its power by doxic ideologies which are set by and favour the dominant class. Such ideologies are followed not only by the dominant class, who benefit from them, but also by the dominated, who "check on" themselves, based on the ideologies set by their dominant counterpart. As Bourdieu (1989) perceived,

Agents, even the most disadvantaged ones, tend to perceive the world as natural and to accept it much more readily than one might image. (ibid, p. 18)

In order to illustrate the efficacy of symbolic violence, Bourdieu gave an example in his Masculine Domination (2001). He presented a doxic ideology that "Men perceive, and women are being perceived" (ibid, p. 63). To elaborate this, he observed that some women in modern society would prefer to sacrifice their breakfast in order to do makeup when faced with limited time: a contentious suggestion to those in the $21 \mathrm{st}$ Century.

\section{A. 4.4.3 Field}

Habitus and doxa occur in a field:

And when habitus encounters a social world of which it is the product, it finds itself "as fish in water," it does not feel the weight of the water and takes the world about itself for granted. (Bourdieu, in Wacquant, 1989, p. 43)

At the same time, a field is where habitus and doxa are conditioned and become meaningful: 
Habitus being the social incorporated, it is "at home" in the field it inhabits, it perceives it immediately as endowed with meaning and interest. (ibid, p. 45)

The state of a field is full of struggles.

The struggles which take place with the field are about monopoly of the legitimate violence (specific authority) which is characteristic of the field in question, which means, ultimately, the conservation or subversion of the structure of the distribution of the specific capital. (Bourdieu, 1993, p. 73)

In these struggles,

Dominant class factions, whose power rests on economic capital, aim to impose the legitimacy of their domination either through their own symbolic production, or through the intermediary of conservative ideologues...the dominated fraction... always tends to set the specific capital, to which it owes to its position, at the top of the hierarchy of the principles of hierarchization...the ideological systems that specialists produce in and for the struggle over the monopoly of legitimate ideological production reproduce in a misrecognized form. (Bourdieu, 1991, p. 168)

Because of the "legitimate" or doxic ideologies, each field not only validates its specific capital but also appreciates (and therefore nurtures) its own habitus.

In order for a field to function, there have to be stakes and people prepared to play the game, endowed with habitus that implies knowledge and recognition of the immanent laws of the field, the stakes, and so on.... A field may simply receive and consecrate a particular type of habitus that is more or less fully constituted. (Bourdieu, 1993, pp. 72-73)

Because they have different capital and habitus, actors in the field are put into different positions in the competition. To succeed in such competition, they will need to take different strategies which correspond to their position as well as the doxic ideologies, so that: 
Those who, in a determinate state of the power relations, more or less completely monopolize the specific capital, the basis of specific power or authority characteristic of a field, are inclined to conservation strategies...whereas those least endowed with capital (who are often also the newcomers...) are inclined to subversion strategies, the strategies of heresy. (ibid, p. 73)

\section{A.4.5 The inter-relationship between capital, habitus and field: the logic of practice}

The relationship between capital, habitus and field, as one can see from the discussion above, is an interactive one. Capital, in particular cultural capital, reflects habitus, a form of cultural disposition. Compared with other forms of capital, such as economic capital and social capital, habitus can be unconscious and hard to be realised by the actor who carries it (Ref: Section 3.5.2). It is nevertheless an important factor that distinguishes one actor from another in the social space.

Capital, habitus and field are explained with and for each other in social actors' practices. On the one hand, capital and habitus must comply with the doxa of the field to claim their legitimate status and practical efficacy; on the other hand, the field is where capital and habitus function and claim their "legitimacy" and potency in practice. The intertwining among capital, habitus, and field (doxa) makes the three an ontological "triad" (Griller, 1996, p. 7): one cannot exist without the existence of the other two, and they must be studied together.

Practice is where capital, habitus and field (doxa) interrelate and where they are manifested. The actors do not need to speak a word; their actions will tell, because:

Practical action may be described by analogy with the orthe doxa of Plato in Meno, as the 'right opinion': the coincidence between dispositions and positions, between 'sense of game' and the game, explains that the agent does 'what he or she has to do' without posing it explicitly as a goal, below the level of 
calculation and even consciousness, beneath discourse and representation. (Bourdieu, in Wacquant, 1989, p. 45)

The "unspeakable" practice is particularly important for studying the unconscious habitus and doxa because they are a "concomitant of practice" (Throop \& Murphy, 2002, p. 195), and practice is their natural proxy which is reflected by social actors.

The habitus is this kind of practical sense for what is to be done in a given situation - what is called in sport a 'feel' for the game, that is, the art of anticipating the future of the game, which is inscribed in the present state of play. (Bourdieu, 1998, p. 24)

The essential part of the modus operandi which defines practical mastery is transmitted in practice...without attaining the level of disclosure. (Bourdieu, 1972, p. 87)

To enact Bourdieu's Theory of Practice in social research, practice has to be studied and it is studied to expose habitus and doxa, the very foundation of his practical theory.

\section{A. 4.6 Operationalising social research using Bourdieu's Theory of Practice}

For social research, Bourdieu offered three approaches: reveal the field as one that is composed of different capital and habitus; map out the field in terms of the relationship between positions and dispositions (habitus); or investigate the doxa which validate the capital and habitus in the field (Bourdieu, in Wacquant, 1989, pp. 41-42). For the mapping-out approach, he used the statistical method. This method is used for "description" but not for "explanation." (His statistical attempt was appraised as less significant than his ethnographical effort: Griller (1996)). For an explanatory study, Bourdieu did not favour the statistical model because it assumes human behaviours are "intrinsically rational and calculative" (Jenkins, 2002, p. 72). This conflicts with his notion of "unconsciousness". Instead, he used the ethnographic method: a method perceived by him (Bourdieu, 1990) as well as by others (e.g., Griller, 1996; Throop \& 
Murphy, 2002; Jenkins, 2002) as the most successful method.

In applying his ethnographic method, Bourdieu made explicit his distinctive stance for relational thinking and "reflexivity" (Bourdieu, 1990, 1993). Relational thinking treats the social world as a world of relations, as discussed. Classes can be subjectively created, but the relations between classes are objective and it is these relations that are objects deserving of a scientific study.

"Reflexivity" acknowledges the situation that the social scientists are studying an object that they themselves are a part of (Chia \& Holt, 2006; Hall \& Callery, 2001). Social scientists need to "attach" to the social actors in their studies in order to get their "native" voices and "practical taxonomies" (Bourdieu, 1980, p. 86), but at the same time keep a distance (Griller, 1996, p. 3) or "epistemological vigilance" (Bourdieu et al., 1991, p. 72) from what they present. While the attachment resembles Husserl's phenomenological stance or Heidegger's “dwelling” (Chia \& Mackey, 2007; Throop \& Murphy, 2002), the "epistemological vigilance" is to avoid the social scientists" "theoretical taxonomies" being undermined by social actors' "practical taxonomies".

"Reflexivity" has a close relationship with the practice of social actors.

Reflexive attention to action itself, when it occurs...remains subordinate to the pursuit of the result and to the search... for maximum effectiveness of the effort expended.... Scientific analysis thus encounters and has to surmount, a practical antinomy when it breaks with every form of presuppositions of practical logic, and when it seeks to understand, in and for itself, and not to improve it or reform it, the logic of practice which understands only in order to act. (Bourdieu, 1980, p. 91)

Do the "presuppositions of practical logic" of social scientists contradict Bourdieu's prioritisation of their theories? It seems not. His reflexivity "objectifies the objectifier" (Griller, 1996, p. 13) to avoid the ethnocentrism (Bourdieu, 1990, p. 34) of social scientists. While he used his practical theory in the themes of capital, habitus, doxa and practice to discover a field, he allowed the social actors' voices "under these themes" 
to reveal their own "practical taxonomies". In this sense, Bourdieu's ethnography is also an approach of phenomenology (Chia \& Mackey, 2007) or even grounded theory (Hall \& Callery, 2001), but under the umbrella of his theoretical constructs.

Returning to Bourdieu's first approach of revealing a field as a field of capital and habitus, one may ask why he took that approach. This is because:

The primary differences, those which distinguish the major classes of conditions of existence, derive from the overall volume of capital, understood as the set of actually usable resources and powers - economic capital, cultural capital and also social capital. (Bourdieu, 1984, p. 108)

And within cultural capital, habitus needs particular attention because it is a result of inculcation in social actors' life trajectories: another important dimension for social distinctions (Bourdieu, 1984). The main thrust behind Bourdieu's approaching a field with the lenses of capital and habitus is as follows: in social battles, it is not really about who is against whom, males against females, blacks against whites and so on; it is their capital and habitus (life trajectories) in the form of different ideologies that conflict.

Then how to investigate the doxa? Doxa is a collective habitus, and part of habitus lies in social actors' unconsciousness. This brings a challenge for social research because, on the one hand, habitus is essential for social actors, but on the other hand, they cannot reflect on it. In dealing with this dilemma, Bourdieu did not provide clear instruction. What can be inferred from his books (in particular, Bourdieu, 1972, 1980, 1984, 1990, 1991) is his attention to practice, the social conditions of the field, Freud's psychoanalysis, and Hegel's dialectics.

Bourdieu believed doxa lies within the social conditions of the field, which are a historical product.

...The unconscious is the forgetting of history...its unconscious is made up of its social conditions of production, masked and forgotten. (Bourdieu, 1993, p. 50) 
For studying social conditions,

Nothing is more urgent than to make a social history of the Marxist tradition, in order to resituate modes of thought or expression. (Bourdieu, 1993, p. 50)

Only in this way can the ideologies of the dominant group be made explicit. For Freud's psychoanalysis, Bourdieu paid particular attention to social actors' self-reflection of their own life trajectories. In his belief, habitus and doxa are reflectable by social actors (Swartz, 2002; Steinmetz, 2006) and it is just a matter of awakening. As he claimed, "Habitus can be awakened" (Bourdieu, 1990, p. 116) and awakening can be used for “awakening of consciousness." (Bourdieu, 1998, p. 55)

He saw the relations between the dominant and dominated groups as reflected in Hegel's dialectics. In The Logic of Practice, Bourdieu claimed:

Levi-Strauss is perfectly justified in stating that the two opposing positions amount to exactly the same thing. (Bourdieu, 1980, p. 164)

In this view, the dominant and dominated is a pair of thesis and antithesis and the thesis can be found in the antithesis. As with a male and a female, the maleness can be found by the female in their in-depth interactions. This said, Bourdieu was particularly interested in Hegel's "slaves" standpoint (Hammond \& Oaks, 1992) in reflecting the slavery structures that bind them (Chia \& Mackey, 2007). The slaves not only hunger for their masters' recognition and appreciation, but most importantly, they are constrained by the structures and therefore are in a better position to reflect the structures that bind them.

The truth of doxa is only ever fully revealed when negatively constituted by the constitution of a field of opinion.... Crisis is a necessary condition for a questioning of doxa. (Bourdieu, 1972, pp. 168-169)

One may ask, who can be seen as being in "crisis"? Perhaps those dominated or 
disadvantaged who are deprived of the required capital.

\section{A.4.7 Concluding a social research project}

Social research starts from theory and returns to theory: Henceforward, the hypothesis is a synthesis. (Bourdieu et al., 1991, p. 63)

Capital, habitus, and the doxa that underpin them, find themselves in social actors' practice. Therefore, the practice becomes the "stone to test for gold" 11 , to validate research, whether its discoveries for capital, habitus and doxa are correct, and whether its explanations behind the discoveries conform to the practical theory. Put another way, if there is no practice, or there is practice that does not corroborate the social actor's capital, habitus and doxa, then it is not a well-validated research (Bourdieu et al., 1991).

This kind of research must be rigourous. For rigour, Bourdieu required research to be performative in terms of having new discoveries (Hall \& Callery, 2001; Bourdieu et al., 1991). Research, although featuring a "strict" positivist stance, is in fact imitating what natural science does. Without new discoveries, research would be valueless. Such research, to most, is an attempt of "spurious neutrality" (Bourdieu et al., 1991, p. 40) and although it may appear to be faithful or truthful to what social actors have said, it is "reportage" if it is without application of a social scientist's theory (Thomas \& James, 2006, p. 18). Social scientists' theory is important because the new discoveries (new analogies and relations) must conform to the theory, and they are good only to the extent that they can be explained by the theory. This point was further stressed by Bourdieu et al. (1991) in advocating for "applied rationalism", a step to validate new discoveries.

Applied rationalism breaks with spontaneous sociology above all by reversing the relationship between theory and experiment. The most elementary of operations, observation, which positivism describes as a recording that will be faithful insofar as it eschews theoretical presuppositions, is in fact scientific only insofar as the theoretical principles with which it is armed are conscious

\footnotetext{
${ }^{11}$ It is a saying in China from the early 1980's that "Practice is the only testing stone for gold to determine real Marxism". It is paraphrased here.
} 
and systematic.... What is observed is often neither relevant nor significant, and what is relevant and significant is often very difficult to observe.... The object, it has been said, is what objects. (ibid, pp. 59-61)

This passage resonates with a Chinese saying, "The one who tied the bell unties it": the theory triggers the research and in the end it is used to conclude the research. 